\title{
DEVELOPMENT OF APTAMER-BASED CAPTURE AND DETECTION SYSTEMS FOR THE IDENTIFICATION OF ANALYTES
}

by

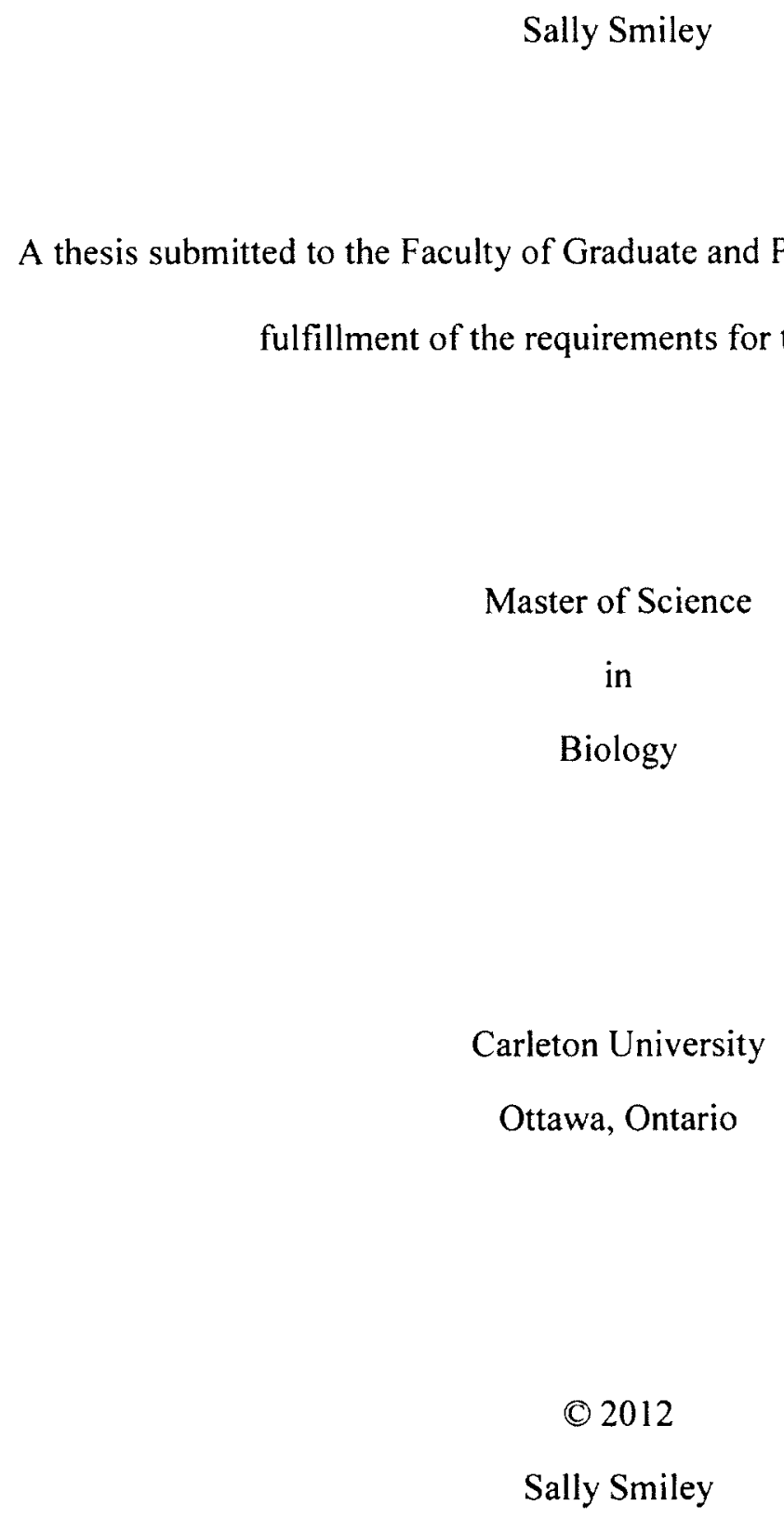

Sally Smiley 
Library and Archives

Canada

Published Heritage

Branch

395 Wellington Street

Ottawa ON K1A ON4

Canada
Bibliothèque et

Archives Canada

Direction du

Patrimoine de l'édition

395 , rue Wellington

Ottawa ON K1A ON4

Canada
Your file Votre référence

ISBN: 978-0-494-93545-3

Our file Notre référence

ISBN: $978-0-494-93545-3$
NOTICE:

The author has granted a nonexclusive license allowing Library and Archives Canada to reproduce, publish, archive, preserve, conserve, communicate to the public by telecommunication or on the Internet, loan, distrbute and sell theses worldwide, for commercial or noncommercial purposes, in microform, paper, electronic and/or any other formats.

The author retains copyright ownership and moral rights in this thesis. Neither the thesis nor substantial extracts from it may be printed or otherwise reproduced without the author's permission.
AVIS:

L'auteur a accordé une licence non exclusive permettant à la Bibliothèque et Archives Canada de reproduire, publier, archiver, sauvegarder, conserver, transmettre au public par télécommunication ou par l'Internet, prêter, distribuer et vendre des thèses partout dans le monde, à des fins commerciales ou autres, sur support microforme, papier, électronique et/ou autres formats.

L'auteur conserve la propriété du droit d'auteur et des droits moraux qui protege cette thèse. $\mathrm{Ni}$ la thèse ni des extraits substantiels de celle-ci ne doivent être imprimés ou autrement reproduits sans son autorisation.
In compliance with the Canadian Privacy Act some supporting forms may have been removed from this thesis.

While these forms may be included in the document page count, their removal does not represent any loss of content from the thesis.
Conformément à la loi canadienne sur la protection de la vie privée, quelques formulaires secondaires ont été enlevés de cette thèse.

Bien que ces formulaires aient inclus dans la pagination, il n'y aura aucun contenu manquant. 


\begin{abstract}
Novel assay systems, in which target-specific single-stranded DNA aptamers were used as high affinity binding reagents, were developed for the specific capture or ultrasensitive detection of test analytes. Two different approaches incorporating aptamers as assay reagents were developed. A proof-of-concept demonstration of these systems used thrombin protein as a model analyte. The first system, termed the aptablot, was a facile assay system which involved the immobilization of thrombin DNA aptamers on macroporous polyester cloth, providing a high affinity capture surface for the model protein analyte thrombin, which was subsequently detected immunoenzymatically. The second approach intended for ultrasensitive detection, termed the Amplified Aptamer Assay $\left(A^{3}\right)$, involved the detection of captured thrombin protein via thrombin-specific DNA aptamer, which was subsequently detected through the generation of an ultrasensitive amplification signal by either nucleic acid sequence-based amplification (NASBA) or polymerase chain reaction (PCR), and visualization of the amplicon by agarose gel electrophoresis.
\end{abstract}




\section{ACKNOWLEDGEMENTS}

I would like to extend my sincere gratitude to my supervisor, Dr. Burton W. Blais. for giving me the opportunity to be a part of this project. for his guidance and support. and for his insightful teachings: it has been a truly enriching experience. I would like to thank Dr. Maria DeRosa, for her assistance and valuable feedback. I would also like to thank Dr. Owen Roland for his support and input as well as Dr. Douglas Johnson for taking time from their busy schedules to serve on my committee and providing me with constructive suggestions and advice. Additionally, I would like to thank my colleagues from the Blais and DeRosa labs for their technical assistance and guidance, which was greatly appreciated. Finally, I would like to thank my parents, Sam and Marie Smiley, my sisters. Sheila and Sandy Smiley, and a very special thank you to my husband Eli Monsour, for all their love, patience, continuous encouragement and support throughout this endeavour. 
TABLE OF CONTENTS

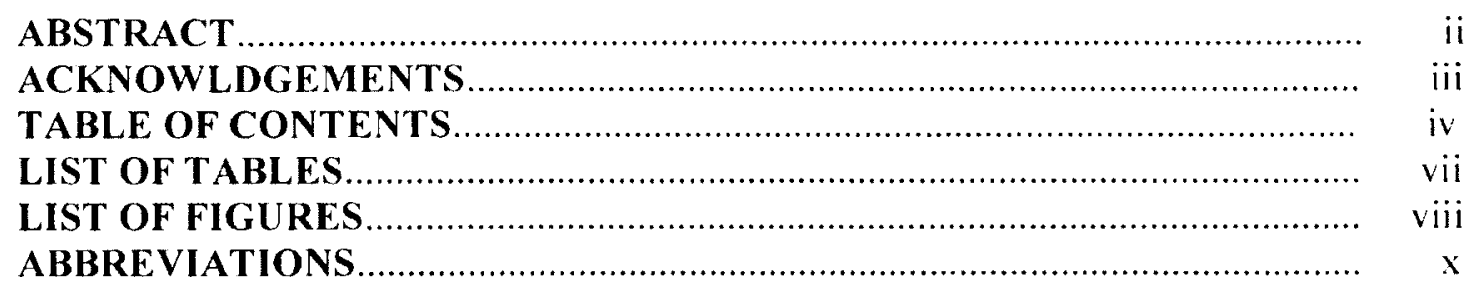

Chapter 1. General introduction ................................................................

1. Causes and incidence of foodborne illnesses.................................... 2

1.1 Bacterial pathogens causing foodborne illness.................................... 2

2. Enhancing food safety.................................................................. 4

3. Methods in food safety testing............................................................ 4

$3.1 \quad$ Conventional methods................................................................. 5

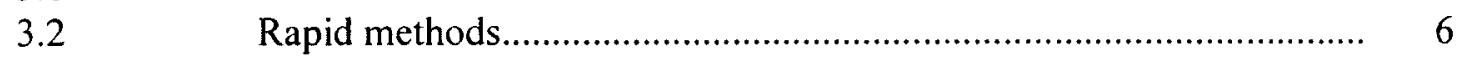

Immunological methods. ......................................................... 7

3.2.1.1 Enzyme-Linked ImmunoSorbent Assay (ELISA) ……....................... 7

3.2.1.2 Lateral flow immunoassays...................................................... 11

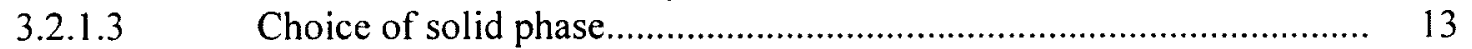

3.2.2 Nucleic acid-based methods........................................................... $\quad 14$

3.2.2.1 Nucleic acid hybridization ....................................................... 14

3.2.2.2 The polymerase chain reaction (PCR) .......................................... 15

3.2.2.3 Multiplex PCR ................................................................... 17

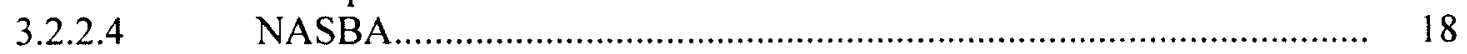

3.2.2.5 Nucleic acid amplification product detection................................ 21

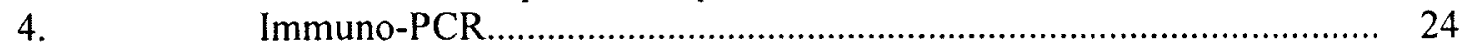

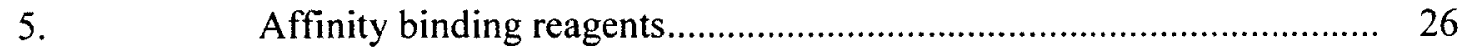

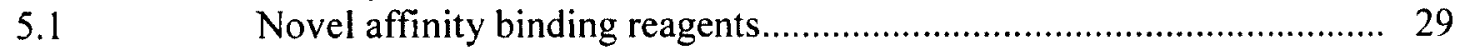

5.1.1 Molecular imprinted polymers................................................. 29

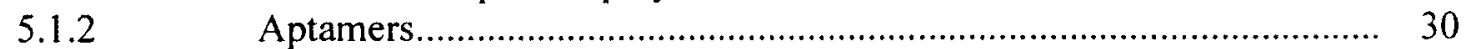

6. Need for simple, rapid, inexpensive methods for pathogen detection... 35

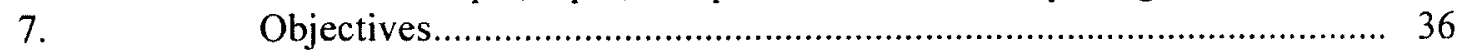

Chapter 2. Immobilization of DNA Aptamers on Polyester Cloth for Antigen Detection by Dot Blot Immunoenzymatic Assay (Aptablot)............................. 42

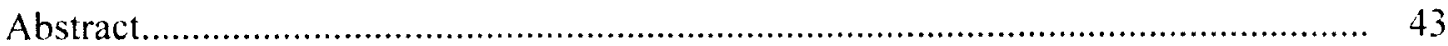

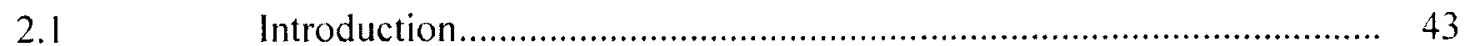

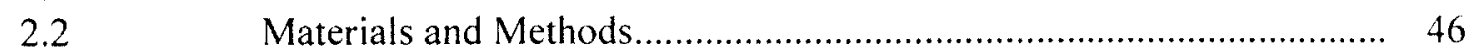

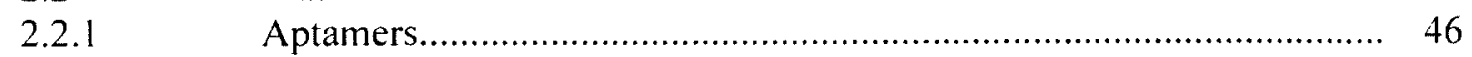

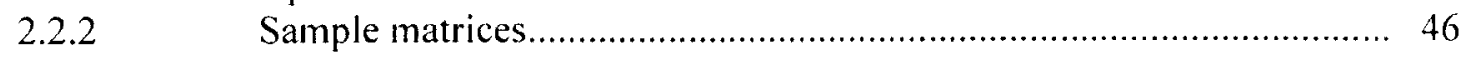

2.2.3 Development of sandwich aptablot assays.................................. 48

2.2.3.1 Preparation of aptamer-coated cloth by spotting............................... 48

2.2.3.2 Preparation of aptamer-coated cloth by saturation.............................. 49 
2.2.3.3 Thrombin sandwich assay on aptamer-coated cloth........................ 49

2.2.3.4 Lysozyme sandwich assay on aptamer-coated cloth........................ 50

2.2.4 Development of competitive aptablot assays................................. 50

2.2.4.1 Thrombin protein conjugation to horseradish peroxidase................ 50

2.2.4.2 Thrombin displacement assay on aptamer-coated cloth................... 51

2.2.4.3 Thrombin inhibition assay on aptamer-coated cloth......................... 52

$2.3 \quad$ Results................................................................................... 52

2.3.1 Immobilization of anti-thrombin oligonucleotides in a sandwich assay format............................................................................ 52

2.3.2 Detection of thrombin in different sample matrices........................ 56

2.3.3 Detection of lysozyme via immobilization of anti-lysozyme aptamer.. 59

2.3.4 Detection of thrombin on aptamer-coated cloth in a competitive

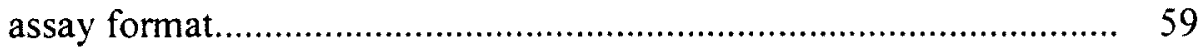

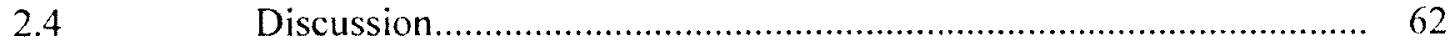

Chapter 3. Development of a nucleic acid sequence-based amplification (NASBA) system for detection of aptamer bound to target analyte................................... 70

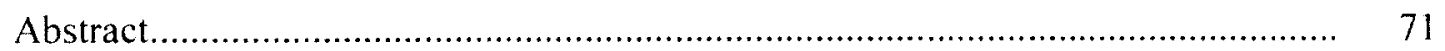

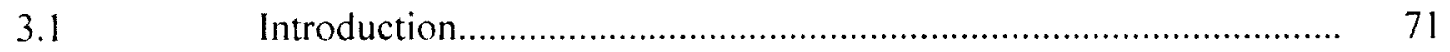

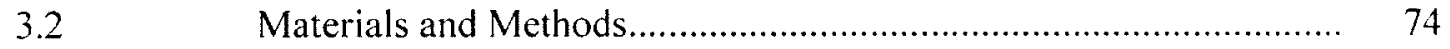

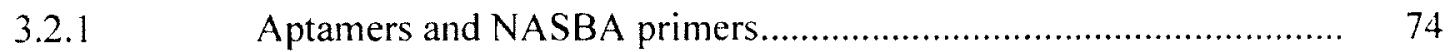

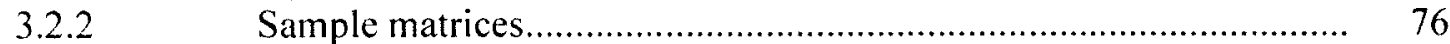

3.2.3 Amplification by NASBA and analysis of amplicons..................... 76

3.2.4 Thrombin Amplified Aptamer Assay............................................... $\quad 78$

3.2.5 Detection of thrombin in complex matrices.................................. 79

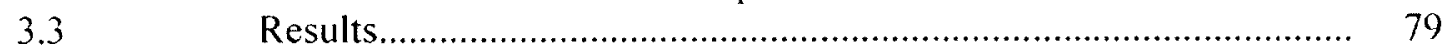

3.3.1 Amplification of thrombin aptamers....................................... 79

3.3.2 Detection of thrombin via Amplified Aptamer Assay..................... 83

3.3.3 Detection of thrombin in complex matrices................................... 84

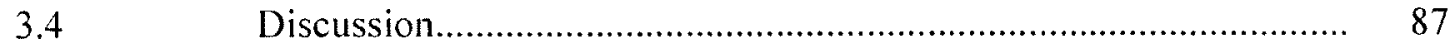

Chapter 4. Development of the polymerase chain reaction (PCR) amplification system for detection of aptamer bound to target analyte................................. 91

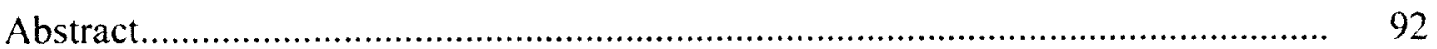

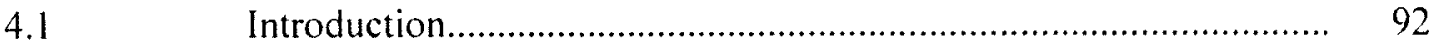

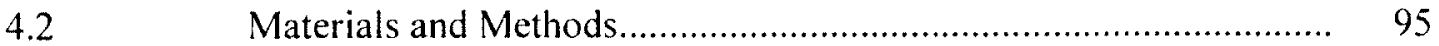

4.2.1 Aptamers and PCR primers..................................................... 95

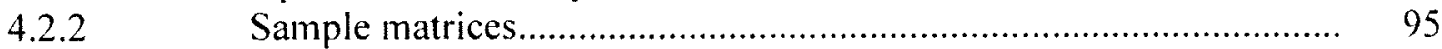

4.2.3 Amplification by PCR and analysis of amplicons........................ 95

4.2.4 Thrombin detection in microtiter plates via PCR Amplified Aptamer Assay ...................................................................... 97

4.2.5 Detection of thrombin in complex matrices................................ 98

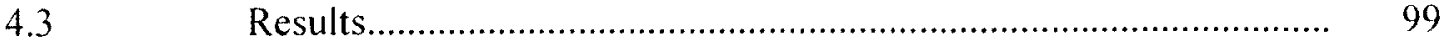

4.3.1 Amplification of thrombin aptamer by PCR ................................ 99 
4.3.2 Thrombin PCR Amplified Aptamer Assay in microtiter plates....... 99

4.3.3 Detection of thrombin in different sample matrices........................ 101

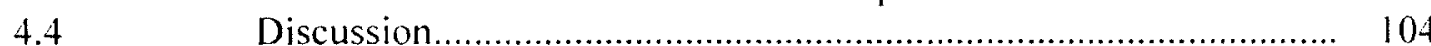

Chapter 5. General conclusion ....................................................... 111

REFERENCES 


\section{LIST OF TABLES}

Table 2.1 Oligonucleotide sequences used for immobilization on polyester cloth.....

Table 3.1 Thrombin aptamer oligonucleotide sequences used for the detection of thrombin protein by amplification via NASBA ............................ 75

Table 3.2 Oligonucleotide primer sequences used for the amplification of thrombin aptamers by NASBA.

Table 4.1 Oligonucleotide primer sequences used for amplification of the SELEX Apt by PCR. 


\section{LIST OF FIGURES}

Figure 1.1 Common immunoassay formats..................................................... 8

Figure 1.2 Schematic of the lateral flow immunoassay test................................ 12

Figure 1.3 Steps of basic PCR amplification of nucleic acid oligonucleotides.... 16

Figure 1.4 Pathways for single stranded RNA and double stranded DNA amplification with NASBA

Figure 1.5 Scheme for the cloth-based hybridization array system (CHAS)...... 25

Figure 1.6 Schematic diagram of immuno-PCR ……………………................ 27

Figure 1.7 Schematic of a specifically folded aptamer..................................... 31

Figure 1.8 Process of the Systematic Evolution of Lignads by EXponential enrichment (SELEX) in the selection of aptamers............................ 34

Figure 1.9 Schematic diagram of aptablot assay system.................................... 38

Figure 1.10 Proposed Amplified Aptamer Assay $\left(\mathrm{A}^{3}\right)$ for the detection of contaminates in samples............................................................ 39

Figure 2.1 Effect of oligonucleotide sequence on immobilization of aptamers to polyester cloth......................................................................... 54

Figure 2.2 Effect of aptamer coating concentration.......................................... 55

Figure 2.3 Effect of the addition of 5'-poly-nucleotide tails on the immobilization of a shorter length aptamer............................................................ 57

Figure 2.4 Effect of the addition of varying length 5'-poly-T tails on the immobilization of a shorter length aptamer................................... 58

Figure 2.5 Effect of sample matrix on the detection of thrombin by aptamer coated polyester cloth..................................................................... 60

Figure 2.6 Detection of chicken egg white lysozyme protein by aptamer-coated polyester cloth.

Figure 2.7 Comparison of thrombin displacement and competitive inhibition aptablots. 
Figure 3.1 Amplification of Mod Apt 1 by NASBA followed by analysis of products by agarose gel electrophoresis............................................

Figure 3.2 Amplification of Mod Apt 2 by NASBA followed by analysis of products by agarose gel electrophoresis.

Figure 3.3 Amplification of SELEX Apt by NASBA followed by analysis of products by agarose gel electrophoresis.

Figure 3.4 Detection of thrombin protein with SELEX Apt followed by amplification by NASBA and analysis of products by agarose gel electrophoresis.

Figure 3.5 Detection of thrombin protein by the SELEX Apt from complex matrices in a microtiter plate, followed by NASBA amplification...

Figure 4.1 Amplification of the SELEX Apt by PCR followed by analysis of amplicons by agarose gel electrophoresis

Figure 4.2 Optimum SELEX Apt concentration for detection of thrombin protein in the wells of a microtiter plate followed by amplification by PCR and analysis of amplicons by agarose gel electrophoresis.....

Figure 4.3 Effect of various blocking agents on non-specific binding of Aptamer

Figure 4.4 Detection of thrombin protein by the SELEX Apt from complex matrices in a microtiter plate, followed by PCR amplification..... 


\section{ABBREVIATIONS}

${ }^{\circ} \mathrm{C}$

$\mu g$

$\mu l$

$\mu \mathrm{M}$

AP

AMV

$\mathrm{BHI}$

$b p$

BoNT

$\mathrm{CaCl}_{2}$

CFIA

CFU

CHAS

$\mathrm{cm}$

DIG

DNA

dNTP

dsDNA

dUTP

ELISA

h

$\mathrm{HCl}$ degree Celsius

microgram

microlitre

micromolar

alkaline phosphatase

avian myeloblastosis virus

brain heart infusion

base pair

botulinum neurotoxin

calcium chloride

Canadian Food Inspection Agency

colony forming units

cloth-based hybridization array system

centimetre

digoxigenin

deoxyribonucleic acid

deoxyribonucleotide triphosphate

double-stranded DNA

deoxyuridine triphosphate

enzyme-linked immunosorbent assay

hour(s)

hydrochloric acid 


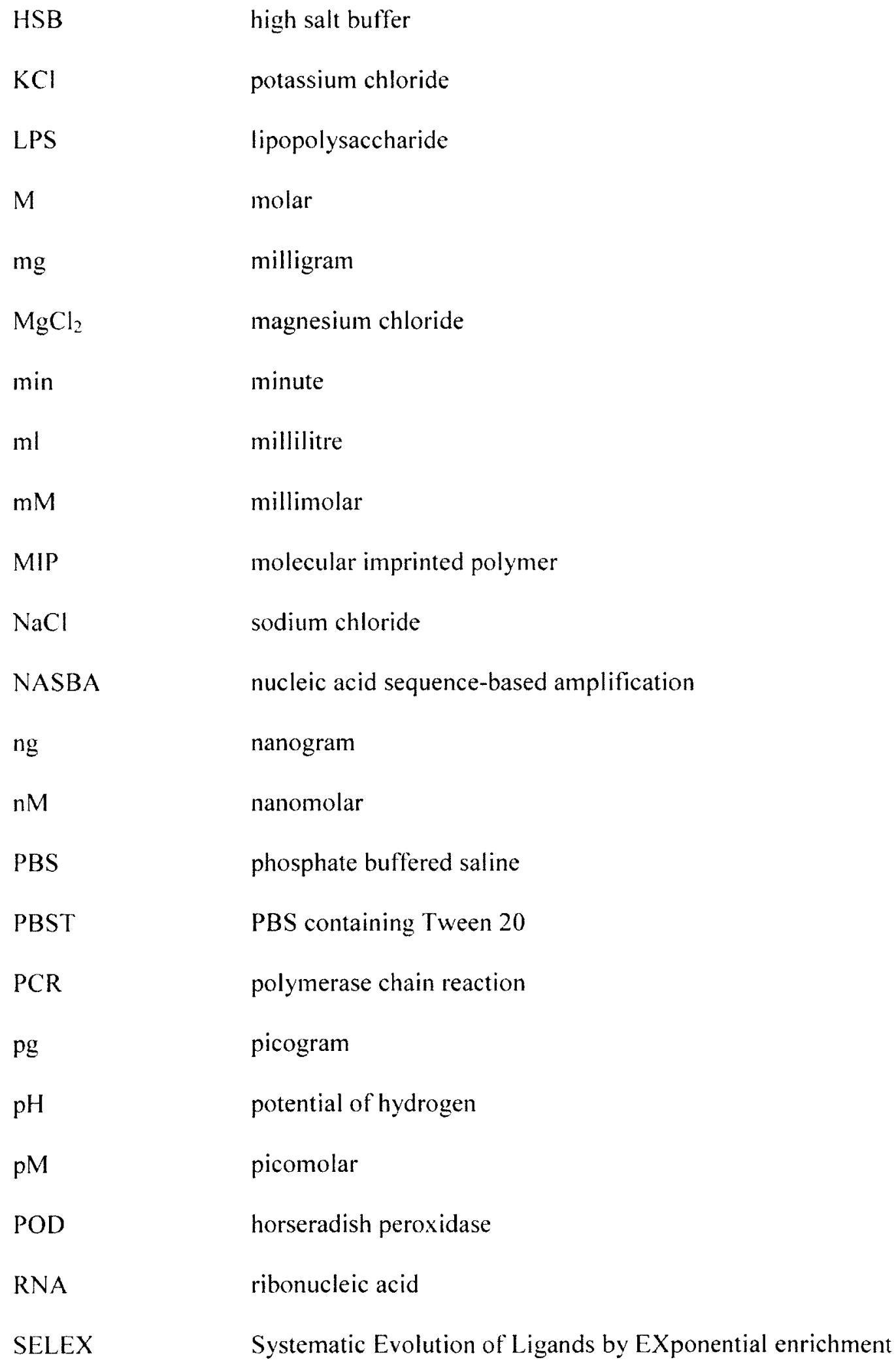


ssDNA

T7

TMB

U

UV

VTI single-stranded DNA

bacteriophage $\mathrm{T7}$

tetramethylbenzidene

units

ultraviolet light

verotoxin 1 


\section{CHAPTER 1}

General Introduction 
Foodborne illness is a widespread and growing public health problem, both in developed and developing countries. The Canadian Food Inspection Agency (CFIA) has estimated 11 million foodborne illnesses occur each year in Canada (CFIA, 2012). The United States Centers for Disease Control and Prevention (CDC) has estimated foodborne diseases cause 48 million illnesses, 128000 hospitalizations, and 3000 deaths each year in the United States due to the consumption of contaminated foods. Of the 48 million illnesses, 9.4 million are caused by 31 known pathogens, $90 \%$ of which are caused by seven select pathogens (CDC, 2012). According to the CDC, the seven pathogens of the greatest concern include Salmonella, Campylobacter, Escherichia coli (E. coli) O157:H7, Listeria monocytogenes, Toxoplasma, Norovirus, and Clostridium perfringens. While not documented as well, developing countries are most affected by contamination of food and drinking water (WHO, 2007). Risks associated with food can generally be divided into three main categories; microbiological, physical contaminants, and chemical contaminants and natural toxins. More than 250 diseases are known to be transmitted through the consumption of foods containing contaminations such as bacteria or their toxic by-products, viruses, or parasites (CDC, 2012). Symptoms can range from mild gastroenteritis, to life-threatening neurological, hepatic, and renal syndromes.

\subsection{Bacterial pathogens causing foodborne illness}

Bacterial foodborne diseases can be classified into three categories, infections, intoxications, and toxicoinfections. Bacterial foodborne infections result from the consumption of food contaminated with pathogenic microorganisms, which colonize the intestine leading to illness, such as salmonellosis, campylobacteriosis, listeriosis, or $E$. coli infections (Lampel et al., 2012). Food products can become contaminated at any 
point along the food continuum, including processing, storage, transportation, preparation, and consumption. Most bacteria are spread through indirect or direct contact with the intestinal contents or excrements of animals, including humans; for instance not washing hands properly after using the washroom or handling infected animals or petrelated objects. Bacteria may also be spread through the cross-contamination of raw meat from processing to consumption. Furthermore, raw fruits and vegetables may become contaminated when washed or irrigated with water contaminated with animal feces or human sewage. Food products most commonly associated with bacterial infections include raw or undercooked meat or poultry, processed meats, fish, eggs or egg-based foods, milk or unpasteurized dairy products, raw fruits and vegetables and water (Altekruse et al., 1997).

A number of foodborne pathogens mediate their harmful effects through the formation of toxins. Foodborne intoxications occur by consuming foods containing these harmful toxins produced by the microorganisms. In this case, the toxin causes the illness rather than an actual bacterial infection of the host; thus, the microorganism need not be present in the food at the point of consumption. Examples of such pathogens include Clostridium botulism, which produces a botilinum neurotoxin (BoNT) (Oguma et al., 1997) or Staphylococcus aureus (Vasconcelos \& da Cunta, 2010), which produce enterotoxins. Some of these toxins are extremely potent and can cause serious illness in humans or even death.

Finally, foodborne toxicoinfections occur through the consumption of food contaminated with a microorganism that grows and produces toxin(s) in the intestinal tract, such as the toxin forming Clostridium perfringens. C. perfringens are spore forming 
bacteria which can spread through the improper cooling and storage of foods. If consumed, the bacteria produce toxins in the intestinal track, which leads to illness (McClane, 2003).

\section{Enhancing food safety}

Due to the presence of various harmful pathogens in our environment, everyone is potentially at risk for foodborne illness. However, some people are more susceptible to foodborne illnesses and are more likely to experience severe illness. These high-risk groups include infants and young children, the elderly, pregnant women, and people with weakened immune systems. Thus consumers have an on-going need for food safety. In Canada, focus is placed on consumer health. The safe production, processing, and sale of food products are nationally regulated by stringent programs implemented by Health Canada, Agriculture and Agri-Food Canada, and CFIA. Due to the importance of food safety, stress is placed on the development and improvement of standards, methods, and assays intended to protect public health. These microbiological monitoring programs are designed to verify manufacturing compliance with applicable food safety standards and regulations, identify and manage food safety risks, respond to food emergencies, carry out food recalls, verify the extent of contamination, and trace sources in the event of foodborne disease outbreaks, eliminating possible threats and contamination emergencies in a timely fashion to safeguard public health.

\section{Methods in food safety testing}

The analysis of food samples for a specific pathogen or toxin can be very challenging. To say the least, food products are intricate. They consist of extremely complex materials, 
such as fats, proteins, carbohydrates, and chemicals and are subject to varying acidities and salt concentrations. Moreover, food products often contain large populations of indigenous microflora. This means the population of target pathogens and contaminants is extremely small in comparison, further making their detection a challenge. Finally, specific pathogens of interest may become injured or stressed during treatments used in food processing, such as heat, cold, drying, freezing, and chemical additives or preservatives, causing the bacteria to be easily missed during testing. Consequently, with such a wide variety of possible contaminants and the difficulties in detecting them, sensitive tests must be designed and available for the detection of the smallest number of colony forming units (CFU) or minimal amounts of toxin that may be harmful to human health. Furthermore, these detections methods must be able to accommodate high throughput analysis of food samples in order to satisfy food testing standards. Therefore, strong emphasis is placed on the study of pathogens and their detection due to zerotolerance of their presence in food.

\section{$3.1 \quad$ Conventional methods}

To overcome detection challenges, microbiologists have relied on culture methods for the detection and identification of pathogens in samples. Traditional methods for detection of foodborne pathogens rely on four main steps. The process starts with a pre-enrichment step in a non-selective media to allow for the recovery of injured or stressed cells, followed by selective enrichment to discriminately increase the concentration of a particular bacterial target in specific culture media, while suppressing the growth of background microflora. Next, the bacterial target is isolated on selective agar plates. In the absence of typical colonies, the analysis is complete and the results are reported as 
negative. In the case of presumptively positive colonies, confirmation is carried out through additional biochemical and/or serological tests to identify bacterial targets. (Swaminathan \& Feng, 1994). While this method is effective, the process is time consuming and labour intensive. Typically, the pre-enrichment and selective enrichment along with the plating step take $24-48$ hour each, plus another week or more for confirmation of a positive sample (Dwivedi \& Jaykus, 2011). As a result, conventional methods are very lengthy.

\subsection{Rapid methods}

Over the last several decades, advancements in scientific technology have introduced a number of molecular biological diagnostic assays that are quicker and automated that have had a large impact on food diagnostics. Though they were mainly laboratory research tools at one time, antibodies and nucleic acids now dominate the field of foodborne pathogen testing; their main advantage is providing more rapid turnaround time to get a presumptive result than conventional methods and facilitating multi-target detection. However, due to the complex nature of food matrices, pre-enrichment of food samples in culture media is still necessary prior to testing to attain optimal detection efficiencies. Therefore, immunology and molecular biology have introduced a newer generation of testing methods for the detection of pathogens and their toxins. These methods can be divided into two categories; antibody-based assays and nucleic acidbased assays. 


\subsubsection{Immunological methods}

The use of antibodies goes back more than a century. The heart of any immunological method is based on the specific and sensitive binding of an antibody to an antigen. Due to the specific nature and high sensitivity of the antibody - antigen reaction, the approach aims to detect an antigen against which a specific antibody has been raised, for example a phenotypic feature of a target bacterium against which an antibody is available. Antibodies have played a large role in the detection and identification of bacterial pathogens, with their earliest use in the 1920 s and 1930 s to identify various Salmonella serotypes (Edwards \& Ewing, 1972). Since then, various techniques have emerged, such as the enzyme-linked immunosorbent assay and the lateral flow immunoassay.

\subsubsection{Enzyme-Linked ImmunoSorbent Assay (ELISA)}

Over the years, several formats of immunoassays have been developed. The emergence of the enzyme-linked immunosorbent assay (ELISA) arose as a safer alternative to the radioimmunoassay in which either antibodies or antigens were labelled with radioisotopes. The ELISA technique is the most widely used format for immunoassays and can be performed with a number of modifications to the basic procedure for the detection of either antigens or antibodies. The binding of the antigen of interest can be accomplished by direct adsorption to the solid phase or indirectly by a capture antibody that has been adsorbed to the solid phase. The antigen is then detected directly through the use of a labelled primary antibody or indirectly via a labelled secondary antibody that recognizes the primary antibody (Figure 1.1 a, b) (Gazzaz et al., 1992). The most commonly used colorimetric enzyme labels for conjugation to antibodies are horseradish 

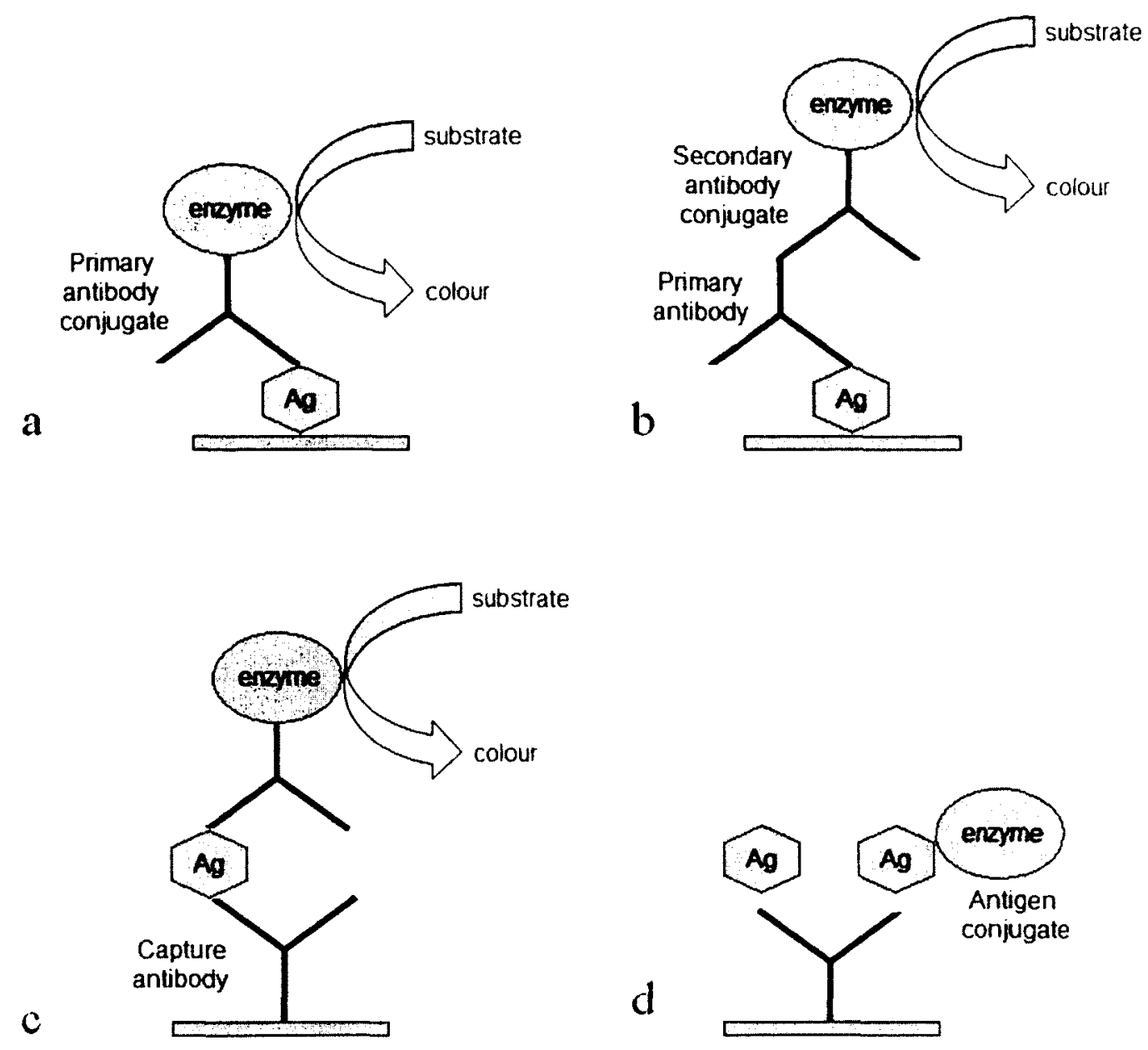

Figure 1.1 Common immunoassay formats. In these assays, the antigen (Ag) of interest is immobilized by direct adsorption to the solid surface ( $a, b)$ or bound by reaction with a capture antibody $(c, d)$. Detection of the antigen can then be performed using an enzyme-conjugated primary antibody (a) or a set of unlabeled primary antibody and conjugated secondary antibody (b). The classic "sandwich ELISA" involves the capture of an antigen between a capture and a conjugated antibody (c). Finally, labeled and unlabeled antigen compete for binding to a capture antibody in the competitive ELISA. 
peroxidase (HRP) and alkaline phosphatase (AP), to which a colorimetric substrate is added to produce a signal (Tijssen, 1985). The results can be recorded visually or with a spectrophotometer.

The most widely used format of the ELISA technique is known as the "sandwich" ELISA (Clark \& Engvall, 1980). This method involves the immobilization of an antigen between two primary antibodies, a capture antibody and a detection antibody, which may be enzymatically labelled, or to which a secondary, labelled antibody binds to (Figure 1.1 c). Between each step of an ELISA, the solid phase is washed with a mild detergent solution to remove any antigen or antibody that is not specifically bound. An ELISA can also be performed as a competitive assay, commonly when the antigen has only one epitope or antibody binding site. One competitive ELISA assay format involves labelling purified antigen. The purified, labelled antigen and unlabelled antigen from the sample are introduced and compete for binding to the capture antibody (Figure $1.1 \mathrm{~d}$ ). A decrease in signal from the purified, labelled antigen indicates the presence of the antigen in samples when compared to assay wells with purified, labelled antigen alone.

The ELISA method has been widely used in the detection of pathogenic bacteria and bacterial toxins in foods. Specific antibodies targeting bacterial cell-surface antigens have allowed researchers to develop these ELISA methods. For instance, an antibody to the outer core polysaccharide of Salmonella, the lipopolysaccharide (LPS) molecule, has been used to detect Salmonella cells in food samples ( $\mathrm{Ng}$ et al., 1996). Furthermore, antibodies specific to certain bacterial toxins has allowed for their detection via the ELISA method. For example, the $E$. coli toxin verotoxin (VT) 1, was detected by specific antibodies (Karmali et al., 1994). 
The ELISA immunoassay has several advantages over conventional detection methods. The use of monoclonal antibodies greatly improves the specificity of the ELISA for detection of foodborne pathogens and their toxins. Also, the method is much shorter than conventional methods, taking about 48 hours for its competition. However, there are some drawbacks. For instance, the sensitivity of the assay is approximately $10^{5}-10^{6}$ $\mathrm{CFU} / \mathrm{ml}$ and $10-100 \mathrm{ng}$ for toxins, thus making pre-enrichment necessary for optimal detection of bacteria cells and some type of concentration of the toxin (Swaminathan \& Feng, 1994). Also coating the solid phase with capture antibody requires large quantities of antibody to drive its adsorption on the surface, which tends to be costly. Antibody production is time consuming and requires the use of an animal host, which is expensive and can result in ethical objections. Furthermore, there are issues associated with their production, such as variability in stability and in the batch to batch quality of the antibody.

Due to the cost associated with antibody-coated surfaces, alternatives to the coating technique have been examined. Polymyxin B has been shown to function as a high affinity capture agent for lipopolysaccharide (LPS) antigens in the detection of various Gram negative pathogenic bacteria in foods. Polymyxin has the advantage of being a relatively inexpensive synthetic agent, which is chemically stable and homogeneous, providing a solution for the use of antibodies as a capture agent (Blais \& Yamazaki, 1991). The use of hemoglobin as a capture agent for LPS has also been employed for the detection of Salmonella in food samples (Blais et al., 1998). However, the use of polymyxin or hemoglobin as a capture agent is impractical given that their 
binding affinity is limited to LPS. This makes it unrealistic as a capture agent in comparison to antibodies, which can accommodate a large variety of targets.

\subsubsection{Lateral flow immunoassays}

Another immunological assay format is the lateral flow immunoassay test or the immunochromatographic strip tests, also commonly known as the dipstick test. The test strips consist of a plastic backing layered with overlapping absorbent pads and a nitrocellulose membrane, which are saturated with the detection and capture antibody, respectively, at a defined distance from one another. Once the sample is absorbed across the pads, any antigen present will react with the detection antibodies conjugated to colloidal latex or gold particles. The antigen-antibody complex moves laterally through the nitrocellulose membrane towards the capture antibodies via capillary action and binds with the capture antibody to form a visible band (Figure 1.2). Results are available in about 5-10 min after application of the sample. The main advantage of this technique is its rapidity, ease of reading results, and simplicity, requiring no washing or other manipulations once the sample is applied (Feng, 1997). This test is versatile and available for a large range of analytes, including foodborne pathogens and bacterial toxins. For example, the lateral flow immunoassay has been used for the detection of verotoxigenic E. coli in matrices such as raw milk, minced beef, apple juice, and salami (Aldus et al., 2003), as well as the detection of Salmonella enterica, C. jejuni, L. monocytogenes, and E. coli $\mathrm{O} 157: \mathrm{H} 7$ in raw and processed meat and poultry products (Bohaychuk et al., 2005). However, one limitation of this assay is the need for culture enrichment (Dwivedi \& Jaykus, 2011). 


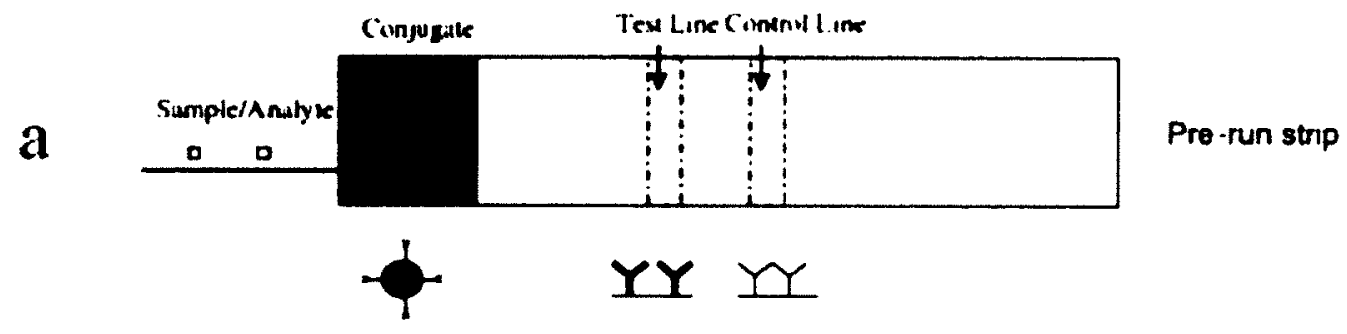

b

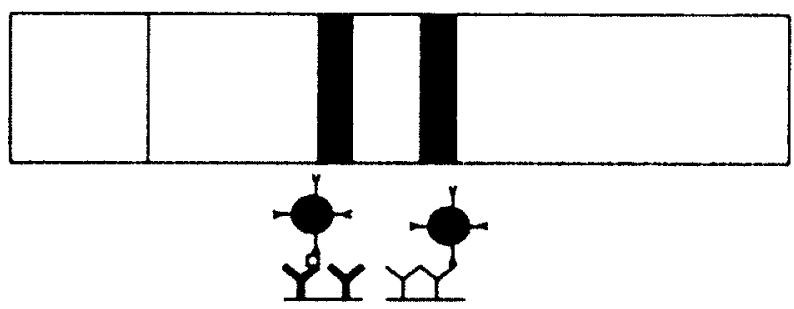

Positrve Result

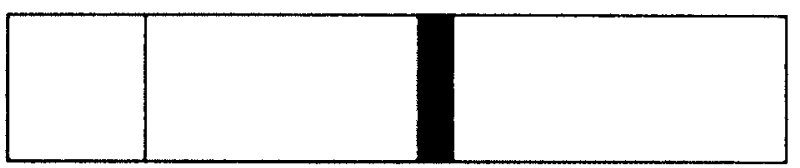

Negative Result

C

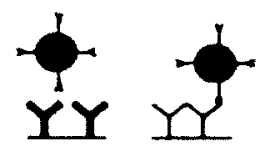

Figure 1.2 Schematic of the lateral flow immunoassay test. Sample is applied to the test strip, allowed to react with detection antibody conjugated to colloidal latex or gold particles, and is absorbed laterally across the strip (a). Any antigen present in the sample reacts with capture antibody producing two visible bands, a positive test line and a positive control line (b). The absence of analyte results in a negative test result and one control line (c) (reproduced from O'Farrell, 2009). 


\subsubsection{Choice of solid phase}

Over the years, a variety of solid phases have been used in immunoassays for immobilization of reagents. The most widely used solid-phase for antibody or antigen

capture is the non-porous 96 -well, polystyrene microtiter plate. However, variations of immunoassays have been designed that involve the use of other non-porous supports such as polystyrene tubes, microporous membranes, such as nitrocellulose or nylon membranes, or particulate solid phases, like magnetic or Sepharose beads (Butler, 2000). While these phases have proven effective, they do have some disadvantages. Due to the limited surface area, lengthy reaction kinetics are required for each immunoreaction, limited volumes of sample can be accommodated on the surface, and there are difficulties in handling, washing between reaction steps, and simultaneously processing multiple samples.

One novel solid phase that has emerged is a macroporous, hydrophobic polyester cloth, the use of which has been demonstrated in immunoassays (Blais \& Yamazaki, 1989a, b; Blais et al., 1989). Compared to non-porous solid phases, the macroporosity of this inexpensive polyester cloth provides a larger surface area for the immobilization of a variety of immunoreagents, such as antibodies and proteins or LPS antigens, resulting in improved reaction kinetics. Also, due to its thickness, compared to conventional microporous membranes like nitrocellulose, the cloth is able to accommodate a larger volume of sample. Finally, the polyester cloth exhibits excellent flow characteristics for easier washing between reaction steps using a simple vacuum filtration apparatus to remove unbound reagents, which is an advantage when testing multiple samples. 


\subsubsection{Nucleic acid-based methods}

With the discovery of the structure of the DNA double helix in the 1950 s came decades of intensive research in the molecular biology and genetics fields, paving the way for innovative techniques. Despite its relatively recent introduction into to the area of food diagnostics, nucleic acid technology has made a large impact on the development of nucleic acid-based assays for the detection and characterization of foodborne pathogens. Some of the more prominent nucleic acid-based techniques include nucleic acid hybridization, polymerase chain reaction, multiplex polymerase chain reaction, and nucleic acid sequence-based amplification.

\subsubsection{Nucleic acid hybridization}

Nucleic acid hybridization was the first nucleic acid-based technique used for the detection of foodborne pathogens, introduced in the early 1980s (Feng, 1997). The technique involves the hybridization of a DNA or RNA molecule present in the target organism with a DNA probe which has a sequence complementary to the target sequence. Probes for detecting bacteria or their toxins are typically between 15 to 30 nucleotides long and are developed by screening of genomic DNA fragments or by targeting specific gene sequences for known products, such as virulence-associated genes or genes coding for bacterial toxins. Thus, the specificity of the hybridization assay is completely controlled by the nucleotide sequence of the probe targeting a gene in the organism, making this assay more specific than antibody-based assays. The first step of this method involves the lysis of bacterial cells to release the double stranded DNA, which is denatured using heat or an alkaline treatment to render it in a single-stranded format and 
is immobilized on a solid support. This allows for hybridization with the complementary DNA probe. Different detection techniques can be used for the detection of the hybrid. In the past, DNA probes were labelled with radioisotopes; however, due to safety risks radioisotopes are no longer used. Instead, probes can now be non-radioactively labelled with small molecules like biotin and digoxigenin (DIG), enzymes such as AP and HRP, or fluorophores (Wetmur, 1991). Nucleic acid hybridization has been used for the detection of Salmonella species (Doran et al., 1993), Listeria monocytogenes (Kim et al., 1991), and Shiga-like-toxin-producing E. coli (Samadpour et al., 1990). Despite the specificity associated with the use of DNA probes, the method's detection threshold ranges from $10^{4}$ to $10^{5} \mathrm{CFU} / \mathrm{ml}$ (Swaminathan \& Feng, 1994). Thus, selective enrichment is necessary to obtain the required sensitivity, lengthening the procedure time.

\subsubsection{The polymerase chain reaction (PCR)}

With the advent of the polymerase chain reaction (PCR) in 1983 (Mullis et al., 1986), the field of molecular biology was forever revolutionized; the popularity of the technique stemming from the small amount of DNA sample required for amplification to the few hours it takes to complete. The PCR technique allows for the in vitro amplification of specific nucleic acid sequences. The amplification of target sequences occurs through the repeated cycling of three steps, denaturation, primer annealing, and primer extension, in a thermocycler resulting in exponential amplification (Figure 1.3). In the first step of the cycle the sample is heated to denature the double-stranded (ds)DNA into single-stranded (ss)DNA. During the second step, specific primers which are complementary to 5 ' and 3'segments flanking the target DNA sequence, anneal to the target sequence. Finally, thermostable DNA polymerase uses free nucleotides from the solution to extend the 


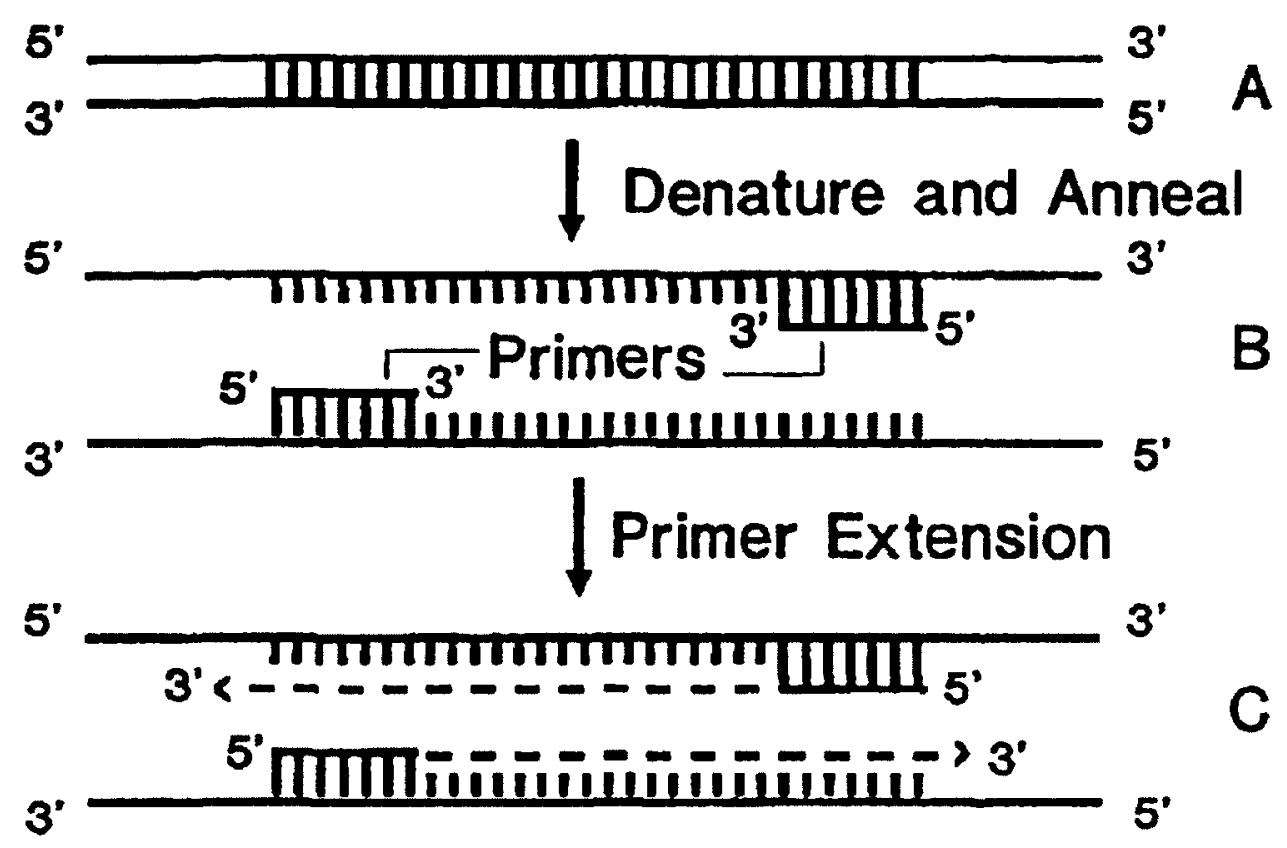

Figure 1.3 Steps of basic PCR amplification of nucleic acid oligonucleotides. A target gene is chosen for amplification. Short oligonucleotide sequences, complementary to the 5' and 3' regions flanking the target sequence, are designed to serve as primers for DNA synthesis (A). The DNA strands are separated by heat denaturation to form single strands. The temperature is lowered to allow for primer annealing to the strands (B). The temperature is subsequently raised to an optimum level for a thermostable polymerase and new strands are synthesized using the original strands as templates, resulting in twice as many copies of the target region as originally present (C). Continued cycling of denaturation, primer annealing, and extension, allows for the exponential amplification of the target sequence (reproduced from Hill, 1996). 
annealed primers using the target DNA as the template. Upon completion of this cycle, another cycle begins, increasing the number of target copies in an exponential manner. Theoretically, this procedure can detect even one molecule of target DNA, which can generate $1.5 \times 10^{6}$ copies after 30 cycles of PCR (Swaminathan \& Feng, 1994). By amplifying a sequence that is unique to pathogenic targets of interest, this in vitro amplification method can be used to detect low concentrations of bacterial pathogens. The most common pathogenic targets include genes for specific enzymes, strain-specific genes, like outer membrane proteins or heat shock proteins, virulence genes or antibiotic resistance genes; essentially, genes that are unique to the target organism and absent in non-target organisms. Many PCR protocols have been described for the detection of foodborne pathogens. Some examples include PCR detection of Salmonella typhimurium (Rahn et al., 1992) and of Listeria monocytogenes (Blais et al., 1995).

Although nucleic acid amplification techniques are more sensitive and specific than conventional culture methods, there are some drawbacks. PCR assays can be inhibited by food matrices, resulting in false-negatives; thus assays continue to need a brief culture enrichment period to overcome these problems. Finally, PCR suffers from the inability to distinguish between live and dead cells since DNA will persist after cell death, resulting in false-positives.

\subsubsection{Multiplex PCR}

In order to increase the efficiency of diagnostic PCR, adaptations to the conventional PCR were made, allowing multiple targets to be amplified at once, a process called multiplex PCR. This method combines multiple primer pairs in one single PCR reaction allowing simultaneous amplification of multiple gene targets. This multiple amplification 
characteristic increases the amount of information that is generated from a sample, an advantage in high throughput analysis. Several examples of multiplex PCR have been seen in the detection of pathogens like multidrug-resistant Salmonella typhimurium DT104 (Khan et al., 2000), Clostridium botulinum types A, B, E, and F (Lindström et al., 2001), enterotoxigenic Escherichia coli strains (Osek, 2001), and enterohemorrhagic Escherichia coli (Blais \& Martinez-Perez, 2011). However, still being a PCR-based method, this technique inherits the same drawbacks as PCR mentioned above.

\subsubsection{NASBA}

An alternative nucleic acid amplification technique providing enormous potential for the amplification of targets is the nucleic acid sequence-based amplification (NASBA) developed in the early 1990 s for the ultrasensitive and selective detection of specific sequences (Compton, 1991). NASBA is a simple and alternative method to PCR, mainly targeting single stranded RNA, but can also amplify DNA. Unlike PCR, it is an isothermal amplification and, therefore, it does not require a thermocycler, which gives it an advantage over PCR. Also, the amplification time for the NASBA reaction is reported to be faster than PCR. DNA amplification via PCR achieves greater than one million-fold replication in about three to four hours whereas NASBA can yield RNA amplification of a billion-fold in about two hours (Compton, 1991). A NASBA reaction uses three enzymes, bacteriophage T7 RNA polymerase, ribonuclease $H$ (RNase $H$ ), and avian myeloblastosis virus reverse transcriptase (AMV-RT) and two specific oligonucleotide primers, a forward primer with a 5' promoter sequence that is recognized by the T7 RNA polymerase enzyme and a reverse primer. 
Briefly, the initial reaction mixture is heated to $65^{\circ} \mathrm{C}$ to denature the RNA and promote annealing of the forward primer before the reaction temperature is reduced to $41^{\circ} \mathrm{C}$ and all three enzymes are added to the mixture (Figure 1.4). The annealed forward primer is extended by AMV-RT, creating an RNA:cDNA hybrid. The RNA strand is hydrolyzed by RNase $\mathrm{H}$ leaving ss-cDNA, to which the reverse primer anneals to and AMV-RT extends. The resulting ds-cDNA product, containing the T7 RNA polymerase promoter incorporated via the forward primer, is transcribed into many copies of RNA by the T7 RNA polymerase enzyme. After this initial non-cyclic phase, NASBA enters the cyclic phase in which the newly formed RNA serves as a template for the reverse primer to bind to and be extended by AMV-RT. Subsequently, the RNA template is digested by RNase $\mathrm{H}$, allowing the forward primer to bind to the cDNA and be extended by AMVRT to form ds-cDNA templates for the T7 RNA polymerase to bind to and synthesize RNA, initiating another cyclic round. Up to 100 RNA copies per ds-cDNA template are reportedly made in each cycle (Compton, 1991; Dwivedi \& Jaykus, 2011).

Using similar pathogenic targets as in PCR, NASBA can be optimized for the detection of pathogenic bacteria, such as for the detection of Campylobacter jejuni (Uyttendaele et al., 1997), the identification of species of mycobacteria (van der Vliet et al., 1993), and for the detection of Cryptosporidium parvum (Baeumner et al., 2001). Although these studies target the detection of RNA from pathogenic bacteria, NASBA can be tailored to amplify DNA targets. To be amplified by NASBA, dsDNA is added to the NASBA reaction mixture and the solution is heat denatured before a brief incubation at $41^{\circ} \mathrm{C}$ to allow forward primer annealing. The forward primer is extended by AMV-RT, followed by a second round of denaturation, producing a sSDNA intermediate to which 


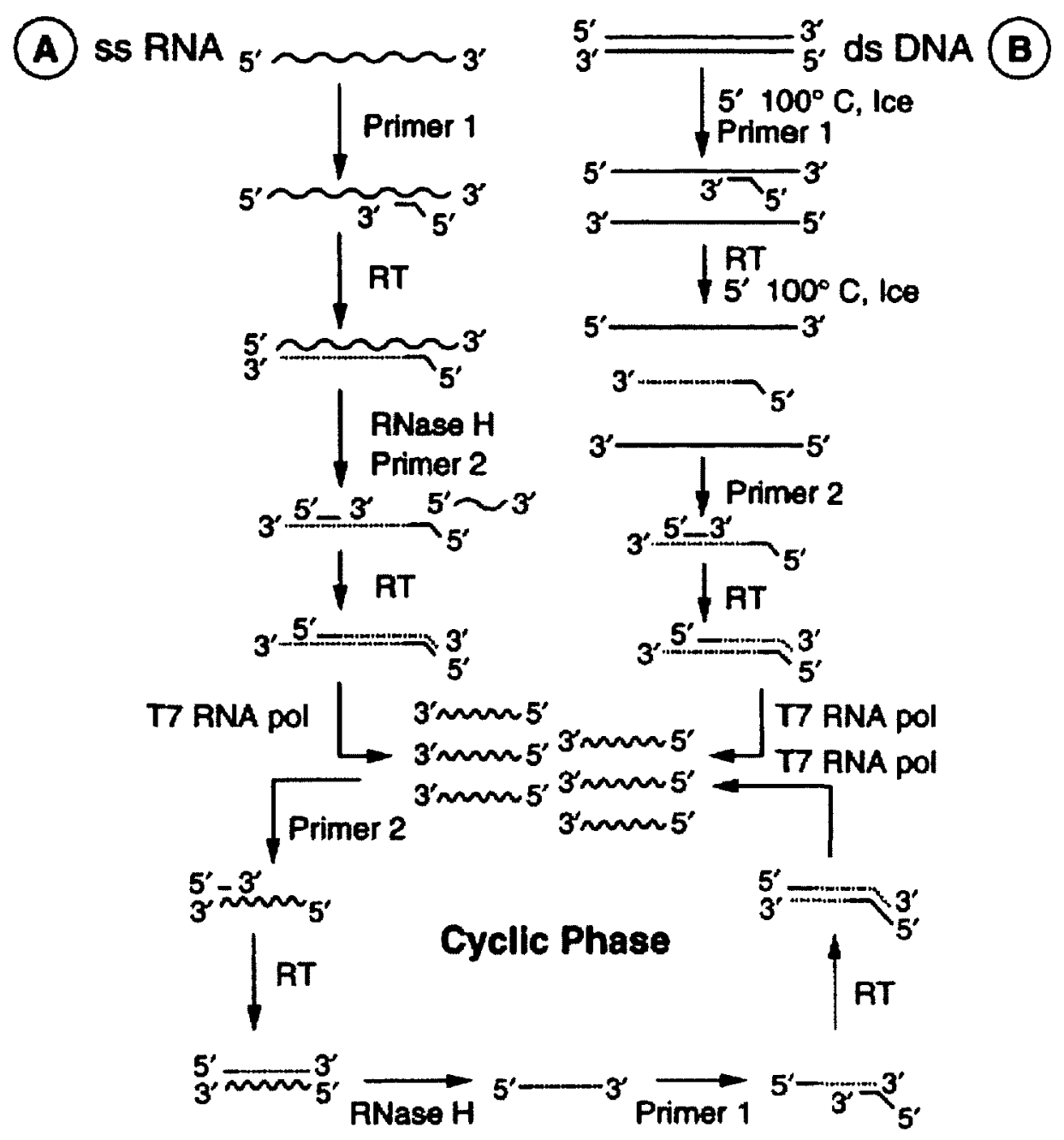

Figure 1.4 Pathways for (A) single-stranded RNA or (B) double-stranded DNA amplification with NASBA. Concerted action of avian myeloblastosis reversetranscriptase (AMV RT), T7 RNA polymerase (pol), and RNase $\mathrm{H}$ to generate multiple copies of RNA. Wavy lines, RNA; broken lines, newly synthesized DNA; solid lines, primers (reproduced from Hondinka, 1998). 
the reverse primer anneals to and continues with the rest of the NASBA amplification as previously described. Some examples of the use of DNA NASBA include the detection of Listeria monocytogenes hlyA genes (Blais et al., 1996) and of hepatitis B virus, herpes simplex virus and Staphylococcus aureus (Deiman et al., 2008).

\subsubsection{Nucleic acid amplification product detection}

To verify that a nucleic acid amplification technique has occurred, the product or amplicon(s) must be detected. One of the most commonly used amplicon detection methods based on molecular size is by agarose gel electrophoresis with ethidium bromide staining of the separated DNA. Although this method is simple, detection via gel electrophoresis does not enable specific confirmation of the identity of the amplicon, since even non-specific PCR products can appear to have a similar molecular size as a target product. Furthermore, gel electrophoresis is not suitable for high throughput screening and results may be difficult to interpret if multiple bands appear on the gel when only one is expected.

The recently introduced real-time PCR involves the detection of PCR products by the incorporation of fluorescently-labelled probes into the mixture that bind to the amplified DNA as it is copied. The resulting fluorescent signal is detected automatically in the PCR thermocycler, allowing for simultaneous amplification and detection of DNA as it occurs, obviating the need for post-amplification processing. Some fluorescent systems used include probe-based platforms like TaqMan or molecular beacon probes. For example, molecular beacon-based real-time PCR has been applied to the detection of Salmonella, with a reported detection range between $10^{4}$ to as few as 2 CFU per PCR 
reaction (Chen et al., 2000). Real-time PCR techniques are of particular interest in food diagnostics in that they provide a shorter analytical turnaround time and can detect organisms quantitatively, providing information not only with respect to the presence or absence of a pathogen, but also giving an indication of the level of hazard associated with a sample. The convenience of this method stems from the fact that amplification and detection occur in the same reaction tube, obviating the need for post-amplification processing, but also minimizing contamination issues. A similar situation can be set up with a NASBA reaction. The exponential amplification of the target RNA resulting from a NASBA reaction allows enough amplicon to be generated so that it can be detected by agarose gel electrophoresis; however, more recent NASBA methods incorporate fluorescent probes so that detection can occur in real time.

The emergence of the DNA microarray has facilitated the identification of DNA sequences and expression levels of specific genes. More recently, DNA microarray technology have been developed for use in the detection of pathogenic bacteria (Chizhikov et al., 2001; Strizhkov et al., 2000). DNA microarrays are small, solid supports, usually glass slides, upon which thousands of probes are immobilized and work by exploiting DNA hybridization. Samples being analyzed are fluorescently labelled and hybridize with the immobilized probes on the microarray. Bound targets are detected using laser technology, the scanner creates a digital image of the array, and the data is stored on a computer, where a special program is used to analyze the fluorescence patterns. Due to the large number of probes that may be immobilized on the microarray, the data generated from a single array can mount up quickly; data which can be highly complex. The main advantages of microarray technology are high throughput, 
miniaturization, speed, and automation. Although this technology and the information garnered from it is advantageous for epidemiologists, such complicated information is not practical for food testing laboratories, which wish to ascertain the presence or absence of a pathogen in food samples or identify key markers, such as virulence, toxin, or antibiotic resistance genes. Furthermore, the microarray systems rely on sophisticated and costly instruments, which are not generally a realistic capability of a typical food microbiology laboratory.

More practical improvements in nucleic acid amplification assays have lead to the incorporation of non-radioactive labels, such as digoxigenin (DIG) into the PCR amplicon. These PCR amplicons are subsequently hybridized with DNA probes immobilized in the wells of a microtiter plate and the bound label is detected with the use of an anti-DIG-peroxidase conjugate (Monteiro et al., 1997). The use of a microtiter plate allows for the analysis of a large number of samples. Another advantage of this technique is the nucleic acid hybridization aspect ensures the specificity between the target and the probe.

More recently, one particular method has been implemented in microbiological laboratories providing a simple and rapid DNA macroarray system, which is known as the cloth-based hybridization array system (CHAS) (Gauthier \& Blais, 2005). This assay makes use of DNA hybridization of DIG-labelled multiplex PCR amplicons, for the identification of many bacterial pathogens based on specific key marker genes such as virulence, toxin, antibiotic resistance and pathogen-specific genes. Multiplex PCR is used to simultaneously amplify many targets as well as incorporate DIG-dUTP into the amplicons. The PCR amplicons are subsequently detected by hybridization with an array 
of probes immobilized on macroporous polyester cloth, followed by immunoenzymatic assay of the bound DIG label (Figure 1.5). Several assays have demonstrated the use of the CHAS assay in the detection of toxin genes associated with major foodborne pathogens (Gauthier \& Blais, 2005), in the detection of multi-drug resistant Salmonella typhimurium DT104 in poultry (Blais et al., 2007) and in the detection of multiple gene markers in E. coli (Blais \& Martinez-Perez, 2011).

\section{Immuno-PCR}

While nucleic acid amplification techniques are suitable for the detection of pathogenic microorganisms themselves, they will not permit the direct detection of bacterial toxins or other contaminants, such as allergens in foods. Since some toxins found in foods are extremely potent and can be lethal, sensitive tests are required to permit the detection of very small amounts of these toxins to assure the safety of foods. Methods based on immunoassay techniques have been reported for the detection of various BoNT types produced by Clostridium botulinum (Poli et al., 2002) and E. coli verotoxins (VT) (Karmali et al., 1994). However, their sensitivity remains limited, reducing their usefulness in the early detection of toxins in foods. This is due to the limited capacity of marker enzymes linked to an antibody to generate a strong enough signal that is detectable when converting a substrate molecule to a chromogenic or fluorogenic product. Furthermore, the fact that detection must occur amid the complexity of the food samples may result in potential assays that are inhibited.

A potential assay for the ultrasensitive detection of bacterial antigens and toxins was first described in 1992 by Sano et al and combines EIA techniques with nucleic acid 


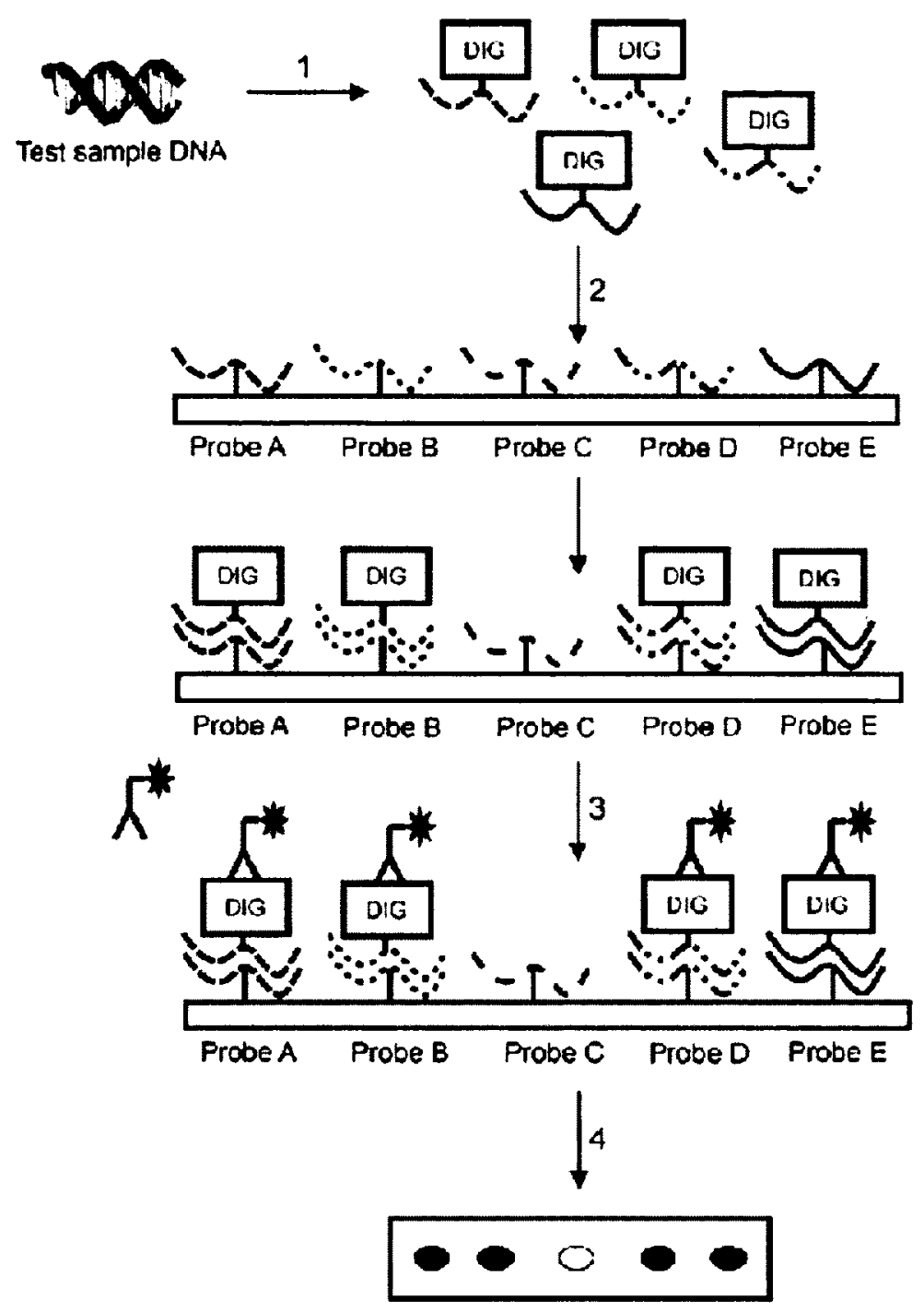

Figure 1.5 Scheme for the cloth-based hybridization array system (CHAS). Amplicons incorporating digoxigenin (DIG)-labelled dUTP generated in multiplex PCR (1) are detected by hybridization with an array of amplicon-specific DNA probes immobilized in discrete spots on a polyester cloth strip (2), followed by immunoenzymatic assay of bound label using anti-DIG antibody-peroxidase conjugate (3), and colorimetric detection using tetramethylbenzidine (TMB) membrane peroxidase substrate solution (4) (reproduced from Blais and Gauthier, 2007). 
amplification is known as immuno-PCR. Immuno-PCR is similar to the antibody-antigen principle of EIA, but instead of an enzyme-conjugated antibody for signal generation, the antibody is conjugated to a DNA fragment that is amplifiable by PCR (Figure 1.6). This method takes advantage of the specificity of antibodies for their antigens and the sensitivity of PCR making it more sensitive than conventional immunoassays. Several studies have compared the sensitivity of immuno-PCR with EIA and report immuno-PCR to be 1000-fold more sensitive than EIA (Kakizaki et al., 1996; Wu et al., 2001; Liang et al., 2003). However, there are limitations associated with immuno-PCR such as the complicated chemistry of linking the antibody to the DNA fragment, impacts on the binding activity of the antibody, uncertain yields, and increased background signals. Despite these limitations, the basic principle of immuno-PCR has the potential to be an effective ultrasensitive technique as alternative amplification and amplicon detection strategies can be explored.

\section{Affinity binding reagents}

Affinity binding reagents play a large role in a variety of experiments in the scientific field, such as ELISA techniques, Western blotting, immunoprecipitation, and affinity chromatography. They are an assortment of ligands that bind specifically to a larger target molecule to identify, capture, or purify the target. Ideal affinity reagents must have diverse target recognition, high specificity or low crossreactivity, high sensitivity, good binding affinity, and adaptability to many different assay designs (Stoevesandt \& Taussig, 2007). The most familiar affinity reagent is the antibody; however, other affinity reagents include peptides or other small chemical molecules. 


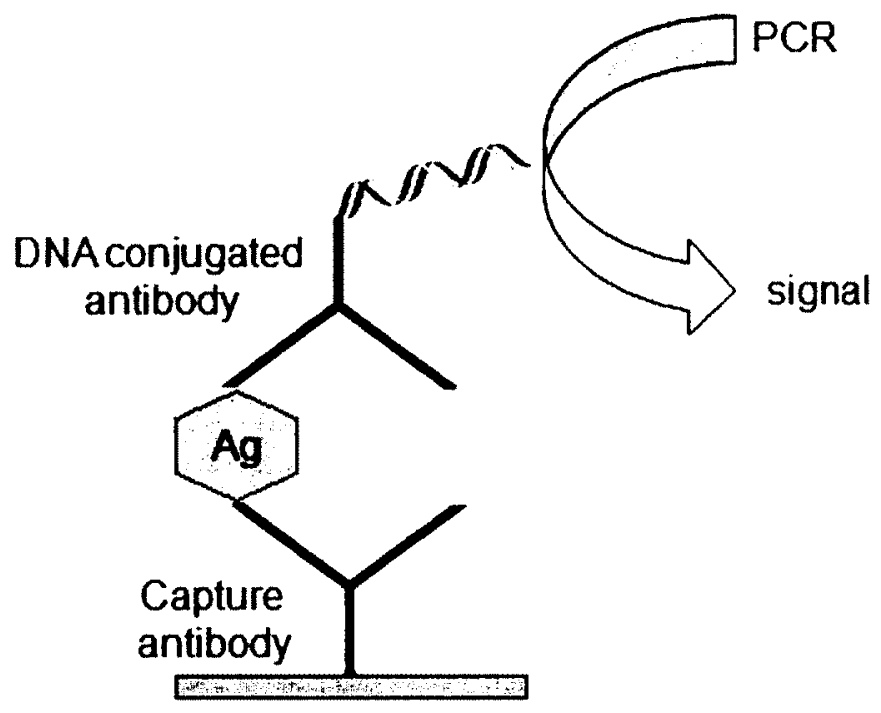

Figure 1.6 Schematic diagram of immuno-PCR. An antigen (Ag) detection system in which the antigen is captured by an antibody-coated surface and an antibody-DNA conjugate is used to detect the antigen through the specific amplification of the DNA fragment by PCR. 
Antibodies are the best established and most widely used affinity reagents for detection of targets due to their high specificity. In some cases, antigens may have manyepitopes that are the same or that differ from one another. Antibodies are defined functionally by the epitope they specifically recognize, making their use advantageous in detection. However, the development of antibodies is time-consuming and expensive. In addition, many antigens may be non-immunogenic or extremely toxic; therefore, they cannot be used to generate antibodies in animals.

Other peptide affinity reagents, such as protein $A, G, A / G$, or $L$ are most often used for antibody purification (Hober et al., 2007). They are bacterial surface proteins and reportedly bind strongly to most species and subclasses of mammalian IgG antibodies and can be bound to a solid matrix to facilitate the immunoprecipitation of antigen-antibody complexes. However, this method also involves antibodies, therefore, inheriting similar disadvantages. Proteins like lectins can also be used as affinity reagents. Lectins, such as Concanavalin $\mathrm{A}$ (con A) are glycoprotein-binding proteins, which can be ideal for the detection of cell surface glycoproteins. As opposed to antibody selection against a target, lectins can only target a defined set of glycoproteins. Finally, the streptavidin-biotin reaction is also a frequently used affinity system. The protein streptavidin has an extremely high affinity for the cofactor biotin. Many compounds can be easily biotinylated without affecting the biological activity of the compound, allowing for a broad range of applications. However, one disadvantage of the strong interaction between streptavidin and biotin is the harsh denaturing conditions required to accomplish dissociation, which may denature targets. Furthermore, since biotin is a biological 
molecule, endogenous biotin in samples can cause high background levels and specificity issues.

\section{$5.1 \quad$ Novel affinity binding reagents}

Although affinity binding reagents such as antibodies have applications in detection, there are several limitations, specifically their production in large quantities and its costs. Alternative affinity reagents with high specificity and affinity and that can be easily and cost-effectively produced are needed. Molecular imprinted polymers and nucleic acid aptamers have similar binding properties to these classical affinity reagents and are becoming viable alternatives.

\subsubsection{Molecular imprinted polymers}

Similar to the "lock and key" model of enzyme-substrate chemistry, molecular imprinting is a technique used for the preparation of synthetic polymers with specific binding sites for a target molecule (Murray et al., 1997). To create a molecular imprinted polymer (MIP), monomers carrying certain functional groups are pre-organized or self-arrange around the template through covalent or noncovalent interactions, respectively. Following the arrangement, the monomers are crosslinked to each other to form a polymer matrix, holding the functional groups in position. Subsequently, the template is removed by solvent extraction or chemical cleavage, and the resulting MIP contains a specific cavity or imprint that is sterically and chemically complementary to the template molecule (Alexander et al., 2006). The specific functional groups are capable of rebinding the target molecule with high specificity, comparable to that of antibodies. 
MIPs have unique binding characteristics, high chemical and physical stability, are durable to harsh chemical media, heat, and pressure, and can be used repeatedly without loss of activity. For these reasons, MIP are sometimes referred to as artificial or "plastic" antibodies and are considered an alternative to antibodies (Ye \& Haupt, 2004). It has been shown that they can be substituted for biological receptors in certain formats of immunoassays and biosensors (Lavignac et al., 2004). Although the majority of MIP research has focused on concentrating or detecting low molecular weight analytes in analytical chemistry, there has been interest in applying MIP's for the detection of food contaminants (Lok \& Son, 2009).

\subsubsection{Aptamers}

Nucleic acid aptamers are another potential source of high affinity binding reagents against several targets, with some distinct advantages in production and amplification. Aptamers, derived from the Latin word "aptus", meaning "to fit" are a relatively new

field. They are synthetic short single-stranded nucleic acids, either DNA or RNA, with similar binding properties as to those of antibodies. They are able to fold into unique and stable structures and bind specifically to their target with high affinity (Figure 1.7) (Silverman, 2007). Rapid association and slow dissociation rates give them an unexpectedly high affinity. Aptamers have a wide range of targets, from small molecules such as antibiotics, biomolecules, and biological co-factors, to macromolecules such as growth factors, marker peptides, immunoglobulins, and toxins to even viruses or live cells (Silverman, 2007). 


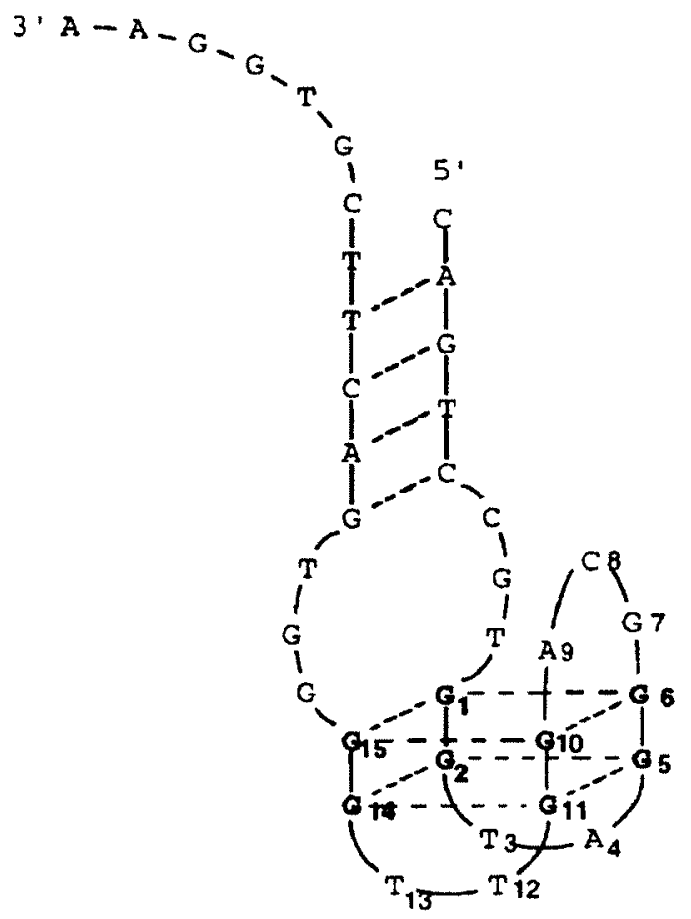

Figure 1.7 Schematic of a specifically folded aptamer. Aptamers are unstructured when in free solution in the absence of their targets, but will take on a specific confirmation when binding to a target. The aptamer structure depicted here is specific to aptamer binding to thrombin protein. Solid lines, phosphodiester bonds; dashed lines, hydrogen bonds (modified from Tasset et al., 1997). 
Due to this large number of possible targets, their unique characteristics, and their chemical structure, aptamers have become ideal candidates for use in many diagnostic, therapeutic, and (bio)analytical applications (Jayasena, 1999; Mairal et al, 2008; Tombelli et al, 2007). Aptamers have been found to be applicable to food safety testing and have been seen in the detection of various small molecule targets, such as pesticides (Stead et al., 2010), toxins (Kuang et al., 2010), antibiotics (Niazi et al., 2008; Kim et al., 2009), and pathogenic targets, such as bacterial targets like Campylobacter jejuni (Bruno et al., 2009), Listeria monocytogenes (Yamamoto et al., 2010), and Salmonella typhimurium (Joshi et al., 2009). Many of these tests involve sophisticated platform technologies. For instance, aptamers have emerged as a viable alternative to antibodies in biosensor platforms. Biosensors are devices designed to detect a target using a combination of a specific molecular recognition element and detection element (Ricci et al., 2007). A specific ligand, often an antibody, acts as a target recognition element to a particular analyte of interest, which produces a primary signal upon binding to the target. This primary signal is converted into a measurable signal by a transducer that acts as a detector element. The signal is obtained, stored, amplified, manipulated, and analyzed. Recently, more aptamer-based biosensors have been developed, with aptamers immobilized on a solid surface to serve in signal transduction upon binding with an analyte (Cho et al., 2009; Zhou et al., 2010). The use of aptamers in biosensors has shown more advantages over the use of antibodies (Song et al., 2008; Tombelli et al., 2007). However, many of these platforms require specialized custom-built devices or complex chemistries for reagent detection, which is not practical for food microbiology analytical testing laboratories. 
Aptamers are isolated from a library of synthetic oligonucleotides through a process called Systematic Evolution of Ligands by EXponential enrichment (SELEX) (Figure 1.8) (Ellington \& Szostak, 1990; Tuerk \& Gold, 1990). The initial aptamer pool consists approximately of $10^{14}-10^{15}$ oligonucleotides that have conserved 5 ' and $3^{\prime}$ primer binding sequences and a randomly generated middle portion. A target molecule is added to allow binding of aptamers in the pool. Aptamers are largely unstructured in the absence of their targets; however, upon introduction of the target to the solution aptamers will take on a specific confirmation when binding occurs to allow for selective target recognition. The target-aptamer complex is isolated and the aptamers with the highest binding affinity are amplified by PCR. This process is repeated until the best aptamer is found. The aptamers that emerges from the SELEX selection are full-length sequences containing the conserved primer binding sequences. These full-length aptamers can be truncated to eliminate nucleotide portions of the aptamer that are not involved in the direct interaction with the target. In the majority of cases, the primer binding sequences are not important for aptamer function and can be eliminated. Once the aptamer sequence is identified, an aptamer is produced by chemical synthesis, providing ample quantity of aptamer and eliminating batch to batch variety. Furthermore, due to their chemical synthesis, modifications can be made to the aptamer to enhance its stability, affinity and specificity.

Aptamers have several distinct advantages over antibodies in their production and amplification, making their use preferable. As previously mentioned, antibody production is time consuming and there is variability in antibody stability and in its batch to batch quality, as well as the need for a cell line and animal model. Aptamer selection occurs in 


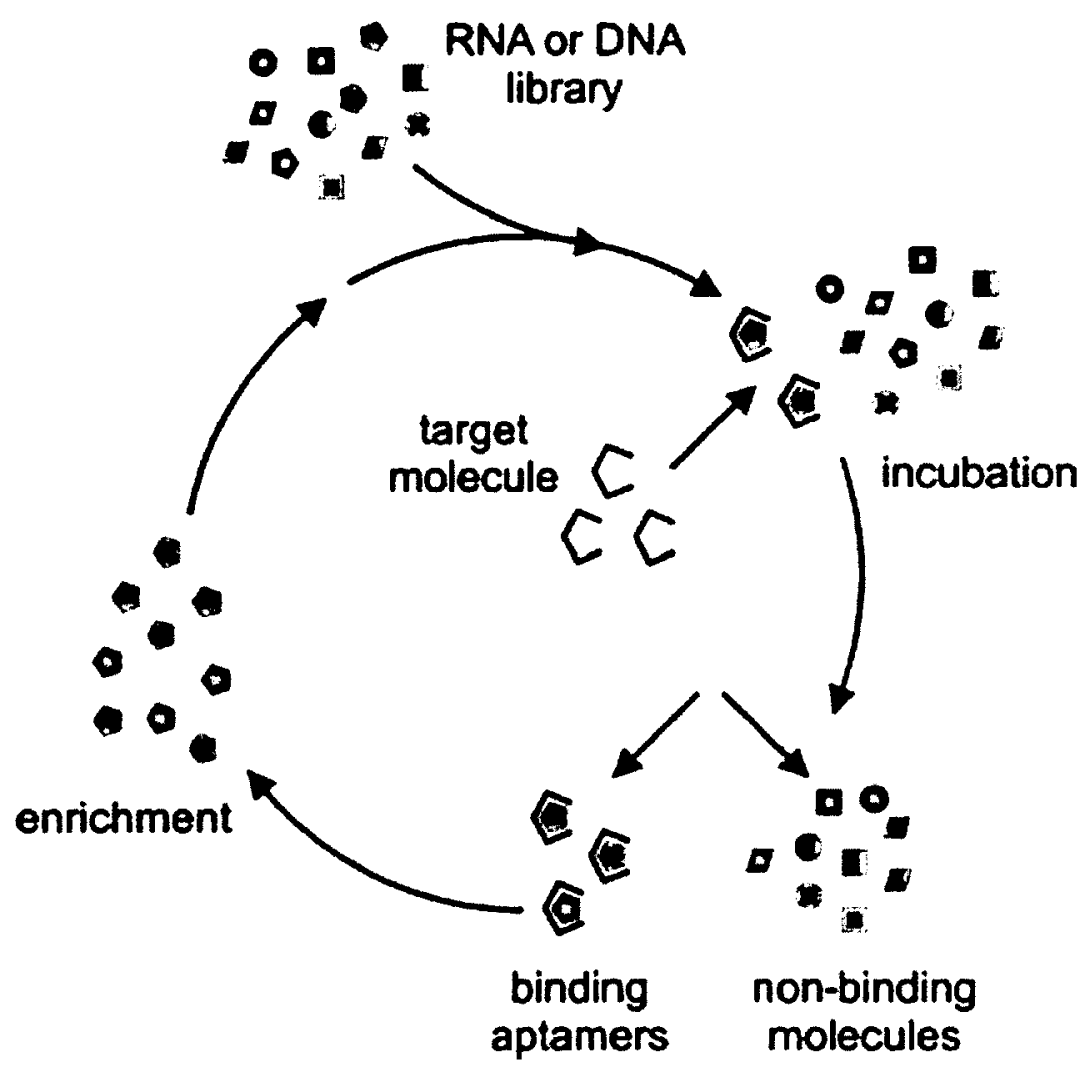

Figure 1.8 Process of the Systematic Evolution of Ligands by EXponential enrichment (SELEX) in the selection of aptamers. An oligonucleotide pool of single stranded DNA or RNA molecules is incubated with a target molecule. Non-binding aptamer molecules are separated from bound aptamers. Bound aptamers are eluted and subsequently amplified by PCR resulting in an enriched pool for sequence binding to the target. The pool is then subjected to further rounds of selection (reproduced from Weigand \& Suess, 2009). 
vitro, which eliminates the use of animals. Due to this in vitro selection, aptamers for many more targets can be developed, such as toxins, which might produce unwanted immune responses in animals, making antibodies against these targets difficult to raise. Furthermore, the chemical synthesis of aptamers makes reproducibility accurate and eliminates batch to batch variability. Finally, aptamers have higher temperature stability. Whereas antibodies are sensitive to temperature and their denaturation is irreversible, aptamers can recover their native confirmation after denaturation. All these advantages over antibodies make aptamers a potentially better alternative.

\section{Need for simple, rapid, inexpensive methods for pathogen detection}

Food safety is an increasingly important public health issue and the detection of contaminants is of the utmost importance to ensure food is safe for consumption. To safeguard public health simple, rapid, and accurate assays for the detection of contaminants are needed to eliminate the sale and consumption of contaminated foods by consumers. Many of the rapid assays that have been developed recently target only a single pathogen, whereas conventional methods can test for multiple pathogens by adjusting the selective media. Furthermore, many rapid method systems require expensive instruments or equipment, which may be a drawback for some laboratories. Also, the usefulness of some rapid methods can be limited depending on the target of detection. For instance, DNA probes and PCR assays target the genetic potential of a pathogen to produce toxins or express virulence but they give no indication of expressed virulence or toxins already present in food samples. Assays using molecular biological techniques are also affected by the various food matrices and normal microflora, thus still 
requiring pre-enrichment. Therefore, most of these techniques are used for screening purposes and all positive results are still required to be confirmed by culture methods.

The primary objective of food testing laboratories is to provide information for the effective analysis of the hazards associated with the distribution and consumption of foods. In addition to testing for many foodborne pathogens, most food testing laboratories are required to have the capacity to process a large number of samples for the presence of specific pathogenic bacteria in foods. Thus, it is imperative for researchers to develop rapid, specific and ultrasensitive detection methods aimed at eliminating pre-test preparation and enhancing high throughput testing in the most efficient manner to safeguard public health.

\section{Objectives}

The goal of this project was to develop novel assay principles by incorporating aptamers, as either capture or detection affinity binding reagents, in the identification of foodborne pathogenic bacteria and other contaminants that are a concern to food safety inspection programs. The first objective was to develop a simple and rapid immunoenzymatic assay system using aptamers immobilized on macroporous polyester cloth to act as a high affinity binding surface for the capture of analytes. The second objective of the thesis was to combine aptamers and amplification techniques in which aptamers provide

ultrasensitive detection signal upon binding to target analytes. Thus the ultimate goal of the project was to exploit aptamer reagents as an alternative to traditional antibodies that could provide ultrasensitive and specific detection of analytes in test samples. 
The development of the dot blot immunoenzymatic assay system, termed "aptablot", was to adapt a simple assay platform to include the use of aptamers as capture reagents (Chapter 2). Based on the advantages of polyester cloth, oilgo-DNA aptamers were to be tested for their immobilization ability on this novel solid phase for their subsequent use in the capture of specific analytes from samples, followed by detection by standard immunoenzymatic procedures, resulting in a "sandwich" aptablot format (Figure 1.9 a). Displacement and competitive inhibition aptablot systems were also developed for the detection of single epitope analytes (Figure $1.9 \mathrm{~b}$ ). The combination of aptamers and cloth provided a simple, rapid, and cost effective assay that can be applied in laboratories for use without the need for sophisticated equipment or technology.

The second half focused on the development of the Amplified Aptamer Assay $\left(A^{3}\right)$. In the development of this novel ultrasensitive assay technology, analyte-specific DNA aptamers were utilized as affinity binding reagents for the detection of test analyte captured on an antibody-coated solid phase, such as a microtiter plate. Based on the hypothesis that single stranded DNA aptamers can be amplified like any other polynucleotide sequence, subsequent detection of the bound aptamer by nucleic acid amplification techniques provided exponential amplification of the aptamer itself in order to facilitate detection of even minute quantities in the microtiter plate (Figure 1.10). Therefore, the first objective of the development of this assay was to establish a suitable nucleic acid amplification method to increase the aptamer copy numbers. The two most viable options for amplification included the ultrasensitive and simple NASBA (Chapter 3) and PCR (Chapter 4) methods. Following the development of an aptamer amplification technique, the goal was to apply the technique to the detection of a specific analyte that 

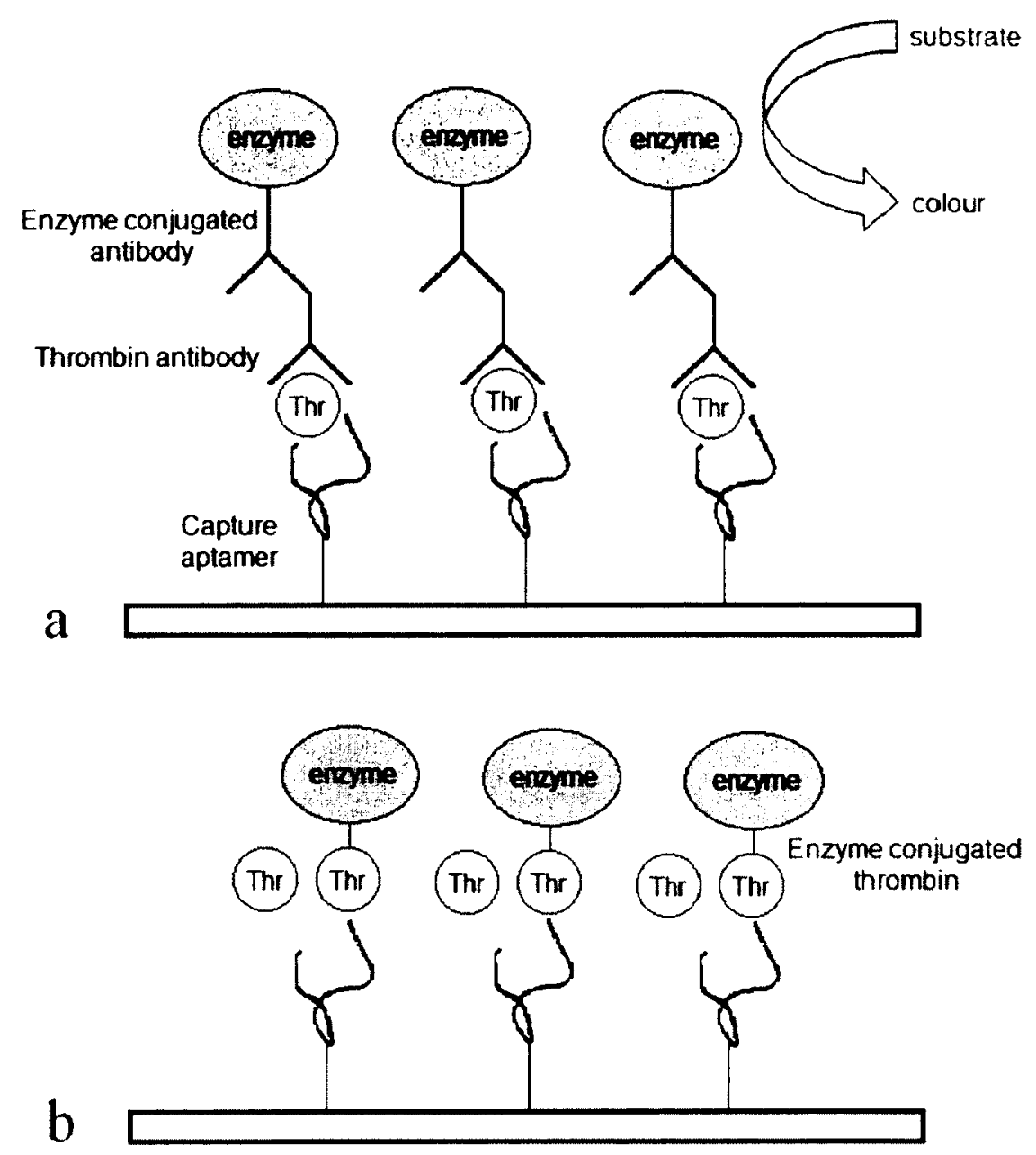

Figure 1.9 Schematic diagram of aptablot assay system. Aptamer-coated cloth is used to capture thrombin analyte from solution in a "sandwich" assay format (a). Thrombin protein is detected immunoenzymatically by subsequent reactions with anti-thrombin antibody, enzyme labeled antibody, and enzyme substrate. Enzyme labeled thrombin may be displaced by or competitively inhibit unlabeled thrombin from binding to aptamer coated cloth (b). 


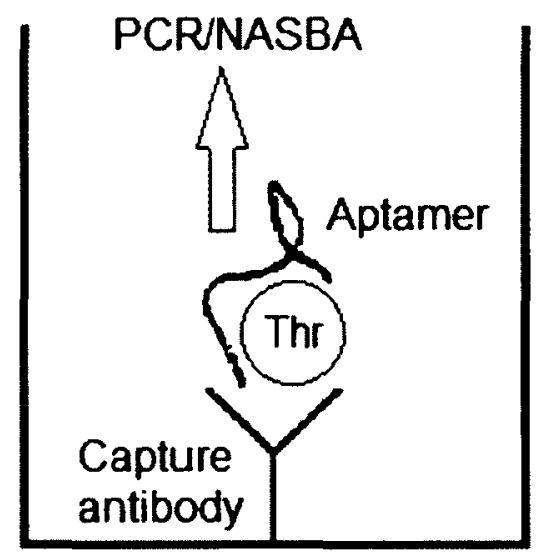

Figure 1.10 Proposed Amplified Aptamer Assay $\left(A^{3}\right)$ for the detection of contaminates in samples. Detection of target thrombin protein analyte (Thr) captured by antibodycoated wells occurs via amplification of thrombin-specific aptamer bound to the protein analyte. Amplification techniques include Nucleic Acid Sequence-Based Amplification (NASBA) or polymerase chain reaction (PCR). 
had been immuno-specifically captured from free solution. Thus an assay of this nature will allow ultrasensitive detection of analytes.

In order to demonstrate a proof-of-concept of the aptablot and $A^{3}$ assays, an appropriate model system had to be chosen. Since a primary limitation in the use of RNA aptamers as capture molecules for targets of interest is their nuclease sensitivity, an appropriate DNA aptamer model system was sought. Thus this thesis focused on the ultrasensitive detection of thrombin protein as a model analyte due to the fact that several DNA aptamers specifically targeting thrombin protein have been reported in the literature and have been well characterized (Bock et al., 1992; Tasset et al., 1997) and specific antithrombin antibodies are commercially available.

As mentioned before, the oligonucleotide pool used in a SELEX selection consists of randomly generated oligonucleotides flanked by 5' and 3' primer binding sequences to allow PCR amplification to occur. Following the SELEX procedure, aptamers are optimized to give a minimal consensus sequence for high affinity binding by removing any superfluous nucleotides that do not play a role in target binding, including the primer binding sequences. Initially, two different thrombin aptamer sequences were chosen for application in the aptablot and $\mathrm{A}^{3}$ system, a 15 nucleotide aptamer (Bock et al., 1992), Apt 1, and a 29 nucleotide aptamer (Tasset et al., 1997), Apt 2. These consensus sequences are a result of two independent thrombin aptamer SELEX selections and are the most optimized aptamer sequences with the highest binding affinity of their respective selections. However, since both aptamers are short, each approximately the general size of a primer, additional primer binding sequences were appended at the $5^{\prime}$ and 
3 ' ends of the aptamers to allow for primer binding and extension in the development of the aptamer amplification technique of the $\mathrm{A}^{3}$ system. 


\section{CHAPTER 2}

Immobilization of DNA Aptamers on Polyester Cloth for Antigen Detection by Dot Blot Immunoenzymatic Assay (Aptablot) 


\section{Abstract}

A dot blot immunoenzymatic assay system was developed using polyester cloth coated with an oligo-DNA aptamer to provide a high affinity macroporous surface for the efficient capture of a model protein analyte, thrombin, in complex sample matrices such as foods. Bound thrombin was detected immunoenzymatically using an anti-thrombin antibody, a peroxidase-linked antibody, and a chromogenic substrate, resulting in a sandwich assay format. A unique feature of this approach, which has been termed "aptablot", is the facile immobilization of DNA aptamers on the polyester surface by cross-linking with brief exposure to ultraviolet light, and the simple assay format eliminating the need for specialized instruments. Immobilization of aptamer sequences of different lengths was feasible in this manner, though for shorter aptamers the addition of a 5'-poly-T tail was necessary to obtain stronger assay signals. Slight modifications to the procedure resulted in the ability to perform competitive inhibition and displacement assays for the detection of analytes with one epitope.

\subsection{Introduction}

The detection of specific antigens in samples, such as bacterial pathogens or toxins, remains an important concern in the fields of human and animal health diagnostics, food safety testing, and basic research. Several rapid methods have been developed to improve testing efficiencies of conventional culture methods. One of the most widely used approaches developed for this purpose is the Enzyme-Linked ImmunoSorbent Assay (ELISA) technique. The classic "sandwich" ELISA utilizes specific antibodies immobilized on a solid phase to create a high affinity surface for the capture of antigens, 
which are subsequently detected by reaction with an enzyme-linked antibody. However, the use of antibodies as assay reagents suffers from the high cost and time required for their production, as well as variability in stability, quality, and yield which may occur from one batch to another. Coating the solid phase with capture antibody consumes a high quantity of the available antibody, which must be applied in large excess to drive its immobilization on the solid phase. A variety of solid phases such as non-porous polystyrene microwells and microporous membranes lend themselves to the immobilization of antibodies for ELISA procedures. For instance, the lateral flow immunoassay test employs nitrocellulose membranes. In this assay, the membrane is saturated with detection and capture antibodies. Any absorbed antigen binds the detection antibodies and move laterally towards the capture antibodies to form a visible band. More recently, the use of macroporous polyester cloth as a solid phase for the immobilization of antibodies has been seen in the development of simple dot blot assays (Blais and Yamazaki, 1997). Compared to non-porous and microporous solid phases, polyester cloth has the advantages of offering a readily available large surface for the immobilization of immunoreagents promoting rapid immunoreaction kinetics and ease of washing between reaction steps.

Aptamers made of DNA or RNA oligonucleotides have emerged as a new class of synthetic receptors, which in some applications may replace antibodies as reagents for the assay of macromolecule analytes, such as proteins associated with pathogenic bacteria (Joshi et al., 2009). Aptamers recognizing a wide array of different proteins have been produced and there have been several reports of their adaptation as detection reagents in biosensors and other assay devices in which they are immobilized on a solid surface to 
serve in signal transduction upon binding with an analyte (Tombelli et al., 2007). Many of these assay systems utilize specialized custom-built devices or complex chemistries for aptamer immobilization and reagent detection, which are not within the scope of food microbiology testing laboratories.

The present study examined the use of polyester cloth as an adsorbent for DNA aptamers in the development of simple assays utilizing cloth strips upon which multiple samples can be blotted, and hence, processed simultaneously. The immobilization of oligo-DNA probes on polyester cloth by brief exposure to ultraviolet light for use in the detection of PCR products by hybridization has previously been shown (Blais \& Martinez-Perez, 2011). Thus it was postulated that this simple approach should also permit the immobilization of DNA aptamers to create a high affinity capture surface for the immunogenic assay of target analytes. The sandwich "aptablot" approach resembles a "sandwich" ELISA assay in which target molecules bearing multiple epitopes or binding sites are captured by an affinity binding agent coated on a solid phase, followed by detection using a second enzyme-linked binding agent.

However, the sandwich aptablot approach would not be successful in the detection of analytes with small molecular size, where there might only be a single binding site thus preventing its capture with one agent and detection with another. Therefore, the development of a "displacement" and a "competitive inhibition" assay for the detection of single epitope analytes was briefly explored. This assay involved a standard preparation of target molecule conjugated to the detector enzyme which can either be displaced from aptamer-coated cloth by free target or compete with free target for binding to aptamer-coated cloth. As mentioned in Chapter 1, a thrombin model 
system was used due to the availability of well characterized DNA thrombin aptamers. Finally, a lysozyme aptamer (Wang et al., 2009) was also selected for the alternative detection of lysozyme to demonstrate broader applications of the sandwich aptablot assay.

\subsection{Materials and Methods}

\subsubsection{Aptamers}

Aptamers used in the present study were selected against the human coagulation protein thrombin (Table 2.1). Apt 1 and Apt 2 are DNA thrombin aptamer consensus sequences resulting from two independent SELEX selections that have been reported in the literature; one 15 nucleotide sequence (Bock et al., 1992) and one 29 nucleotide sequence (Tasset et al., 1997), respectively. Modified (Mod) Apt 2 was designed by appending additional randomly generated primer binding sequences at the $5^{\prime}$ and $3^{\prime}$ ends (Chapter 3). SELEX Apt is the 105 nucleotide original SELEX library sequence used in the SELEX selection of Apt 2, the sequence for which was provided in the literature. Finally, Lyso Apt was selected against chicken egg white lysozyme. In addition to the thrombinand lysozyme-binding sequences, a 50-mer oligonucleotide probe originally conceived for hybridization with a verotoxin (VT 1) PCR amplicon (Blais \& Martinez-Perez, 2011) was also chosen to serve as a negative control for aptamer binding. All oligonucleotides were synthesized by Sigma Genosys (Oakville, ON, Canada).

\subsubsection{Sample matrices}

Sample matrices used to study detection of target analyte thrombin included pasteurized $1 \%$ milk and beef broth (ingredients: beef broth [water, beef stock], yeast extract, salt, 
Table 2.1 Oligonucleotide sequences used for immobilization on polyester cloth

\begin{tabular}{|c|c|c|c|}
\hline Aptamer & Sequence $\left(5^{\prime}-3^{\prime}\right)$ & $\begin{array}{l}\text { Length } \\
\text { (bp) }\end{array}$ & Source \\
\hline Apt 1 & GGTTGGTGTGGTTGG & 15 & $\begin{array}{l}\text { Bock et al., } \\
1992\end{array}$ \\
\hline Apt 2 & AGTCCGTGGTAGGGCAGGTTGGGGTGACT & 29 & $\begin{array}{l}\text { Tasset et } \\
\text { al., } 1997\end{array}$ \\
\hline $\begin{array}{l}\text { Mod Apt } \\
\quad 2\end{array}$ & $\begin{array}{l}\text { GCTCCTACAAATGCCATCATTAGTCCGTG } \\
\text { GTAGGGCAGGTTGGGGTGACTGCTGCAG } \\
\text { CGAGCTTACG }\end{array}$ & 67 & This study \\
\hline $\begin{array}{l}\text { SELEX } \\
\text { Apt }\end{array}$ & $\begin{array}{l}\text { AGATGCCTGTCGAGCATGCTCTTTGGAGA } \\
\text { CAGTCCGTGGTAGGGCAGGTTGGGGTGA } \\
\text { CTTCGTGGAAGAAGCGAGACGGTGTAGC } \\
\text { TAAACTGCTTTGTCGACGGG }\end{array}$ & 105 & $\begin{array}{l}\text { Tasset et } \\
\text { al., } 1997\end{array}$ \\
\hline $\begin{array}{l}\text { Lyso } \\
\text { Apt }\end{array}$ & $\begin{array}{l}\text { ATCTACGAATTCATCAGGGCTAAAGAGTGC } \\
\text { AGAGTTACTTAG }\end{array}$ & 42 & $\begin{array}{l}\text { Wang et al., } \\
2009\end{array}$ \\
\hline VT 1 & $\begin{array}{l}\text { ACTGGATGATCTCAGTGGGCGTTCTTATG } \\
\text { TAATGACTGCTGAA }\end{array}$ & 50 & $\begin{array}{l}\text { Blais \& } \\
\text { Martinez- } \\
\text { Perez, } 2011\end{array}$ \\
\hline
\end{tabular}


flavour, salted onion juice, caramel, disodium inosinate, disodium guanylate) purchased from a local grocer, and the microbial growth medium brain heart infusion (BHI) broth (ingredients per litre: $12.5 \mathrm{~g}$ brain infusion solids, $5.00 \mathrm{~g}$ beef heart infusion solids, $10.0 \mathrm{~g}$ proteose peptone, $2.00 \mathrm{~g}$ glucose, $5.00 \mathrm{~g}$ sodium chloride, and $2.50 \mathrm{~g}$ disodium phosphate) (Oxoid CM1135, Ottawa, ON).

\subsubsection{Development of sandwich aptablot assays}

\subsubsection{Preparation of aptamer-coated cloth by spotting}

Polyester cloth (DuPont Sontara 8100; DuPont, Mississauga, ON) cut into $2 \times 5 \mathrm{~cm}$ strips and bearing a printed sample location grid with 5 cells were prepared by contract with Dave's Custom Promotions, Inc. (Ottawa, Ontario, Canada), and washed with 95\% $(v / v)$ ethanol followed by rinsing with deionized distilled water on a filter with vacuum suction. The strips were air dried overnight prior to use for aptamer immobilization.

DNA thrombin aptamers and VT 1 (Table 2.1) were prepared in high salt buffer (HSB: $0.1 \mathrm{M}$ Tris- $\mathrm{HCl}(\mathrm{pH} 8.0), 0.01 \mathrm{M} \mathrm{MgCl}_{2}$, and $0.15 \mathrm{M} \mathrm{NaCl}$ ) containing $30 \%(\mathrm{v} / \mathrm{v}$ ) ethanol. A concentration of $10 \mu \mathrm{M}$ for each oligonucleotide, previously shown to be satisfactory for the immobilization of capture probes in PCR applications (Blais \& Martinez-Perez, 2011), was used in these experiments. Aptamer solution was applied in discrete spots $(5 \mu \mathrm{l})$ on the polyester cloth strips, followed by incubation for $3 \mathrm{~h}$ at $37^{\circ} \mathrm{C}$ in a dry incubator. The aptamers were cross-linked to the dried strips by exposing the

strips to ultraviolet (UV) light using a UV cross-linker set at $254 \mathrm{~nm}, 120 \mathrm{~mJ} \mathrm{~cm}^{-2}$ (Stratalinker model 1800; Stratagene, La Jolla, CA), and then washed five times with $0.01 \mathrm{M}$ phosphate-buffered saline, $(\mathrm{pH} 7.4), 0.85 \%(w / v) \mathrm{NaCl}(\mathrm{PBS})$ containing $0.05 \%$ 
Tween 20 (PBST) on a filter under vacuum suction. The strips were blocked by incubation for $1 \mathrm{~h}$ at $37^{\circ} \mathrm{C}$ with $0.5 \%(\mathrm{w} / \mathrm{v})$ Bio-Rad protein blocking reagent (Bio-Rad 170-6404, Hercules, CA) in PBST, followed by washing with PBST.

\subsubsection{Preparation of aptamer-coated cloth by saturation}

Aptamer was prepared in HSB containing 30\% (v/v) ethanol. Polyester cloth strips were saturated with $1 \mathrm{ml}$ of $1 \mu \mathrm{M}$ aptamer solution and incubated for $3 \mathrm{~h}$ at $37^{\circ} \mathrm{C}$ in a dry incubator. The aptamer was cross linked to the dried strips by UV exposure as described above, then washed with PBST, and blocked.

\subsubsection{Thrombin sandwich assay on aptamer-coated cloth}

The following reactions were carried out at room temperature in the dark. Cloth strips coated by spotting aptamer in discrete areas were reacted with thrombin by saturating with $1 \mathrm{ml}$ of PBS containing $13.5 \mathrm{nM}$ of human $\alpha$-thrombin (Haematological Technologies Inc, HCT-0020, Essex Junction, VT) and incubated for 20 min. Strips coated by saturation of the entire surface with aptamer were reacted with thrombin samples by discretely spotting $5 \mu \mathrm{l}$ of thrombin at various concentrations in different sample matrices (PBS, 1\% milk, BHI broth, and beef broth), then incubated for $20 \mathrm{~min}$. Strips were then washed five times with PBST on a filter with vacuum suction. Bound thrombin was assayed by sequential $20 \mathrm{~min}$ reactions of the strips with $1 \mathrm{ml}$ containing anti-human thrombin antibody (Haematological Technologies Inc., AHT-5020, Essex Junction, VT) diluted 1:1000 in PBST, and $1 \mathrm{ml}$ of anti-mouse IgG-peroxidase conjugate (Sigma-Aldrich, A3673, Oakville, ON) diluted 1:1000 in PBST, with PBST washes after each step. Finally, the strips were saturated with $1 \mathrm{ml}$ of TMB membrane peroxidase 
substrate (Kirkegaard \& Perry Laboratory, 50-77-02, Gaithersburg, MD) and incubated for $10 \mathrm{~min}$. Reactions were graded qualitatively as follows: positive (blue spot), negative (no spot).

\subsubsection{Lysozyme sandwich assay on aptamer-coated cloth}

The detection of lysozyme was used as an alternative model system to demonstrate the applicability of the aptablot system. Lyso Apt (Table 2.1) was prepared in HSB in a similar fashion as the aptamers described above. Polyester cloth strips were saturated with $1 \mathrm{ml}$ of aptamer solution and incubated for $3 \mathrm{~h}$ at $37^{\circ} \mathrm{C}$ in a dry incubator. The aptamer was cross-linked to the dried strips by UV exposure, then washed with PBST, and blocked as described above. The following reactions were carried out at room temperature in the dark. Strips were reacted with lysozyme from chicken egg whites (Sigma-Aldrich, L3790, Oakville, ON) by discretely spotting $5 \mu$ l of lysozyme at various concentrations in PBS and incubated for $20 \mathrm{~min}$. Strips were washed with PBST and bound lysozyme was assayed by saturating strips with $1 \mathrm{ml}$ of anti-lysozyme antibody peroxidase conjugate (Rockland Immunochemicals, Inc., 200-4372, Gilbertsville, PA) diluted 1:1000 in PBST and incubated for $20 \mathrm{~min}$. Finally, the strips were saturated with $1 \mathrm{ml}$ of TMB membrane peroxidase substrate and incubated $10 \mathrm{~min}$. Reactions were graded qualitatively as follows: positive (blue spot), negative (no spot).

\subsubsection{Development of competitive aptablot assays}

\subsubsection{Thrombin protein conjugation to horseradish peroxidase}

Human $\alpha$-thrombin protein was conjugated to horseradish peroxidase using an EZ-Link $®$ Plus Activated Peroxidase (Fisher Scientific Ltd., 31487, Ottawa, ON). Thrombin was 
diluted $0.5 \mathrm{mg}$ in $0.5 \mathrm{ml}$ of $0.06 \mathrm{M}$ carbonate buffer, $\mathrm{pH} 9.6$ and loaded into a Slide-ALyzer® dialysis cassette (Fisher Scientific Ltd., 66003, Ottawa, ON). Dialysis was run overnight at $4^{\circ} \mathrm{C}$ in $0.06 \mathrm{M}$ carbonate buffer $(\mathrm{pH} 9.6)$. The peroxidase was rehydrated in $10 \mathrm{mM}$ sodium carbonate buffer $(\mathrm{pH} 9.5)$ to a final concentration of $69.9 \mu \mathrm{M}$. The following reactions were carried out at room temperature in the dark. After dialysis of thrombin, $0.5 \mathrm{ml}$ of the thrombin protein was mixed gently with $0.5 \mathrm{ml}$ of the rehydrated peroxidase for $3 \mathrm{~h}$ and then $1 \mathrm{mg}$ of sodium borohydride (Sigma-Aldrich, 452882, Oakville, ON) was added and incubated for $15 \mathrm{~min}$. Finally, $20 \mu \mathrm{l}$ of $3 \mathrm{M}$ ethanolamine, $\mathrm{pH} 10.5$ was added and incubated for $15 \mathrm{~min}$. The thrombin-peroxidase conjugate was dialyzed using a dialysis cassette and PBS overnight at $4^{\circ} \mathrm{C}$.

\subsubsection{Thrombin displacement assay on aptamer-coated cloth}

Polyester cloth strips were coated with aptamer at various concentrations by spotting, followed by UV cross-linking, blocking, and washing, as described above. The following reactions were carried out at room temperature in the dark. Strips were reacted with thrombin-peroxidase conjugate by saturating the cloth with thrombin-peroxidase diluted 1:1000 in PBST and incubated 20 min. Following washing, the strips were saturated with $1 \mathrm{ml}$ of thrombin protein diluted $27.2 \mathrm{nM}$ in PBST and incubated for $40 \mathrm{~min}$. Finally, the

strips were saturated with $1 \mathrm{ml}$ of TMB membrane peroxidase substrate and incubated 10 min. Reactions were graded qualitatively as follows: positive (no spot), negative (blue spot). 


\subsubsection{Thrombin inhibition assay on aptamer-coated cloth}

Polyester cloth strips were coated with aptamer at various concentrations by spotting, followed by UV cross-linking, blocking, and washing, as described above. The following reactions were carried out at room temperature in the dark. Strips were saturated with a solution containing thrombin-peroxidase conjugate diluted 1:1000 and free thrombin diluted $27.2 \mathrm{nM}$ in PBST and incubated $40 \mathrm{~min}$. Following washing, the strips were saturated with $1 \mathrm{ml}$ of TMB membrane peroxidase substrate and incubated $10 \mathrm{~min}$. Reactions were graded qualitatively as follows: positive (no spot), negative (blue spot).

\subsection{Results}

\subsubsection{Immobilization of anti-thrombin oligonucleotides in a sandwich assay format}

Initial experiments examined the immobilization and subsequent thrombin-capturing abilities of different aptamer sequences reported in the literature. For this purpose, oligonucleotides ranging in size from 15 to 105 nucleotides and ranging in sequence were immobilized in discrete spots on a strip of polyester cloth and then assessed for binding activity by flooding the entire strip with thrombin solution, followed by detecting bound thrombin by sequential reactions of the strip with anti-thrombin monoclonal antibody, anti-mouse IgG-peroxidase conjugate, and TMB substrate. In addition to the thrombinbinding sequences, a VT 1 probe was also immobilized on the cloth strip to serve as a negative control for thrombin binding.

Shorter aptamer sequences of 15 and 29 nucleotides in length did not produce any visible reaction with thrombin, whereas the longer 67 and 105 nucleotide aptamers crosslinked to the polyester cloth by UV light exhibited significant thrombin-binding activity 
manifested as localized immunoenzymatic reactivity on the strip where these aptamers had been spotted (Figure 2.1). No reactivity was observed with the verotoxin probe spot. Neither was thrombin-binding activity observed for any of the aptamers in the absence of UV exposure.

The preceding experiment involved the immobilization of aptamers at a concentration of $10 \mu \mathrm{M}$. However, for future applications the optimum concentration for coating the polyester cloth was determined by spotting different amounts of the SELEX Apt and then assaying using the immunoenzymatic procedure as before. A minimum of $0.25 \mu \mathrm{M}$ aptamer solution spotted on the strip produced a detectable assay signal, though the least concentration to give strong signal intensity was $1 \mu \mathrm{M}$ (Figure 2.2), which was therefore used in subsequent experiments.

As observed in Figure 2.1, longer oligonucleotides were successfully immobilized on the cloth surface whereas shorter oligonucleotides were not. Since longer oligonucleotides contain primer-binding sequences at their $5^{\prime}$ and 3 ' ends, which are not involved in aptamer binding but may provide an immobilization link with the polyester surface, it was hypothesized that a poly-nucleotide tail at the end of an aptamer may act to link the aptamer to the cloth. Thus an investigation into the possibility of enhancing the immobilization of shorter aptamers was made. The 29 nucleotide Apt 2 was modified by synthesizing versions of Apt 2 bearing the following short $(n=5) 5^{\prime}$-poly-nucleotide tails, poly-A, poly-C, poly-G or poly-T, followed by immobilization on strips of polyester cloth by UV cross-linking as before. The ability of the immobilized aptamer to capture thrombin was determined by reacting the strips with thrombin solution, followed by immunoenzymatic assay of the bound thrombin as previously described. The addition of 


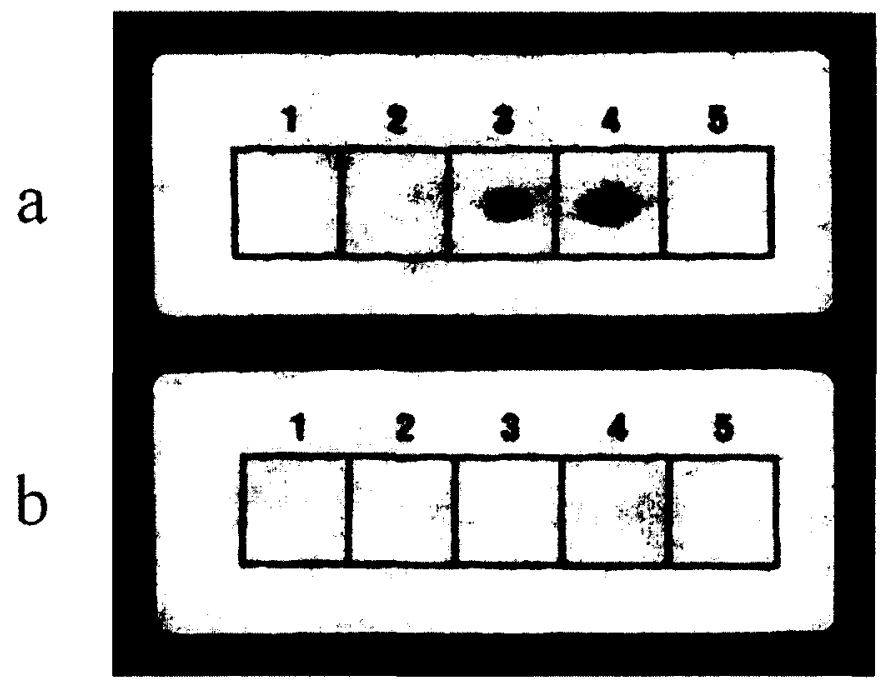

Figure 2.1 Effect of oligonucleotide sequence on immobilization of aptamers to polyester cloth. Different oligonucleotides (1, Apt 1; 2, Apt 2; 3, Mod Apt 2; 4, SELEX Apt; 5, VT 1) were spotted on polyester cloth. The strips were either UV cross-linked (a) or not (b) and then saturated with thrombin solution followed by immunoenzymatic assay of bound thrombin as described in Methods. These experiments were repeated in a separate trial with identical results (not shown). 


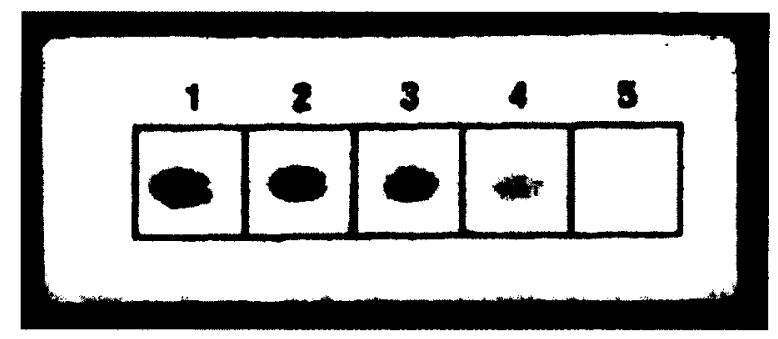

Figure 2.2 Effect of aptamer coating concentration. SELEX Apt was spotted on polyester cloth at different concentrations $(1,2.00 \mu \mathrm{M} ; 2,1.00 \mu \mathrm{M} ; 3,0.50 \mu \mathrm{M} ; 4,0.25$ $\mu \mathrm{M} ; 5,0.12 \mu \mathrm{M})$. After UV cross-linking the strips were saturated with thrombin solution followed by immunoenzymatic assay of bound thrombin as described in Methods. These experiments were repeated in a separate trial with identical results (not shown). 
a poly-G tail produced a weak assay signal, but a more striking result was obtained with a poly-T tail, which produced a signal intensity equivalent to that observed with the full length SELEX Apt (Figure 2.3).

Upon the successful immobilization of $5 \cdot(n=5)$ poly-T tailed Apt 2, further studies were performed to optimized tail length and to determine if a 3'-poly-T tail has similar effects. Thus Apt 2 was synthesized with $5^{\prime}-$ and $3^{\prime}-\left(n^{\prime}=5,=10\right.$, and $\left.=15\right)$ poly-T tails, spotted on the cloth at various concentrations, reacted with thrombin, and detected immunoenzymatically as described above. The longer length 5 '-poly-T tail $(n=15)$ seemed to have the best signal intensity than the $(n=5)$ or $(n=10)$ poly- $T$ tail when aptamer was spotted at the lowest concentration of $0.1 \mu \mathrm{M}$ (Figure 2.4). The addition of a 3'-poly-T tail gave similar results as the 5'-poly-T tail (not shown).

\subsubsection{Detection of thrombin in different sample matrices}

The preceding experiments utilized aptamer applied in localized spots on a strip of polyester cloth. The aptamer-thrombin interaction occurred in a defined buffer devoid of extraneous materials which might produce interference with the binding reaction. Thus, the ability of the immobilized aptamer to detect thrombin analyte from among a variety of ingredients was also tested. Strips of polyester cloth were entirely coated by saturation with SELEX Apt solution. These were then used for the capture of thrombin from samples spotted in the cells of the printed grid. To determine the impact of the sample matrix, thrombin was diluted in different types of liquid samples containing complex mixtures of ingredients, PBS, $1 \%$ milk, BHI broth, and beef broth. The minimum quantity of thrombin producing a visible assay signal was $1.35 \mathrm{nM}$ in PBS, $0.27 \mathrm{nM}$, with 


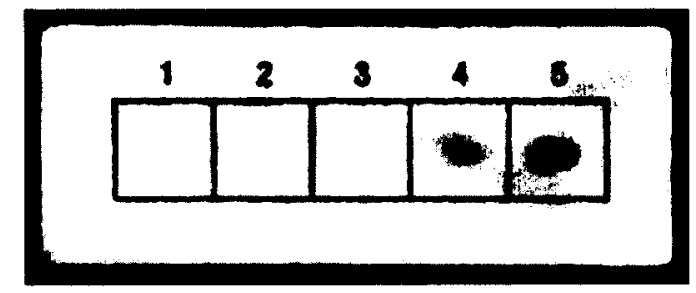

Figure 2.3 Effect of the addition of 5'-poly-nucleotide tails on the immobilization of a shorter length aptamer. Apt 2 was synthesized with different polynucleotide $(n=5)$ tails at the $5^{\prime}$ end (1, untailed Apt 2; 2, 5'-poly-A-tailed; 3, 5'-poly-C-tailed; 4, 5'-poly-G-tailed; 5, 5'-poly-T-tailed) and each was spotted on polyester cloth then UV cross-linked. The strips were saturated with thrombin solution followed by immunoenzymatic assay of bound thrombin as described in Methods. These experiments were repeated in a separate trial with identical results (not shown). 


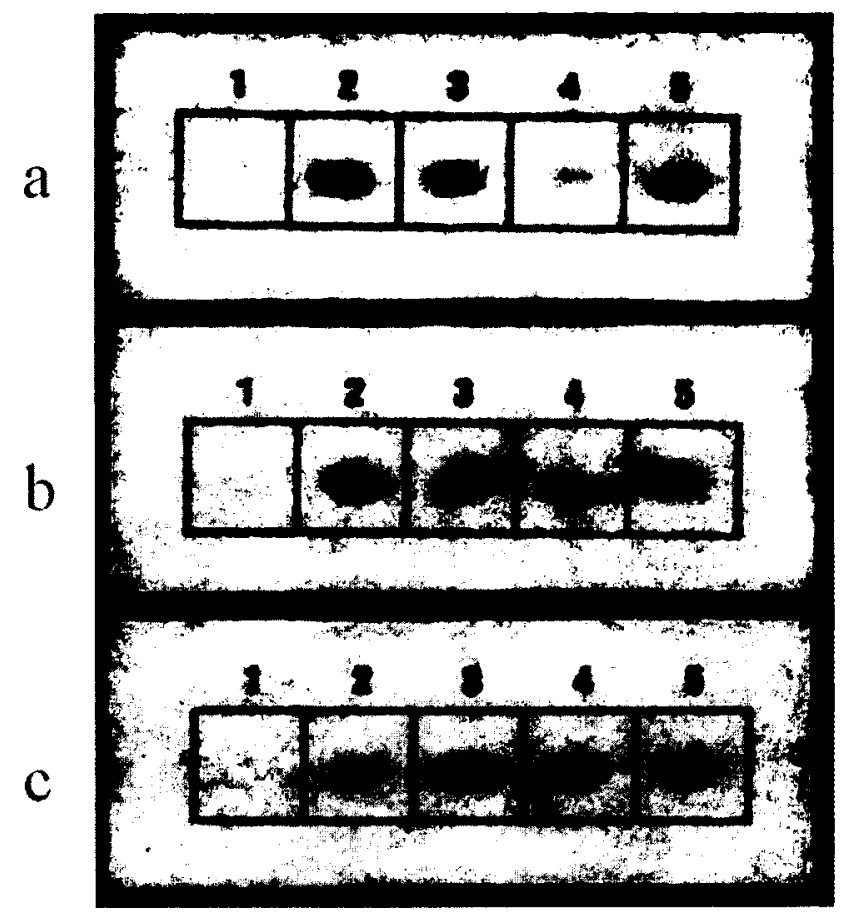

Figure 2.4 Effect of the addition of varying length 5'-poly- $T$ tails on the immobilization of a shorter length aptamer. Apt 2 was synthesized with a poly-T tail at the 5 ' end at various lengths $(a, n=5 ; b, n=10 ; c, n=15)$. Untailed, tailed, and the SELEX aptamer were spotted at various concentrations $(1,1.00 \mu \mathrm{M}$ untailed Apt $2 ; 2,1.00 \mu \mathrm{M}$ tailed Apt 2; 3, $0.50 \mu \mathrm{M}$ tailed Apt 2; 4, $0.10 \mu \mathrm{M}$ tailed Apt 2; 5, $1.00 \mu \mathrm{M}$ SELEX Apt) and cross-linked. The strips were saturated with thrombin solution followed by immunoenzymatic assay of bound thrombin as described in Methods. These experiments were repeated in a separate trial with identical results (not shown). 
weak spot intensity, in $1 \%$ milk and $\mathrm{BHI}$ broth, and $0.27 \mathrm{nM}$, with stronger spot intensity, in beef broth, which corresponds to $6.75 \times 10^{-3}$ pmol of thrombin in PBS and $1.36 \times 10^{-3} \mathrm{pmol}$ of thrombin in the $1 \%$ milk, BHI broth, and beef broth (Figure 2.5 ).

\subsubsection{Detection of lysozyme via immobilization of anti-lysozyme aptamer}

To demonstrate the applicability of the aptablot system in the detection of other analytes, a lysozyme aptamer to chicken egg white lysozyme protein was chosen for immobilization on polyester cloth in a similar fashion as the thrombin aptamer. Polyester cloth strips were prepared as described above by saturation with Lyso Apt or just buffer, followed by a blocking step. Finally, lysozyme was added and binding activity was detected by sequential reactions of the strip with anti-lysozyme antibody-peroxidase conjugate and TMB substrate. However, the results showed no binding signal for the reaction of lysozyme with Lyso Apt (not shown). Following the successful immobilization results observed for the 5'-poly-T tailed aptamer versions of the thrombin system, a $(n=5)$ 5'-poly-T tailed Lyso Apt was synthesized and tested like untailed Lyso Apt, as described above. Results for the binding of lysozyme to the 5'-poly-T tailed Lyso Apt showed a significant signal at the highest concentration of lysozyme spotted. Weaker signal intensity of lysozyme binding on cloth in the absence of aptamer was observed when compared to that of aptamer-coated cloth (Figure 2.6).

\subsubsection{Detection of thrombin on aptamer-coated cloth in a competitive assay format}

Following the detailed study and optimization of the aptamer-thrombin interaction on polyester cloth in a sandwich assay format, the possibility of a thrombin displacement 


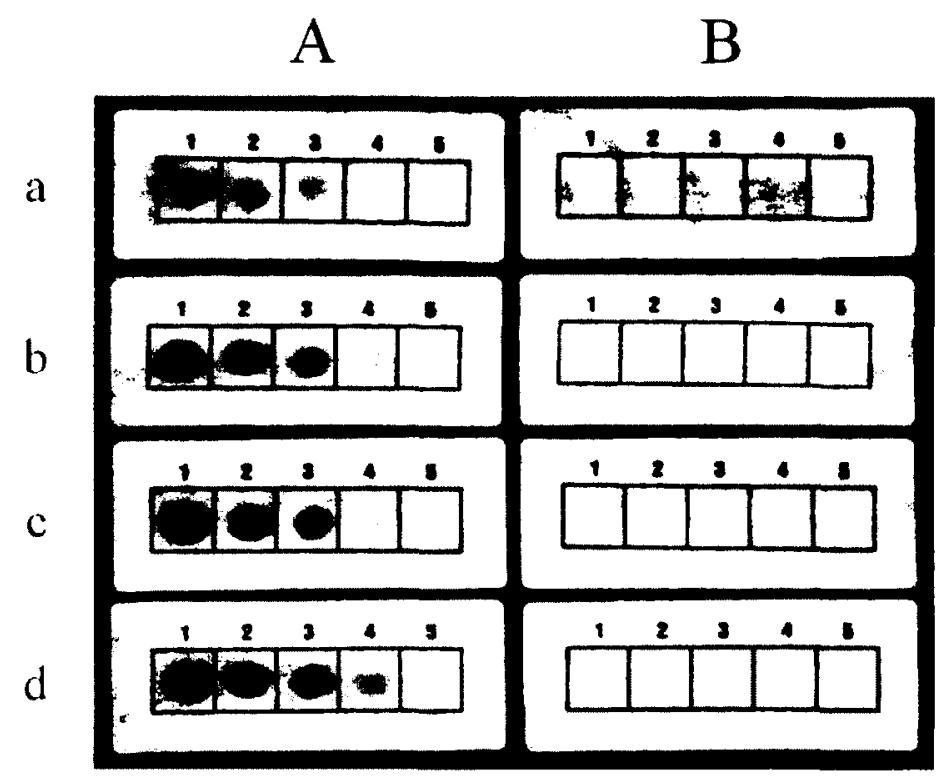

Figure 2.5 Effect of sample matrix on the detection of thrombin by aptamer-coated polyester cloth. Thrombin was prepared at different concentrations $(1,13.5 \mathrm{nM} ; 2,2.70$ $\mathrm{nM} ; 3,1.35 \mathrm{nM} ; 4,0.27 \mathrm{nM} ; 5,0 \mathrm{nM})$ in a variety of matrices (a, PBS; b, 1\% milk; c, BHI broth; d, beef broth) and then spotted on polyetster cloth strips with (A) and without (B) immobilized SELEX Apt, followed by immunoenzymatic assay of bound thrombin as described in Methods. These experiments were repeated in a separate trial with identical results (not shown). 


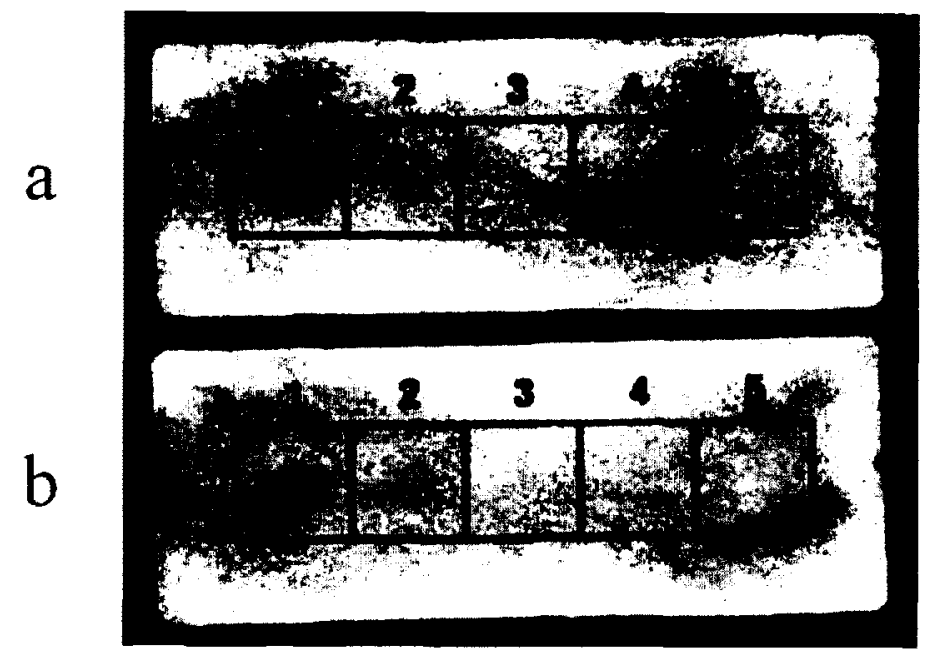

Figure 2.6 Detection of chicken egg white lysozyme protein by aptamer-coated polyester cloth. Cloth strips were either saturated with (a) or without (b) 1.00 uM 5'-polyT-tailed Lyso Apt. Following UV cross-linking, the strips were spotted with chicken egg white lysozyme protein $(1,3.50 \mu \mathrm{M} ; 2,0.70 \mu \mathrm{M} ; 3,0.35 \mu \mathrm{M} ; 4,0.07 \mu \mathrm{M} ; 5,0 \mu \mathrm{M})$ followed by immunoenzymatic assay of bound lysozyme as described in Methods. These experiments were repeated in a separate trial with identical results (not shown). 
assay was explored. To demonstrate this concept using aptamer-coated polyester cloth, strips were coated by spotting with SELEX Apt (Table 2.1) solution and used to capture thrombin-peroxidase conjugate. Once it was confirmed that thrombin-peroxidase is able to bind to the aptamer immobilized on the cloth and produce a strong positive signal (not shown), strips were prepared with aptamer and reacted with thrombin-peroxidase. Next, strips were saturated with free thrombin solution. Furthermore, to demonstrate an inhibition assay, aptamer-coated cloth was prepared and then saturated with one solution containing both thrombin-peroxidase conjugate and free thrombin. Results for the displacement and competitive inhibition assay show similar, weak intensity signals when compared to a cloth strip with only thrombin-peroxidase bound to the immobilized aptamer in the absence of competing free thrombin, which displayed strong signal intensity (Figure 2.7).

\subsection{Discussion}

The present experiments demonstrated the applicability of a simple aptablot system using a DNA aptamer as an inexpensive synthetic capture agent for the sensitive assay of a protein analyte in complex samples. A unique feature of the aptablot system is the simple means by which the aptamer was immobilized on the polyester cloth surface by brief exposure to UV light.

Based on the previously observed immobilization of oligo-DNA probes on polyester cloth by brief exposure to UV light for use in the detection of PCR products by hybridization (Blais \& Martinez-Perez, 2011), it was hypothesized that DNA aptamers could also be immobilized on polyester cloth to allow for the detection of analytes. Initial 


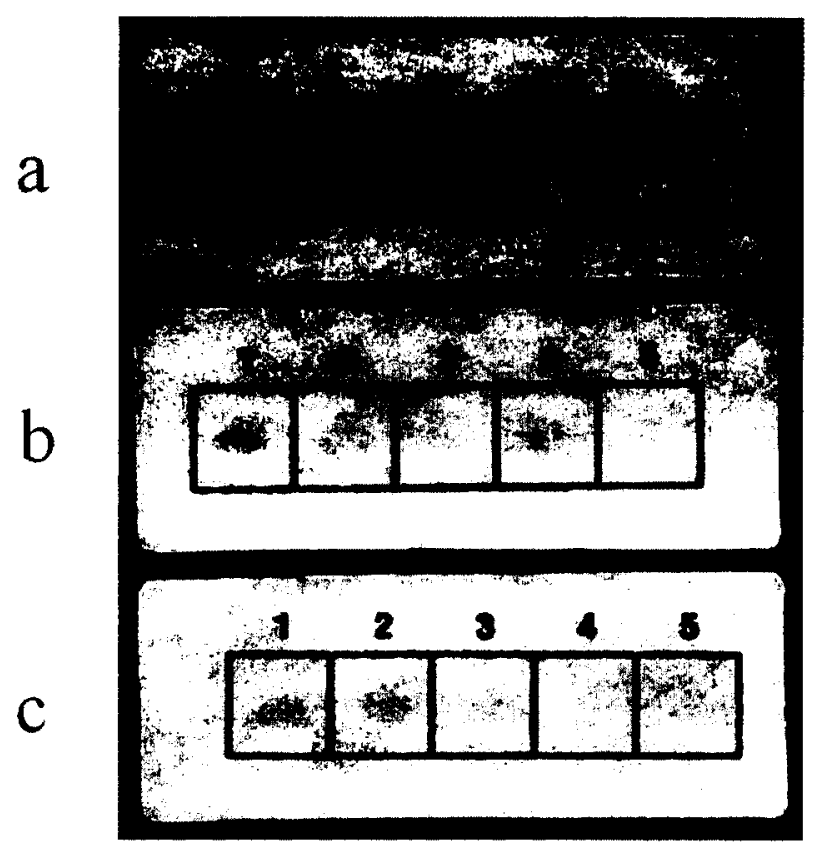

Figure 2.7 Comparison of thrombin displacement and competitive inhibition aptablots. SELEX Apt spotted at various concentrations (1, $2.00 \mu \mathrm{M} ; 2,1.00 \mu \mathrm{M} ; 3,0.50$ $\mu \mathrm{M} ; 4,0.25 \mu \mathrm{M} ; 5,0.12 \mu \mathrm{M})$ on polyester cloth, followed by binding of thrombinperoxidase conjugate diluted 1:1000 (a). Thrombin-peroxidase conjugate bound to aptamer-spotted polyester cloth displaced with $27.2 \mathrm{nM}$ of free thrombin solution (b). Aptamer-spotted cloth was reacted with a solution containing both 1:1000 diluted thrombin-peroxidase conjugate and $27.2 \mathrm{nM}$ free thrombin protein (c). These experiments were repeated in a separate trial with identical results (not shown). 
experiments demonstrated longer length aptamers showed thrombin-binding activity following cross-linking to the polyester cloth by UV light (Figure 2.1). The lack of reactivity observed in the absence of UV light exposure suggested that cross-linking the aptamers to the polyester surface is essential for stable immobilization of aptamers. Furthermore, the lack of reactivity for the 50 -mer oligonucleotide control probe originally conceived for hybridization with a verotoxin (VT 1) PCR amplicon (Blais \& MartinezPerez, 2011) confirmed that the reactions observed with the aptamers were due to their specific thrombin-binding activities (Figure 2.1).

Contrary to the immobilization ability of the longer length aptamers, the shorter length aptamer sequences did not product a visible reaction with thrombin (Figure 2.1). The lack of reactivity of the shorter aptamers may be due to an inability of small DNA molecules to bind to the polyester surface or to a perturbation in their thrombin-binding conformation caused by the cross linking reaction. The longer oligonucleotides contained primer-binding sequences at their 5' and 3' ends which are not directly involved in aptamer function but may serve to provide an immobilization link with the polyester surface sparing the conformational integrity of the aptamer portion.

After investigating the enhancement of immobilization of the shorter length aptamers by the addition of 5'-poly-nucleotide tails, it was observed that although the 5 'poly-G tail produced a weak signal, the 5'-poly-T tail increased the signal intensity of the shorter length Apt 2 to match that of the longer length SELEX Apt (Figure 2.3). Furthermore, the optimum length observed to provide effective immobilization at lower aptamer concentrations is a $(n=15)$ poly-T tail (Figure 2.4). Similar results were observed for the addition of a 3'-poly-T tail (not shown). These results suggest that poly-T tailing 
was particularly effective in enhancing the immobilization of the short aptamer in the correct form for analyte capture, thus allowing some flexibility in the choice of aptamer length. The mechanism for enhanced immobilization of the short aptamer by poly-Ttailing may involve the activation of thymine reactivity by UV irradiation, which is known to occur when genomic DNA is damaged by UV radiation in living cells (Pfeifer, 1997 ) or activation of double bonds or other active groups on the polyester (polyethylene terephthalate) surface. Whatever mechanism is involved in the immobilization of the DNA aptamers, these results clearly indicate that a suitable capture surface can be prepared using either a longer sequence, such as the SELEX Apt, or a 5'- or 3'-poly-Ttailed aptamer sequence like poly-T-Apt 2 . However, the addition of too many thymine nucleotides onto the tail of an aptamer may induce the formation of other secondary structures, thus interrupting normal aptamer folding and target binding. Therefore, for each new aptamer onto which a poly- $T$ tail is appended, length optimization is recommended.

One foreseeable application of the "sandwich" aptablot system is the detection of a target analyte in different sample types, such as allergens or pathogenic bacteria in various foods submitted for laboratory analysis. In such a scenario, it would be essential that the aptamer-target interaction be capable of proceeding in various sample matrix compositions, as might be encountered in food sample suspensions or enrichment broth cultures. Furthermore, the ideal assay format would utilize a cloth strip in which the entire surface is coated with the capturing agent, such that the strip could accommodate multiple test samples. To demonstrate how such a principle might work and to demonstrate the impact of the sample matrix on the detection of thrombin, strips of 
polyester cloth were saturated with SELEX Apt solution and were used for the detection of thrombin diluted in various sample matrices (Figure 2.5). Stronger signal intensity was observed in the cases where thrombin was diluted in the complex matrices, $1 \%$ milk, BHI broth, and beef broth, with thrombin detectability at $1.36 \times 10^{-3} \mathrm{pmol}$, when compared to thrombin diluted in PBS buffer, where the thrombin detectability was $6.75 \times 10^{-3} \mathrm{pmol}$. The reason for the slight improvement in thrombin detectability in the complex sample matrices is not known. The possibility that this might be attributable to the presence of elevated levels of salts which may affect the formation of active aptamer structures (Hamaguchi et al., 2001) was verified by repeating the assay of thrombin diluted in PBS containing $10 \mathrm{mM} \mathrm{MgCl}_{2}$ and $10 \mathrm{mM} \mathrm{CaCl}_{2}$, but the detectability in these buffers remained unchanged from that observed with PBS alone (not shown).

To verify the strong signal intensity observed in the binding of thrombin to its aptamers is not a phenomenon exclusive to the thrombin model, the sandwich aptablot method was applied to another model system. The detection of chicken egg white lysozyme by lysozyme aptamer-coated cloth was observed (Figure 2.6). Although some weak signal of lysozyme was evident in the absence of 5' poly-T-tailed Lyso Apt immobilized on the cloth, despite the inclusion of a blocking step, stronger signal was observed for lysozyme on aptamer-coated cloth. This difference in binding signal of lysozyme on aptamer-coated cloth versus the absence of aptamer immobilized on cloth can be attributed to the binding of lysozyme to its specific aptamer. Furthermore, the initial lysozyme sandwich aptablot performed with the untailed Lyso Apt gave no binding signal (not shown). So the results of the poly-T tailed Lyso Apt provide further confirmation of the previous conclusion of the benefits of poly- $T$ tailing on 
immobilization. However, due to time constraints the length and orientation of the poly-T tails were not optimized. Thus further work is needed to optimize the poly- $T$ tailing conditions of the Lyso Apt.

Although the "sandwich" aptablot system is a promising application for the testing of many target analytes examined in microbiological analytical laboratories, it may not be appropriate for the analysis of all types of potential targets. Analytes with lower molecular weights, such as mycotoxins, may not be large enough to accommodate multiple epitope biding sites; thus not allowing for the binding of a capture aptamer and a detection antibody, as observed in the sandwich assay format. Therefore, the use of the proposed displacement or competitive inhibition assays may be ideal for the detection of single epitope binding target analytes. In the first situation, aptamer-spotted cloth could already have labelled antigen bound and, with the addition of unlabelled antigen in the sample, the labelled antigen would be displaced from the aptamer, indicating the presence of target antigen in the sample. Alternatively, the labelled antigen and unlabelled antigen from the sample would be applied to aptamer-spotted cloth and would compete for binding with the aptamer. The lack of reactivity would indicate the presence of antigen in the sample. To demonstrate this concept using the thrombin model, a solution containing thrombin conjugated to peroxidase and unlabelled thrombin was added to cloth spotted with SELEX Apt solution. Furthermore, this was compared with the signals generated from the displacement of thrombin conjugate bound to aptamer-spotted cloth with the addition of free thrombin solution (Figure 2.7). The signal intensities of both assays were similar to one another and were much weaker when compared to the strong signal intensity resulting from thrombin-peroxidase conjugate bound to aptamer-spotted cloth. 
The difference in the signal intensities between the displacement and competitive inhibition assays compared to the thrombin-peroxidase conjugate bound to the aptamer indicated that the free thrombin protein was binding to the aptamer by either successfully displacing or successfully inhibiting the binding of the thrombin-peroxidase conjugate. However, when comparing the signal intensity of the displacement and competitive inhibition aptablots, there did not seem to be a significant difference in the signal intensity. This may be explained through the reversible binding equilibrium between thrombin and the thrombin aptamer. Although the results are promising for the detection of single epitope analytes, one limitation is that even under conditions of strong inhibition, there remains a weak signal spot on the strip. Whereas the results of the "sandwich" aptablot are more conclusive, where the presence of a spot gives a clear indication of analyte contamination, the presence of a spot on a displacement or competitive inhibition aptablot does not give a clear indication of analyte contamination. Thus, results are subjective and analysts must exercise judgement in comparing the intensity of spots.

While the present approach does not eliminate the use of an antibody detector reagent, it does promote conservation of precious antibody stocks due to their application in a highly diluted form. It also enables the use of monoclonal detector antibodies in instances where the corresponding epitope on the target molecule is only present in one copy, which is likely the case in the detection of a monomeric protein such as thrombin. Furthermore, antibodies to many diagnostically relevant molecules are available from commercial sources and it may be reasonably expected that the number of aptamer sequences to different analytes published in the scientific literature will grow at a great 
rate as this new reagent technology continues to evolve, expanding the scope of applications amenable to the aptablot approach. The de novo development of reagent aptamers to other analytes of interest using established protocols is not beyond the capabilities of most basic biochemistry laboratories, and future applications in which even the detector antibody used in the present approach may be replaced with a second aptamer bearing an enzyme or other readily assayable marker. More work is needed to expand the scope of application of the aptablot approach from the present thrombin model system to the assay of diagnostically relevant analytes, such as microbial toxins, protein allergens and environmental contaminants. However, the success of the proposed aptablot system is highly dependent on the identification of a suitable aptamer. Whereas the results of the thrombin aptablot demonstrated excellent binding signals, the results of the lysozyme aptablot were slightly more ambiguous. Therefore, the aptablot system may not be applicable to all scenarios, since some aptamers may become unreactive upon immobilization. 


\section{CHAPTER 3}

Development of a nucleic acid sequence-based amplification (NASBA) system for detection of aptamer bound to target analyte 


\begin{abstract}
The development of an ultrasensitive method for the detection of specific foodborne contaminants was examined. The proposed novel assay, termed the Amplified Aptamer Assay $\left(\mathrm{A}^{3}\right)$, combines the use of a DNA aptamer as a target-specific binding reagent with a nucleic acid amplification technique for the ultrasensitive generation of the assay signal. A thrombin model system was chosen to demonstrate the proposed assay due to the availability of thrombin aptamer sequences. A specific thrombin aptamer was used as a binding reagent for the detection of captured thrombin on a solid phase, such as the wells of a microtiter plate. The aptamer was then amplified by Nucleic Acid Based Sequence Amplification (NASBA) to generate a signal that was detectable via agarose gel electrophoresis. Three thrombin aptamer sequences were assessed for their ability to bind to thrombin protein and subsequently be amplified by NASBA. A 105 nucleotide aptamer was determined to successfully meet these criteria.
\end{abstract}

\title{
3.1 Introduction
}

Research in the realm of food diagnostics emphasizes the development of simple and rapid assays for the detection of trace amounts of foodborne pathogenic and toxic contaminants in food samples. Current technologies for the detection of analytes, such as enzyme immunoassays targeting antigenic constituents of pathogens or toxins, use an enzyme linked to a reagent antibody to generate an assay signal. However, the enzymes linked to reagent antibodies, used for the assay's signal generation, have a limited capacity to generate a signal through conversion of substrate molecules to a detectable product, such as a chromogenic or fluorogenic compound. Nucleic acid amplification 
techniques have greater sensitivity and specificity over immunoassays. The Nucleic Acid Based Sequence Amplification (NASBA) (Figure 1.4) method is particularly attractive due to its isothermal reaction, great exponential amplification, and shorter reaction time. Many NASBA reactions have been optimized for the detection of pathogenic Campylobacter jejuni (Uyttendaele et al., 1997) and Listeria monocytogenes (Blais et al., 1996). Although these techniques are effective in providing information on the presence of bacteria in the sample, they lack the ability to provide information on the presence of toxins or expressed virulence in samples.

Nucleic acid amplification techniques can be used for signal generation in immunogenic-based assays and can significantly increase the detection sensitivity of the traditional immunoassay, as observed in the immuno-PCR method (Sano et al., 1992). In this situation, detection antibodies are conjugated with an amplifiable DNA fragment that can be efficiently amplified by PCR; the resulting amplified product giving an indication of the presence of an antigen. Although the incorporation of nucleic acid amplification into an immunoassay makes detection much more sensitive than enzyme immunoassays (Kakizaki et al., 1996; Wu et al., 2001; Liang et al., 2003), several limitations have prevented the widespread use of immuno-PCR over traditional ELISAs. For instance, the technique's reliance on conventional thermocyclers for amplification, subsequent product analysis by agarose gel electrophoresis, non-specific binding of DNA to the solid phase, and complex chemistries required to link the DNA fragment to the antibody (Adler et al., 2008).

The recently emerged field of RNA or DNA aptamers has provided an alternative to affinity binding reagents in many applications in diagnostic testing by providing target 
analyte binding capabilities. The unique and stable structures formed by aptamers in the presence of a wide variety of targets exhibit great potential for use in place of traditional antibody reagents (Jayasena, 1999). Several aptamers have been developed against microbial targets such as outer membrane protein on Salmonella enterica (Joshi et al., 2009), surface proteins of Campylobacter jejuni (Bruno et al., 2009), and Staphylococcus aureus enterotoxin B (DeGrasse, 2012) to name a few. The application of aptamers has been seen in a variety of assays. For instance, biosensor technology utilizes aptamers immobilized on a solid surface to serve as specific molecular recognition elements to a target analyte and produce a signal, which is converted to a measurable signal by a transducer that can then be analyzed. However, this technique requires specialized devices that are not practical for the high throughput analysis of food samples in analytical microbiological laboratories.

This project proposes a novel assay signal generation principle, termed the Amplified Aptamer Assay $\left(\mathrm{A}^{3}\right)$, developed for the ultrasensitive detection of microbial analytes. The proposed $\mathrm{A}^{3}$ method merges aptamer technology with ultrasensitive nucleic acid amplification. In this approach, specific DNA aptamers were utilized as affinity binding agents for the detection of an analyte captured on a solid surface, such as a microtiter plate, with subsequent detection of the bound aptamer by NASBA. The basis of the $\mathrm{A}^{3}$ assay is the hypothesis that single stranded DNA aptamers can be amplified exponentially like any other polynucleotide sequence by NASBA, PCR, or any other suitable nucleic acid amplification technique, provided they are long enough to enable annealing with primers. So based on this amplification hypothesis and the use of aptamers for the specific detection of a wide range of target analytes, such as bacterial or 
viral pathogens, and toxins, exponential amplification of the bound aptamer will allow ultrasensitive signal generation based on the specific binding of the aptamer to the target. As with the detection of amplicons resulting from nucleic acid amplification techniques, the signal generated in this assay can be detected via visualization by agarose gel electrophoresis or fluorescence signal resulting from the specific binding of fluorescently labeled probes to the amplicons. For the demonstration of the $A^{3}$ system, amplicon detection was performed by agarose gel electrophoresis. Again, the same thrombin model system was used for the demonstration of the detection of thrombin via the $\mathrm{A}^{3}$ assay, since DNA aptamers for this protein are available (Bock et al., 1992; Tasset et al., 1997) and were successful in the development of the aptablot system.

\subsection{Materials and Methods}

\subsubsection{Aptamers and NASBA primers}

Aptamers used in this study were selected against the human coagulation protein thrombin (Table 3.1). Modified (Mod) Apt 1 and Modified (Mod) Apt 2 were designed for this study by modifying Apt 1 and Apt 2 from Chapter 2, respectively, to incorporate additional randomly generated primer binding sequences appended at the 5' and 3' ends to allow for nucleic acid amplification. The same sequences were added to each aptamer. SELEX Apt is the full-length thrombin aptamer used in the SELEX selection of Apt 2 (Table 2.1), including the originally incorporated 5' and 3' end primer binding sequences used in the SELEX selection. 
Table 3.1 Thrombin aptamer oligonucleotide sequences used for the detection of thrombin protein by amplification via NASBA

\begin{tabular}{|c|c|c|c|}
\hline Aptamer & Sequence $\left(5^{\prime}-3^{\prime}\right)^{\mathrm{a}}$ & $\begin{array}{l}\text { Length } \\
\text { (bp) }\end{array}$ & Source \\
\hline Mod Apt & $\begin{array}{l}\text { GCTCCTACAAATGCCATCATTGGTTGGTG } \\
\text { TGGTTGGGCTGCAGCGAGCTTACG }\end{array}$ & 53 & This study \\
\hline $\begin{array}{l}\text { Mod Apt } \\
2\end{array}$ & $\begin{array}{l}\text { GCTCCTACAAATGCCATCATTAGTCCGTG } \\
\text { GTAGGGCAGGTTGGGGTGACTGCTGCAGC } \\
\text { GAGCTTACG }\end{array}$ & 67 & This study \\
\hline $\begin{array}{l}\text { SELEX } \\
\text { Apt }\end{array}$ & $\begin{array}{l}\text { AGATGCCTGTCGAGCATGCTCTTTGGAGACA } \\
\text { GTCCGTGGTAGGGCAGGTTGGGGTGACTTCGT } \\
\text { GGAAGAAGCGAGACGGTGTAGCTAAACTGCT } \\
\text { TTGTCGACGGG }\end{array}$ & 105 & $\begin{array}{l}\text { Tasset et } \\
\text { al., } 1997\end{array}$ \\
\hline
\end{tabular}


NASBA primers used in this study were designed to bind to the 5' and 3 ' primer binding sequences of the thrombin aptamers (Table 3.2). Forward primers (P1 and P3) for the aptamers were modified to include a T7 RNA polymerase promoter binding sequence at the 5' end (Baeumner et al., 2001). All oligonucleotides and NASBA primers were synthesized by Sigma Genosys (Oakville, ON, Canada).

\subsubsection{Sample matrices}

Sample matrices used to study detection of target analyte thrombin included pasteurized $1 \%$ milk and beef broth (ingredients: beef broth [water, beef stock], yeast extract, salt, flavour, salted onion juice, caramel, disodium inosinate, disodium guanylate) purchased from a local grocer, and the microbial growth medium brain heart infusion (BHI) broth (ingredients per litre: $12.5 \mathrm{~g}$ brain infusion solids, $5.0 \mathrm{~g}$ beef heart infusion solids, $10.0 \mathrm{~g}$ proteose peptone, $2.0 \mathrm{~g}$ glucose, $5.0 \mathrm{~g}$ sodium chloride, and $2.5 \mathrm{~g}$ disodium phosphate) (Oxoid CM1135, Ottawa, ON).

\subsubsection{Amplification by NASBA and analysis of amplicons}

For the NASBA reaction, $10 \mu \mathrm{l}$ of aptamer template at various concentrations was added to $40 \mu \mathrm{l}$ of NASBA reaction mixture in the wells of a microtiter plate [ $40 \mathrm{mM}$ Tris $-\mathrm{HCl}$ (pH 8.5), $50 \mathrm{mM} \mathrm{KCl}, 2 \mathrm{mM}$ each rNTP, $1 \mathrm{mM}$ each dNTP, $12 \mathrm{mM} \mathrm{MgCl}, 10 \mathrm{mM}$ dithiothreitol, $0.2 \mu \mathrm{M}$ of each primer, $5.2 \mu \mathrm{g}$ BSA, 15\% v/v DMSO, 80 U T7 RNA polymerase, $16 \mathrm{U}$ AMV reverse transcriptase, $0.4 \mathrm{U}$ RNase $\mathrm{H}$, and $25 \mathrm{U}$ RNasin]. The plate was sealed with tape and incubated at $41^{\circ} \mathrm{C}$ for $3 \mathrm{~h}$. Amplified DNA was visualized by electrophoresing $4 \mu \mathrm{l}$ of NASBA product with $1 \mu \mathrm{l}$ ethidium bromide loading dye (Lonza, 50463, Walkersville, MD) in a 2.2\% (w/v) agarose FlashGel cassette (Lonza, 
Table 3.2 Oligonucleotide primer sequences used for the amplification of thrombin aptamers by NASBA

Primer Sequence $\left(5^{\prime}-3^{\prime}\right)^{\mathrm{a}}$

Mod Apt 1 and Mod Apt 2 primers

P1 CTAATACGACTCACTATAGGGCGTAAGCTCGCTGCAGC

P2 GCTCCTACAAATGCCATCATT

SELEX Apt primers

P3 CTAATACGACTCACTATAGGGCCCGTCGACAAAGCAGTTTAGCTAC

P4 AGATGCCTGTCGAGCATGCT

${ }^{a}$ Underlined sequences indicate T7 RNA polymerase promoter recognition binding site 
57031, Walkersville, MD) at $275 \mathrm{~V}$ for $6 \mathrm{~min}$. DNA on the gels was visualized by fluorescence under UV light and photographed. The size of the amplified fragments was determined by including $5 \mu \mathrm{l}$ of FlashGel DNA marker (Lonza, 57033, Walkersville, MD) on each gel, with the following band sizes, $50,100,150,200,300,500,800,1500$ bp.

\subsubsection{Thrombin Amplified Aptamer Assay}

Anti-human thrombin antibody (Haematological Technologies Inc., AHT-5020, Essex Junction, VT) was prepared in $0.01 \mathrm{M}$ phosphate-buffered saline (pH 7.4), 0.85\% (w/v) $\mathrm{NaCl}$ (PBS). A concentration of $10 \mu \mathrm{g} / \mathrm{ml}$ of the antibody was immobilized in the wells of a microtiter plate $(100 \mu \mathrm{l})$ by overnight incubation at $37^{\circ} \mathrm{C}$. The wells were washed six times with $0.01 \mathrm{M}$ phosphate-buffered saline $(\mathrm{pH} 7.4), 0.85 \%(\mathrm{w} / \mathrm{v}) \mathrm{NaCl}$ (PBS) containing $0.05 \%$ Tween 20 (PBST) using an automated plate washer. Next, the wells were blocked by incubation for $1 \mathrm{~h}$ at $37^{\circ} \mathrm{C}$ with $0.5 \%(\mathrm{w} / \mathrm{v})$ Bio-Rad protein blocking reagent (Bio-Rad 170-6404, Hercules, CA) in PBST, followed by six washes with PBST. The subsequent reactions were performed at room temperature for $30 \mathrm{~min}$ followed by six washes with PBST. The wells were reacted with $100 \mu \mathrm{l}$ of PBS containing $2.72 \mathrm{nM}$ human $\alpha$-thrombin protein (Haematological Technologies Inc, HCT-0020, Essex Junction, VT) then with $100 \mu \mathrm{l}$ of aptamer sample at various concentrations in aptamer binding buffer (50 mM Tris- $\mathrm{HCl}(\mathrm{pH} 7.5), 100 \mathrm{mM} \mathrm{NaCl}, 1 \mathrm{mM} \mathrm{MgCl}, 5 \mathrm{mM} \mathrm{KCl}) . A$ NASBA reaction mixture was prepared as described above and $40 \mu 1$ was added to each reaction well and topped up to $50 \mu \mathrm{l}$ with $\mathrm{ddH}_{2} \mathrm{O}$. The plate was sealed with tape and incubated for $3 \mathrm{~h}$ at $41^{\circ} \mathrm{C}$. Amplicon was analyzed by the FlashGel system as described above. 


\subsubsection{Detection of thrombin in complex matrices}

Antibody-coated wells were prepared as describe above. The wells were blocked by incubation for $1 \mathrm{~h}$ at $37^{\circ} \mathrm{C}$ with $0.5 \%(\mathrm{w} / \mathrm{v})$ Bio-Rad protein blocking reagent in PBST, followed by six washes with PBST. The subsequent reactions were performed at room temperature for $30 \mathrm{~min}$ followed by six washes with PBST. The wells were reacted with thrombin at various concentrations in different sample matrices (PBS, $1 \%$ milk, BHI broth, and beef broth), followed by subsequent reaction with $100 \mu \mathrm{l}$ of the SELEX Apt solution prepared at $0.10 \mathrm{nM}$ in aptamer binding buffer. A NASBA reaction mixture was prepared as described above and $40 \mu \mathrm{l}$ was added to each reaction well and topped up to $50 \mu \mathrm{l}$ with $\mathrm{ddH}_{2} \mathrm{O}$. The plate was sealed with tape and incubated for $3 \mathrm{~h}$ at $41^{\circ} \mathrm{C}$. Amplicon was analyzed by the FlashGel system as described above.

\subsection{Results}

\subsubsection{Amplification of thrombin aptamers}

As a prelude to developing the actual $A^{3}$ system, it was first necessary to verify the amplifiability of different aptamers by NASBA. Mod Apt 1, Mod Apt 2, and the SELEX Apt were assessed by subjecting these serially diluted aptamers to a NASBA reaction with the use of primer pair P1 and P2 for Mod Apt 1 and Mod Apt 2 and primer pair P3 and P4 for the SELEX Apt (Table 3.1; Table 3.2). The amplicons were subsequently analyzed by agarose gel electrophoresis to determine if amplification took place. The gel electrophoresis results revealed the production of amplicons of the expected size range; an RNA product of $53 \mathrm{bp}$ for Mod Apt 1 (Figure 3.1), 67 bp for Mod Apt 2 (Figure 3.2), and 105 bp for the SELEX Apt (Figure 3.3). For both Mod Apt 1 and Mod Apt 2, a 


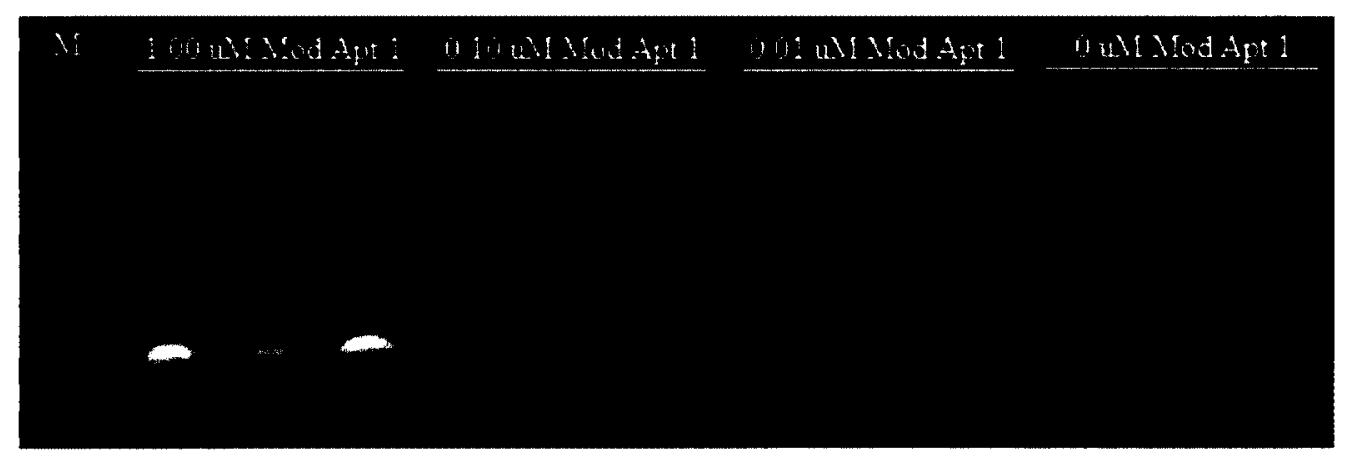

Figure 3.1 Amplification of Mod Apt 1 by NASBA followed by analysis of products by agarose gel electrophoresis. Mod Apt 1 was amplified by NASBA using the primer pair $\mathrm{P} 1$ and P2 to generate amplicons at an expected size of 53 bp RNA. DNA aptamer template was applied at three different concentrations, in triplicate, followed by NASBA detection as described in Methods. Samples were run alongside a DNA marker (M). These experiments were repeated in a separate trial with identical results (not shown). 


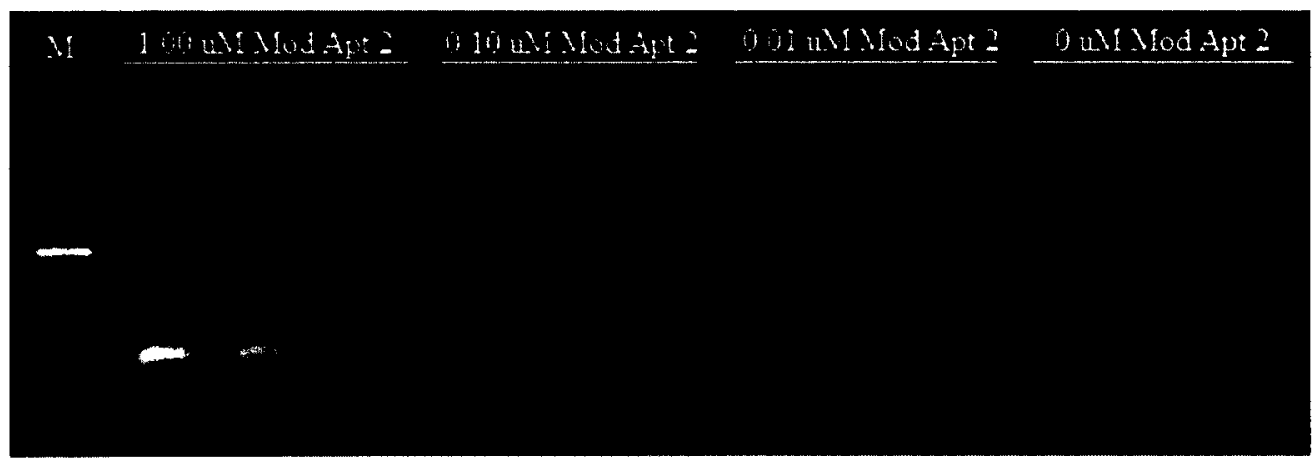

Figure 3.2 Amplification of Mod Apt 2 by NASBA followed by analysis of products by agarose gel electrophoresis. Mod Apt 2 was amplified by NASBA using the primer pair P1 and P2 to generate amplicons at an expected size of 67 bp RNA. DNA aptamer template was applied at three different concentrations, in triplicate, followed by NASBA detection as described in Methods. Samples were run alongside a DNA marker (M). These experiments were repeated in a separate trial with identical results (not shown). 

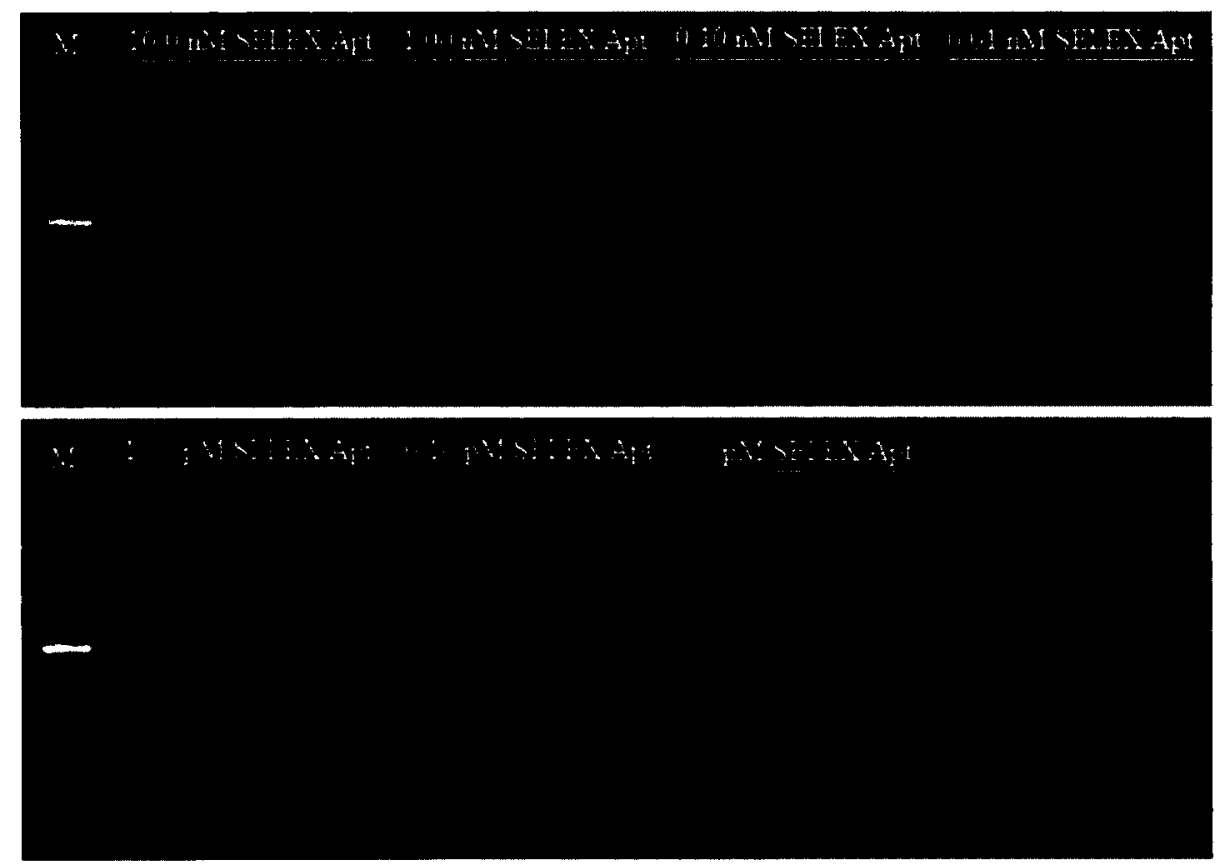

Figure 3.3 Amplification of SELEX Apt by NASBA followed by analysis of products by agarose gel electrophoresis. SELEX Apt was amplified by NASBA using the primer pair P3 and P4 to generate an expected $105 \mathrm{bp}$ RNA product. A concentration gradient of DNA aptamer template was applied in triplicate, followed by NASBA detection as described in Methods. Samples were run alongside a DNA marker (M). These experiments were repeated in a separate trial with identical results (not shown). 
visible amplification band was observed, resulting from the addition of $0.01 \mu \mathrm{M}$ initial aptamer concentration to the NASBA reaction, corresponded to the addition of $0.819 \mathrm{ng}$ and $1.04 \mathrm{ng}$ of DNA aptamer, respectively. The addition of the SELEX Apt at an initial concentration of $0.01 \mathrm{nM}$ to the NASBA reaction, producing a visible amplification band, corresponded to the addition of $1.64 \mathrm{pg}$ of DNA aptamer. Furthermore, the intensity of the signal from the bands decreased as the concentration of initial aptamer decreased. Finally, as expected, no amplification product was observed in the absence of aptamer template.

\subsubsection{Detection of thrombin via Amplified Aptamer Assay}

The preceding results demonstrated the amplifiability of three candidate thrombinbinding aptamers by NASBA. The development of the ultrasensitive $\mathrm{A}^{3}$ detection assay using aptamers as detection reagents and their subsequent amplification resulting in signal generation was examined. The proposed assay involves the detection of a bound analyte by an aptamer, the amplification of which provides signal generation and thus an indication of the presence or absence of test analyte. Using the thrombin model system, anti-thrombin antibody was immobilized in the wells of a microtiter plate, followed by reaction with thrombin protein and then aptamer samples at various concentrations in aptamer binding buffer. NASBA reaction mixture was added to each reaction well with the appropriate primer pairs and the plate was incubated at $41^{\circ} \mathrm{C}$. Aptamer amplification product was analyzed by gel electrophoresis. Based on the amplification results for Mod Apt 1 and Mod Apt 2 (Figure 3.1, Figure 3.2) RNA products at 53 bp and 67 bp were expected, respectively. However, following the $\mathrm{A}^{3}$ assay procedure described above, no 
amplification product was observed for either aptamer at the appropriate band size when reacted with thrombin (not shown).

Based on the lack of successful thrombin detection by Mod Apt 1 and Mod Apt 2, the experiment was repeated using the SELEX Apt. Again, based on the amplification results of this aptamer (Figure 3.3), a 105 bp RNA product was expected. Following the $\mathrm{A}^{3}$ procedure described above, an amplification signal was observed using SELEX Apt when reacted with thrombin captured in antibody-coated wells (Figure 3.4). Also, there was no amplification product when aptamer was reacted with wells that did not contain captured thrombin, suggesting the SELEX Apt was binding specifically to thrombin. The presence of bands on the gels below the $50 \mathrm{bp}$ marker band indicates the presence of primer dimers.

\subsubsection{Detection of thrombin in complex matrices}

To test the ability of the NASBA $\mathrm{A}^{3}$ system for the detection of analytes in complex matrices, liquid samples of thrombin in complex matrices were prepared. Thrombin protein was diluted in different types of liquid samples containing complex mixtures of ingredients, PBS, $1 \%$ milk, BHI broth, and beef broth, and captured in antibody-coated wells, followed by detection of bound thrombin by the SELEX Apt and subsequent amplification via NASBA. The thrombin protein detectability, producing a visible signal, was $2.72 \mathrm{nM}$ in all four sample matrices, which corresponds to $0.27 \mathrm{pmol}$ of thrombin protein (Figure 3.5). 


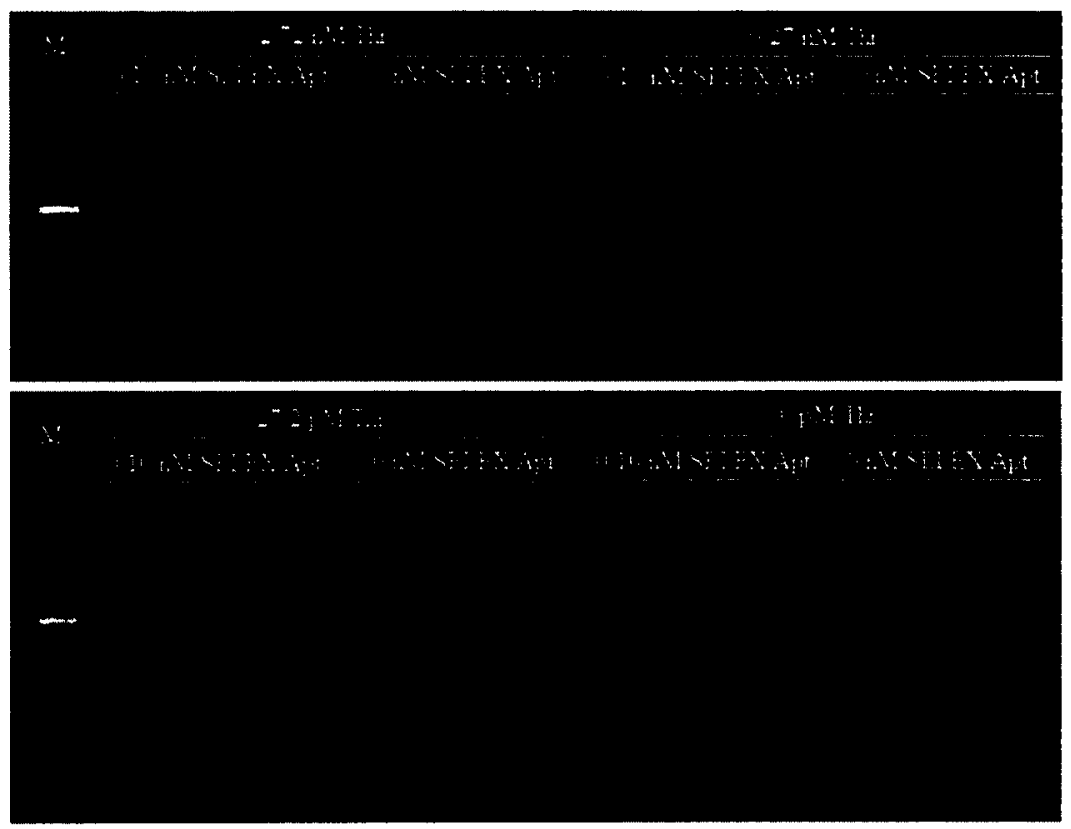

Figure 3.4 Detection of thrombin protein with SELEX Apt followed by amplification by NASBA and analysis of products by agarose gel electrophoresis. Thrombin protein was captured in antibody-coated wells at various concentrations, followed by reaction with SELEX Apt at various concentrations, in triplicate. Bound SELEX Apt was amplified by NASBA as described in Methods. Samples were run alongside a DNA marker (M). These experiments were repeated in a separate trial with identical results (not shown). 


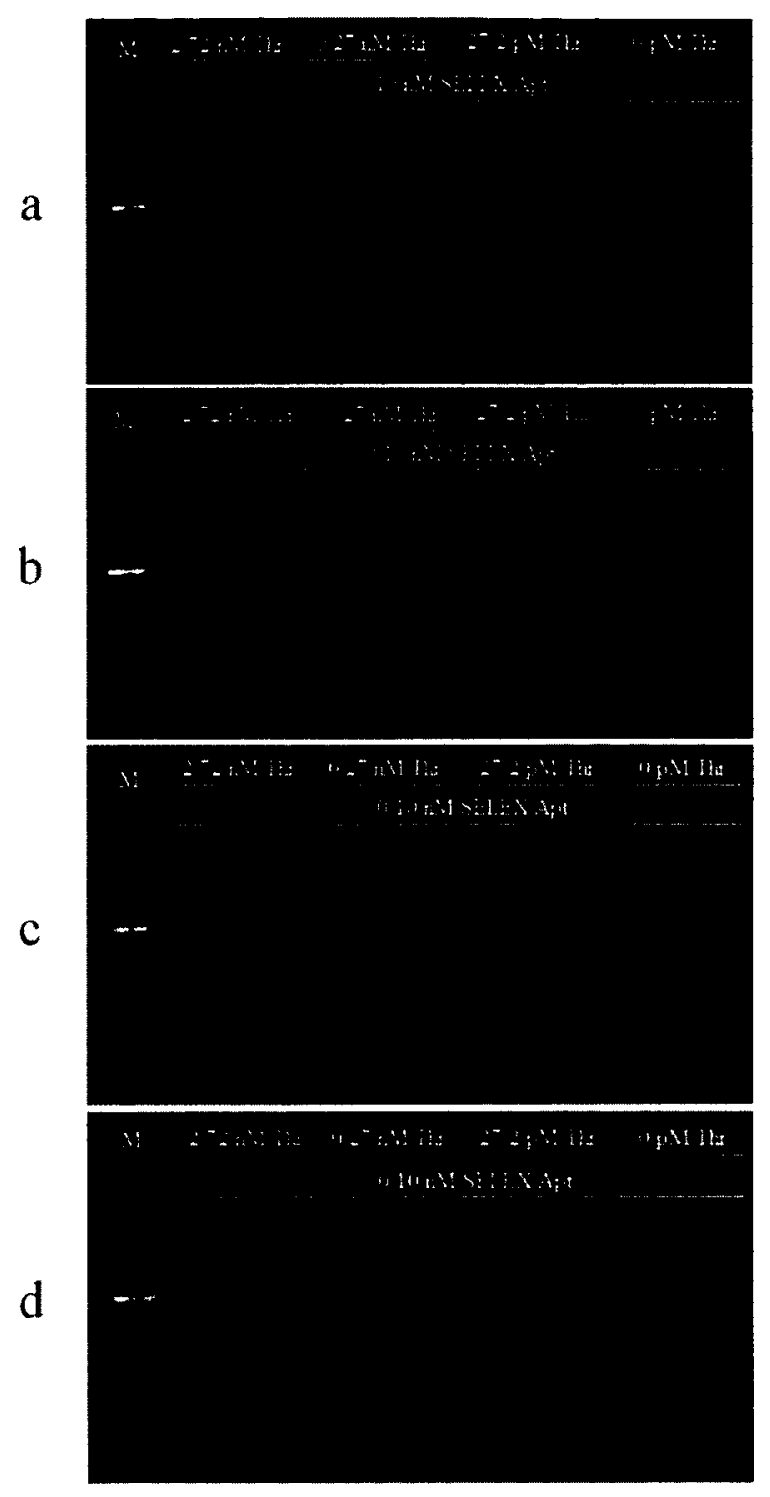

Figure 3.5 Detection of thrombin protein by the SELEX Apt from complex matrices in a microtiter plate, followed by NASBA amplification. Various concentrations of thrombin diluted in PBS (a), 1\% milk (b), BHI broth (c), and beef broth (d) were added to antibody coated wells in duplicate, detected by the SELEX Apt, followed by NASBA amplification as described in Methods. Samples were run alongside a DNA marker (M). These experiments were repeated in a separate trial with identical results (not shown). 


\subsection{Discussion}

Based on the hypothesis that single stranded DNA aptamers may be amplified by nucleic acid amplification techniques, the amplification of the well characterized thrombin aptamers was examined. In order to develop an $\mathrm{A}^{3}$ model system for the detection of thrombin, a nucleic acid amplification technique for the ultrasensitive signal generation from the model thrombin DNA aptamer had to be established. Within this model system, thrombin analyte was bound to the wells of a microtiter plate and was reacted with a DNA aptamer, which served as a detection reagent. The aptamer was subsequently subjected to a NASBA amplification technique, in situ. The idea is to allow for exponential amplification of the aptamer to facilitate the detection of even minute quantities of target captured on a solid phase.

Primer binding sequences were designed for the 5' and 3' ends of two short length thrombin aptamers reported in the literature, the 15 nucleotide Apt 1 and the 29 nucleotide Apt 2 (Table 2.1). These aptamers have the highest binding affinity for thrombin (Bock et al., 1992, Tasset et al., 1997); however, they are too short to allow primer binding. Thus, for Apt 1 and Apt 2 to be amplifiable by NASBA, randomly generated primer binding sequences were appended to the 5' and 3' end of each aptamer, resulting in Mod Apt 1 and Mod Apt 2. Furthermore, in order to allow binding of the T7 RNA polymerase enzyme in the NASBA reaction, a T7 RNA polymerase promoter binding sequence was included at the 5 , end of the forward primer. Initial experiments demonstrated that these aptamers were successfully amplified by NASBA with the use of the appropriate primers confirmed by the presence of bands at the appropriate size (Figure 3.1, Figure 3.2). This is relevant since such amplifiability shows the aptamer is 
able to generate a signal that could then be detected by agarose gel electrophoresis. Although bands of the expected amplicon size were observed, the exact size of the product could not be identified via agarose gel electrophoresis. Using this amplicon detection method, NASBA RNA products were compared to a DNA molecular weight marker ladder. However, RNA and DNA product gel migration can be affected by their length, whether they are single or double stranded, and any adoption of secondary RNA structures due to intramolecular base pairing (Rio et al., 2010).

Once the amplifiability of these two aptamers was established, the detection of thrombin protein immobilized in wells of a microtiter plate was attempted. Mod Apt 1 and Mod Apt 2 were allowed to bind to thrombin protein and were subsequently amplified by NASBA. However, upon analysis of the resulting amplification product, there were no visible bands present on the gel (not shown). Since it was confirmed that Mod Apt 1 and Mod Apt 2 could be amplified by NASBA, it is surmised that the absence of amplicon bands on the gels indicated the aptamers did not successfully bind to the thrombin protein. The lack of successful binding of Mod Apt 1 and Mod Apt 2 to thrombin may be due to the improper folding of the modified aptamers resulting from the appended primer binding sequences, thus impacting their ability to successfully bind to thrombin.

Therefore, further studies were performed with the SELEX Apt. As previously mentioned, this 105 nucleotide aptamer was developed for the original SELEX selection of the 29 nucleotide core consensus sequence Apt 2 (Chapter 2). Since the SELEX selection involves a PCR amplification step, the SELEX aptamer was already designed to include primer binding sites, which should not interfere with the aptamer's binding 
affinity to thrombin. Therefore, NASBA primers were designed to be complementary to these primer binding sequences. Again, a T7 RNA promoter binding sequence was appended at the $5^{\prime}$ end of the forward primer. Initial experiments were conducted to verify this aptamer could be amplified by NASBA. Using the appropriate primer pair, an expected 105 bp product was observed following NASBA amplification (Figure 3.3). Upon confirmation of its amplifiability, this aptamer was studied in the detection of thrombin protein immobilized in microtiter plates. The SELEX Apt successfully detected immobilized thrombin and generated an amplification signal observed by agarose gel electrophoresis (Figure 3.4). The resulting amplicon bands corresponded to the expected amplicon size range for the SELEX Apt and the signal intensity of the bands decreased with the concentration of the aptamer, showing a causal relationship between the appearance of bands on the gel and the binding of the SELEX Apt to thrombin in the wells. Furthermore, the absence of amplification product when aptamer was reacted with wells that did not contain captured thrombin implies that the resulting bands present in cases where thrombin was present was due to the specific amplification of aptamer bound to thrombin protein.

To assess the detectability of this proposed ultrasensitive detection method by means of NASBA amplification and to determine if the thrombin - aptamer interaction is detectable in the presence of complex materials, thrombin was diluted in various complex matrices and detected by the SELEX Apt. Results for all four matrix conditions were similar and the thrombin detection limit seemed to be $0.27 \mathrm{pmol}$. When compared to the thrombin detection limit of the aptablot, $1.36 \times 10^{-3}$ pmol (Chapter 2), the thrombin 
detectability of the aptablot system is 200 times better than the NASBA $\mathrm{A}^{3}$ system for the detection of thrombin from all four sample matrices.

In the previous chapter, it was demonstrated that aptamers may be used as capture reagents in the detection of specific analytes, thus eliminating the need for costly capture antibodies. The present experiments demonstrate an alternative use of single stranded DNA aptamers in order to improve detection methods. It was shown that the ability of single stranded DNA aptamers to be amplified by a nucleic acid amplification technique allows for specific signal generation following the detection of a particular target analyte. Based on the obtained results, it was confirmed that single stranded DNA aptamers can be amplified by NASBA and in one instance the aptamer was able to successfully detect bound thrombin. However, the detectability of the assay was not as sensitive as expected. Therefore, focus shifted to the use of an alternative aptamer amplification method, PCR, to demonstrate an ultrasensitive $\mathrm{A}^{3}$ system, as demonstrated in Chapter 4. 


\section{CHAPTER 4}

Development of the polymerase chain reaction (PCR) amplification system

for detection of aptamer bound to target analyte 


\section{Abstract}

The use of the nucleic acid amplification technique, polymerase chain reaction (PCR), as an alternative detection approach for the Amplified Aptamer Assay $\left(\mathrm{A}^{3}\right)$ was examined. In the proposed assay, a single stranded DNA aptamer is used as an affinity binding reagent for the specific detection of a target analyte, and the bound aptamer is detected through the generation of an amplification signal. A specific 105 bp thrombin aptamer model system was used in the detection of thrombin protein captured in the antibodycoated wells of a microtiter plate, followed by PCR amplification of this aptamer and visualization of the amplicon by agarose gel electrophoresis. The SELEX Apt was determine to be amplifiable by PCR and was found to successfully generate amplification signal upon binding to thrombin protein.

\subsection{Introduction}

Within the field of food diagnostic testing, there is a need to improve detection methods to facilitate highly sensitive detection of antigenic analytes. These analytes can range from contaminants such as veterinary drugs or antibiotics, toxins, allergens, and chemical residues, to pathogenic organisms such as bacteria and viruses. One molecular biology technique with ultrasensitive potential is nucleic acid amplification. The most popular amplification technique, the polymerase chain reaction (PCR), amplifies specific

segments of DNA through the denaturation of double stranded DNA, annealing of primers to the 5' and 3' ends of the target DNA sequence, followed by primer extension. Many PCR protocols for the detection of foodborne bacteria and viruses have been described, which target different regions of the bacterial genome (Hill, 1996; Allmann et 
al., 1993; Blais et al., 1995). The detection of amplification product is possible through gel electrophoresis with ethidium bromide staining and visual examination of the gel using ultraviolet light. More recent advances in technology have lead to the real-time detection of PCR amplicons by the incorporation of fluorescently labeled probes into the reaction mixture, which can bind to the amplicons and provide a detection signal as they are produced (Espy et al., 2006).

It has been stated that the PCR technique can detect even one molecule of target DNA (Swaminathan and Feng, 1994), thus emphasizing its ultrasensitivity. Furthermore, DNA amplification is specific since PCR relies on specially designed primers to target certain genome sequences. However, this makes the technique only applicable to targets with a genome, limiting its use in the detection of non-genomic contaminants, such as toxins or allergens. Another limitation of the use of PCR in the detection of pathogenic bacteria and viruses is the resulting amplification product cannot distinguish between live and dead cells and it cannot give an indication of expressed virulence or toxins already present, but rather reflects the presence of the target nucleic acid sequence in the sample (Scheu et al., 1998). Thus amplification resulting from DNA from dead microorganisms may lead to false-positives. Therefore, it is necessary to have an ultrasensitive method which targets the wide array of potential contaminants.

Aptamers, a newly emerged alternative to affinity binding reagents, are designed to bind specifically to a particular target with high affinity. As previously mentioned, aptamers are isolated through a process known as Systematic Evolution of Ligands by EXponential enrichment (SELEX) (Ellington \& Szostak, 1990; Tuerk \& Gold, 1990). The oligonucleotide pool used for the SELEX selection is designed so that the randomly 
generated middle portion of the aptamer is flanked by primer binding sequences at the 5 , and 3 ' ends, thus enabling its PCR amplification. Specific aptamers can be selected against all potential contaminants mentioned above, which becomes the main advantage of the proposed Amplified Aptamer Assay $\left(\mathrm{A}^{3}\right)$.

The $\mathrm{A}^{3}$ system is a proposed ultrasensitive analyte detection method, which can provide a more accurate representation of harmful contaminants actually present in the sample due to the specific binding of aptamers to their targets. Aptamers are used as detection reagents in this method by bind specifically to their target, followed by amplification of the bound aptamer to generate a detection signal. To achieve ultrasensitive amplification of the aptamers, an appropriate technique had to be selected. The results of the preceding chapter demonstrated the use of the NASBA technique in the $A^{3}$ system. However, due to the low detectability of the NASBA results, a different amplification technique was analyzed. As mentioned before, PCR techniques have been established for the detection of pathogenic targets in samples. Furthermore, since aptamers are designed to incorporate primer binding sequences to be amplified during their selection process, it seemed fitting to evaluate the use of PCR in the amplification of target-bound aptamer in the $\mathrm{A}^{3}$ system. In continuing with previous experiments, the same thrombin model system was used. In particular, the thrombin SELEX Apt was chosen since this aptamer was used in the original SELEX selection of the 29 nucleotide core Apt 2 (Chapter 2) thus was specifically designed for amplification by PCR. Furthermore, due to the successful results obtained with the use of this aptamer, it became an ideal candidate for the demonstration of the PCR $\mathrm{A}^{3}$ system. 


\subsection{Materials and Methods}

\subsubsection{Aptamers and PCR primers}

SELEX Apt is the full-length 105 nucleotide thrombin aptamer used in the SELEX selection of the 29 nucleotide core thrombin Apt 2 (Chapter 2), including the originally incorporated 5' and 3' end primer binding sequences used in the SELEX selection (Table 2.1). PCR primers used in this study were designed to bind to the 5' and 3' sequences of the SELEX Apt (Tasset et al., 1997) (Table 4.1). All PCR primers and the SELEX Apt were synthesized by Sigma Genosys (Oakville, ON, Canada).

\subsubsection{Sample matrices}

Sample matrices used to study detection of target analyte thrombin included pasteurized $1 \%$ milk and beef bouillon (ingredients: beef broth [water, beef stock], yeast extract, salt, flavour, salted onion juice, caramel, disodium inosinate, disodium guanylate) purchased from a local grocer, and the microbial growth medium brain heart infusion (BHI) broth (ingredients per litre: $12.5 \mathrm{~g}$ brain infusion solids, $5.0 \mathrm{~g}$ beef heart infusion solids, $10.0 \mathrm{~g}$ proteose peptone, $2.0 \mathrm{~g}$ glucose, $5.0 \mathrm{~g}$ sodium chloride, and $2.5 \mathrm{~g}$ disodium phosphate) (Oxoid CM1135, Ottawa, ON).

\subsubsection{Amplification by PCR and analysis of amplicons}

SELEX Apt was subjected to a PCR incorporating the primer pair P5 and P6 (Table 4.1). For the PCR, $5 \mu \mathrm{l}$ of aptamer template was added to $45 \mu \mathrm{l}$ of PCR reaction mixture [1X PCR buffer containing $1.5 \mathrm{mM} \mathrm{MgCl}_{2}, 200 \mu \mathrm{M} \mathrm{dNPT}$ mix, $0.1 \mu \mathrm{M}$ of each primer, and 2.5 U Taq polymerase enzyme]. The PCR was carried out in a Mastercycler gradient 
Table 4.1 Oligonucleotide primer sequences used for amplification of the SELEX Apt by PCR

\begin{tabular}{cl}
\hline Primer & Sequence $\left(5^{\prime}-3^{\prime}\right)^{\mathrm{a}}$ \\
\hline P5 & CCC GTC GAC AAA GCA GTT TAG CTA C \\
P6 & AGA TGC CTG TCG AGC ATG CT \\
\hline
\end{tabular}

${ }^{\mathrm{a}}$ Primer sequences from Tasset et al., 1997 
thermal cycler (Eppendorf) using the following program: initial heating at $94^{\circ} \mathrm{C}$ for 15 min, followed by 34 cycles of denaturation at $94^{\circ} \mathrm{C}$ for $1 \mathrm{~min}$, primer annealing at $55^{\circ} \mathrm{C}$ for $1 \mathrm{~min}$, and primer extension at $72^{\circ} \mathrm{C}$ for $1.5 \mathrm{~min}$, with an additional $2 \mathrm{~min}$ at $72^{\circ} \mathrm{C}$ following the last cycle. PCR amplicon was visualized by electrophoresing $4 \mu \mathrm{l}$ of NASBA product with $1 \mu \mathrm{l}$ ethidium bromide loading dye (Lonza, 50463, Walkersville, MD) in a $2.2 \%(w / v)$ agarose FlashGel cassette (Lonza, 57031, Walkersville, MD) at 275 $\mathrm{V}$ for $6 \mathrm{~min}$. DNA on the gels was visualized by fluorescence under UV light and photographed. The size of the amplified fragments was determined by including $5 \mu$ l of FlashGel DNA marker (Lonza, 57033, Walkersville, MD) on each gel, with the following band sizes, 50, 100, 150, 200, 300, 500, 800, $1500 \mathrm{bp}$.

\subsubsection{Thrombin detection in microtiter plates via PCR Amplified Aptamer Assay}

Anti-human thrombin antibody (Haematological Technologies Inc., AHT-5020, Essex Junction, VT) was prepared in $0.01 \mathrm{M}$ phosphate-buffered saline $(\mathrm{pH} 7.4), 0.85 \%(\mathrm{w} / \mathrm{v})$ $\mathrm{NaCl}$ (PBS). A concentration of $10 \mu \mathrm{g} / \mathrm{ml}$ of the antibody was immobilized in the wells of a microtiter plate, followed by an overnight incubation at $37^{\circ} \mathrm{C}$. The wells were washed six times with $0.01 \mathrm{M}$ phosphate-buffered saline $(\mathrm{pH} 7.4), 0.85 \%(\mathrm{w} / \mathrm{v}) \mathrm{NaCl}$ (PBS) containing $0.05 \%$ Tween 20 (PBST) using an automated plate washer. The wells were blocked by incubation for $1 \mathrm{~h}$ at $37^{\circ} \mathrm{C}$ with either $0.5 \%(\mathrm{w} / \mathrm{v})$ Bio-Rad protein blocking reagent (Bio-Rad 170-6404, Hercules, CA) in PBST, $1 \mu \mathrm{g} / \mathrm{ml}$ baker's yeast transfer RNA (tRNA) (Sigma-Aldrich, R8508, Oakville, ON) in PBST, $1 \mu \mathrm{g} / \mathrm{ml}$ calf thymus DNA (Sigma-Aldrich, D0805, Oakville, ON) in PBST followed by washing with

PBST. The following reactions were incubated $30 \mathrm{~min}$ at room temperature followed by six washes with PBST. The wells were reacted with $100 \mu \mathrm{l}$ of aptamer binding buffer (50 
$\mathrm{mM}$ Tris- $\mathrm{HCl}(\mathrm{pH} 7.5), 100 \mathrm{mM} \mathrm{NaCl}, 1 \mathrm{mM} \mathrm{MgCl} 2,5 \mathrm{mM} \mathrm{KCl})$ containing $2.72 \mathrm{nM}$ human $\alpha$-thrombin protein (Haematological Technologies Inc, HCT-0020, Essex Junction, VT) then with $100 \mu$ l of the SELEX Apt solution prepared at various concentrations in aptamer binding buffer. Finally, bound aptamer was eluted in $100 \mu l$ $0.01 \mathrm{M}$ glycine- $\mathrm{HCl}$ buffer (Sigma-Aldrich, G7126, Oakville, ON) at $\mathrm{pH} 2.0$ for 5 minutes at room temperature before $5 \mu$ l of sample from each well was transferred to PCR tubes containing $45 \mu \mathrm{l}$ of PCR reaction mixture. After amplification, the amplicons were run on agarose gels for analysis.

\subsubsection{Detection of thrombin in complex matrices}

Antibody-coated wells were prepared as described above. The wells were blocked by incubation for $1 \mathrm{~h}$ at $37^{\circ} \mathrm{C}$ with $2 \mu \mathrm{g} / \mathrm{ml}$ baker's yeast transfer RNA (tRNA) in PBST followed by washing with PBST. The following reactions were incubated $30 \mathrm{~min}$ at room temperature followed by six washes with PBST. The wells were reacted with thrombin at various concentrations in different sample matrices (PBS, $1 \%$ milk, BHI broth, and beef broth), followed by subsequent reaction with $100 \mu$ l of the SELEX Apt solution prepared at $4.00 \mathrm{pM}$ in aptamer binding buffer. Finally, bound aptamer was eluted in $100 \mu \mathrm{l}$ of $0.01 \mathrm{M}$ glycine- $\mathrm{HCl}$ buffer at $\mathrm{pH} 2.0$ for 5 minutes at room temperature before $5 \mu \mathrm{l}$ of sample from each well was transferred to PCR tubes containing $45 \mu$ of PCR reaction mixture. After amplification, the PCR amplicons were run on agarose gels for analysis. 


\subsection{Results}

\subsubsection{Amplification of thrombin aptamer by PCR}

An essential step in the development of the $\mathrm{A}^{3}$ system was to confirm the amplifiability of the SELEX Apt by PCR. The PCR reaction mixture was made using primer pair P5 and P6 (Table 4.1) and varied concentrations of the SELEX Apt were added in triplicate. Upon completion of the reaction, the samples were visualized by gel electrophoresis to confirm amplification had taken place. The production of amplicons of the expected size, $105 \mathrm{bp}$, was observed on the resulting gel (Figure 4.1). The addition of the SELEX Apt at an initial concentration of $0.01 \mathrm{pM}$ to the PCR reaction mixture to produce a visible amplification band corresponded to $1.64 \times 10^{-3} \mathrm{pg}$ of DNA aptamer. As expected, samples with higher concentrations of template had stronger band intensity, which decreased with concentration. Finally, no amplification bands were present for samples without template.

\subsubsection{Thrombin PCR Amplified Aptamer Assay in microtiter plates}

The previous results demonstrate the amplifiability of the SELEX Apt by PCR. Thus, the development of an $\mathrm{A}^{3}$ system was examined using a similar procedure as the NASBA $\mathrm{A}^{3}$ of chapter 3; however, in this case, amplification was achieved through PCR. Thrombin protein was allowed to react with antibody-coated wells, which was subsequently detected by the SELEX Apt solution at $8.00 \mathrm{pM}, 4.00 \mathrm{pM}, 2.00 \mathrm{pM}$ and $1.00 \mathrm{pM}$. Glycine- $\mathrm{HCl}$ buffer ( $\mathrm{pH} 2.0)$ was used to elute the aptamer so it could be transferred to PCR tubes in which the PCR reaction took place. Following gel electrophoresis of the 


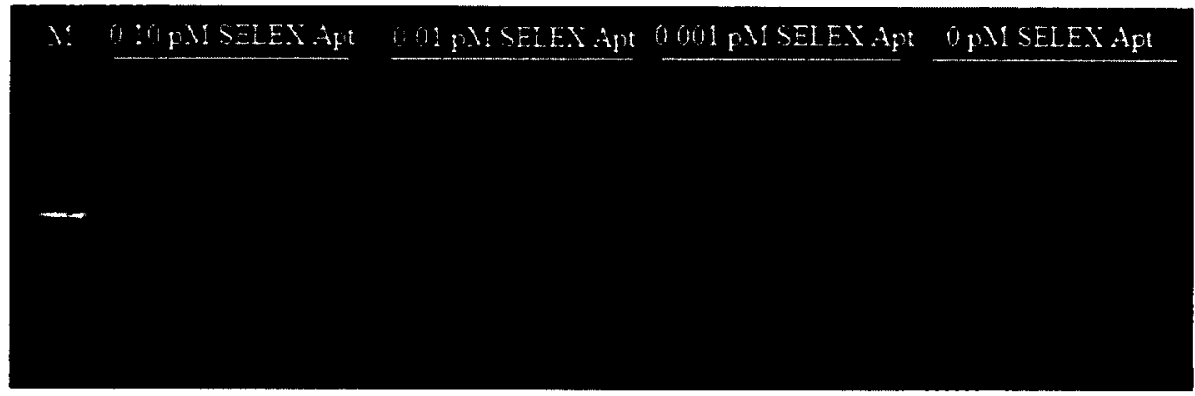

Figure 4.1 Amplification of the SELEX Apt by PCR followed by analysis of amplicons by agarose gel electrophoresis. Thrombin aptamer was amplified by PCR using primer pair P5 and P6 to generate an expected 105 bp product. Aptamer template was applied at three different concentrations, in triplicate, followed by PCR as described in Methods. Samples were run alongside a DNA marker (M). These experiments were repeated in a separate trial with identical results (not shown). 
amplicon, an amplification signal was observed at the expected $105 \mathrm{bp}$ amplicon size for the SELEX Apt (Figure 4.2 a). However, some faint amplification signal was also observed where there was no thrombin present in the antibody-coated wells, possibly due to non-specific binding of the aptamer (Figure $4.2 \mathrm{~b}$ ).

Based on the preceding results, various blocking agents were analyzed for their ability to most effectively reduce the non-specific binding observed. Thus following the same procedure for the PCR $\mathrm{A}^{3}$ assay described above, wells were blocked with $0.5 \%$ (w/v) Bio-Rad protein blocking reagent, $1 \mu \mathrm{g} / \mathrm{ml}$ baker's yeast transfer RNA (tRNA), or $1 \mu \mathrm{g} / \mathrm{ml}$ calf thymus DNA in PBST followed by reaction with thrombin protein, SELEX Apt, and eluted in glycine-HCl buffer before PCR amplification. It was observed yeast tRNA was the most effective in blocking non-specific binding of the aptamer over the Bio-Rad blocker and calf thymus DNA (Figure 4.3).

\subsubsection{Detection of thrombin in different sample matrices}

The preceding experiments analyzed the aptamer - thrombin interaction in defined buffer conditions in the absence of extraneous material. To determine if the aptamer - thrombin interaction could be detected amid complex materials, the assay was performed in the presence of various sample matrix compositions. Thrombin antibody-coated wells were reacted with thrombin diluted in various types of liquid matrices, $\mathrm{PBS}, \mathrm{BHI}$ broth, $1 \%$ milk, and beef broth. The SELEX Apt was used to detect the captured thrombin from the complex matrices, upon which PCR was performed and gels were run. Results for all four matrix conditions were 


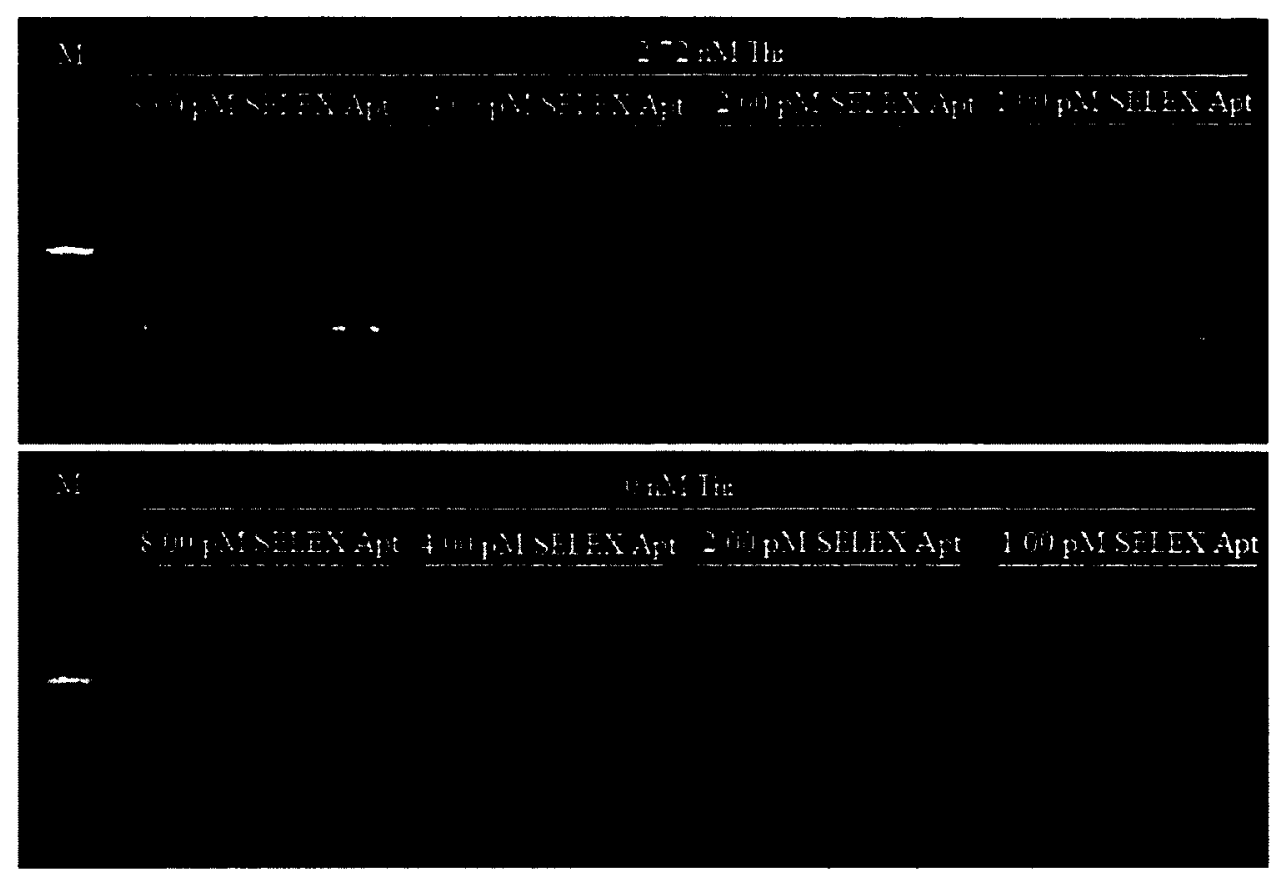

Figure 4.2 Optimum SELEX Apt concentration for detection of thrombin protein in the wells of a microtiter plate followed by amplification by PCR and analysis of amplicons by agarose gel electrophoresis. Thrombin was reacted with antibody-coated wells and detected by reaction with the SELEX Apt at different concentrations, in triplicate, followed by glycine elution and PCR detection as described in Methods. Samples were run alongside a DNA marker $(\mathrm{M})$. These experiments were repeated in a separate trial with identical results (not shown). 


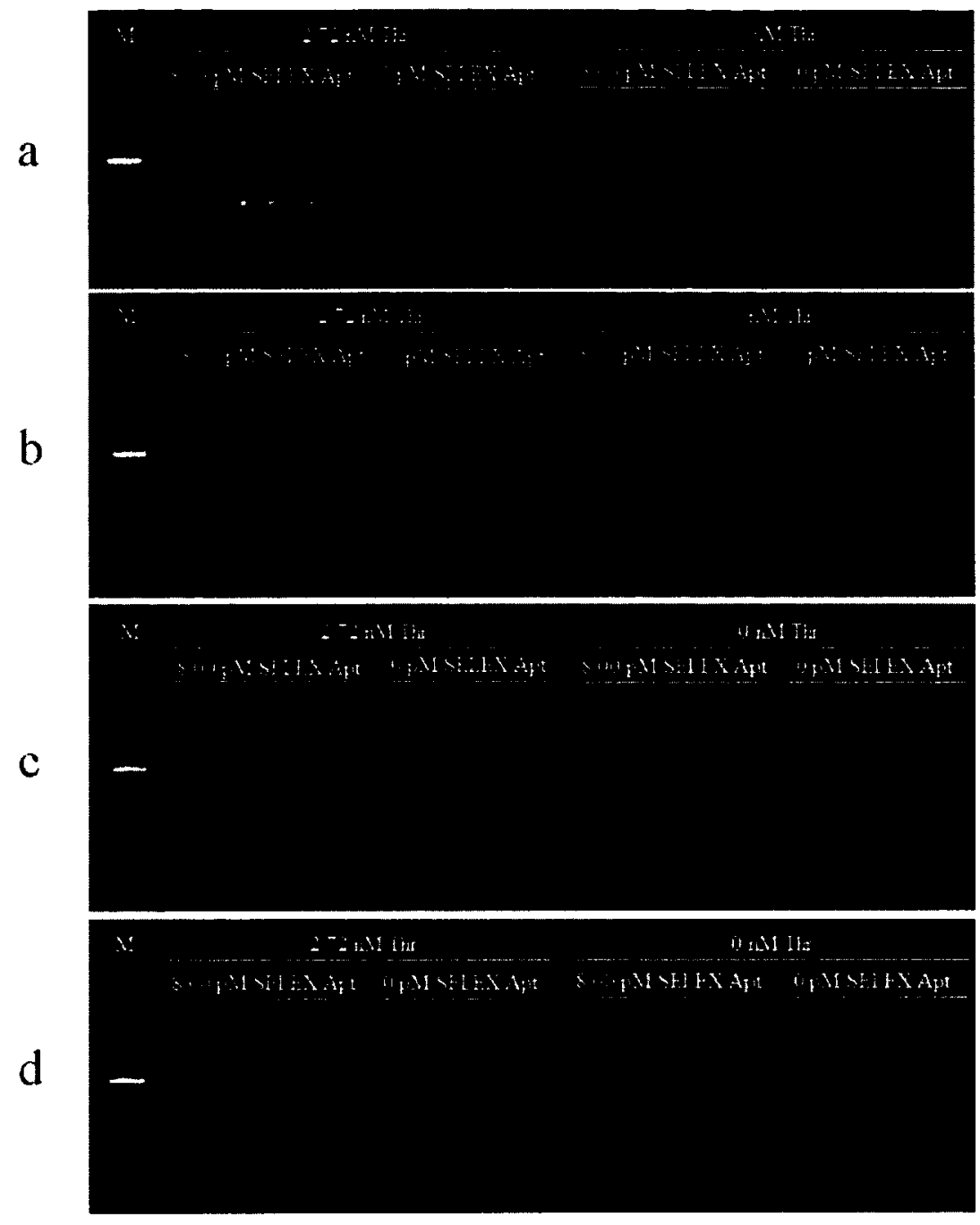

Figure 4.3 Effect of various blocking agents on non-specific binding of aptamer. Antibody-coated wells were blocked with either $0.5 \%$ Bio-Rad blocker protein (a), 1 $\mu \mathrm{g} / \mathrm{ml}$ yeast tRNA (b), $1 \mu \mathrm{g} / \mathrm{ml}$ calf thymus DNA (c) in PBST or PBST (d). Thrombin was reacted with antibody-coated wells, detected by SELEX Apt at different concentrations, in triplicate, followed by glycine elution and PCR detection as described in Methods. Samples were run alongside a DNA marker (M). These experiments were repeated in a separate trial with identical results (not shown). 
similar. The presence of a 105 bp DNA amplicon was observed and its signal intensity seemed to decrease as thrombin protein concentration decreased (Figure 4.4). When assessing the detectability of the thrombin protein, all four cases seemed to have similar results, $2.72 \mathrm{pM}$ of thrombin protein was detected by the SELEX Apt, which corresponds to $2.72 \times 10^{-4} \mathrm{pmol}$ of detectable thrombin protein. However, there also seemed to be slight amplification signal present in the wells where PBS, $1 \%$ milk, BHI broth, and beef broth were added devoid of diluted thrombin protein that was attributed to the nonspecific binding of aptamer to the solid phase.

\subsection{Discussion}

The present experiments demonstrate the use of an aptamer in the detection of a protein analyte in a PCR $\mathrm{A}^{3}$ system. In this case, the aptamer acted as a detector in which its ultrasensitive amplification by PCR resulted in signal generation to indicate the presence of target analytes. Based on the success of the SELEX Apt in the experiments described in the preceding chapters, this aptamer was applied to demonstrate the detection of thrombin protein in this application.

In order to develop the $\mathrm{A}^{3}$ system where aptamers generate signal by amplification, a suitable amplification technique had to be selected that could successfully amplify single-stranded aptamers. The preceding chapter investigated the use of NASBA for the amplification of a thrombin DNA aptamer. Although it was demonstrated the thrombin aptamer could be amplified by NASBA, its application for signal generation in the NASBA $\mathrm{A}^{3}$ method did not improve the detectability of thrombin when compared to the aptablot system. Furthermore, NASBA reactions require multiple 


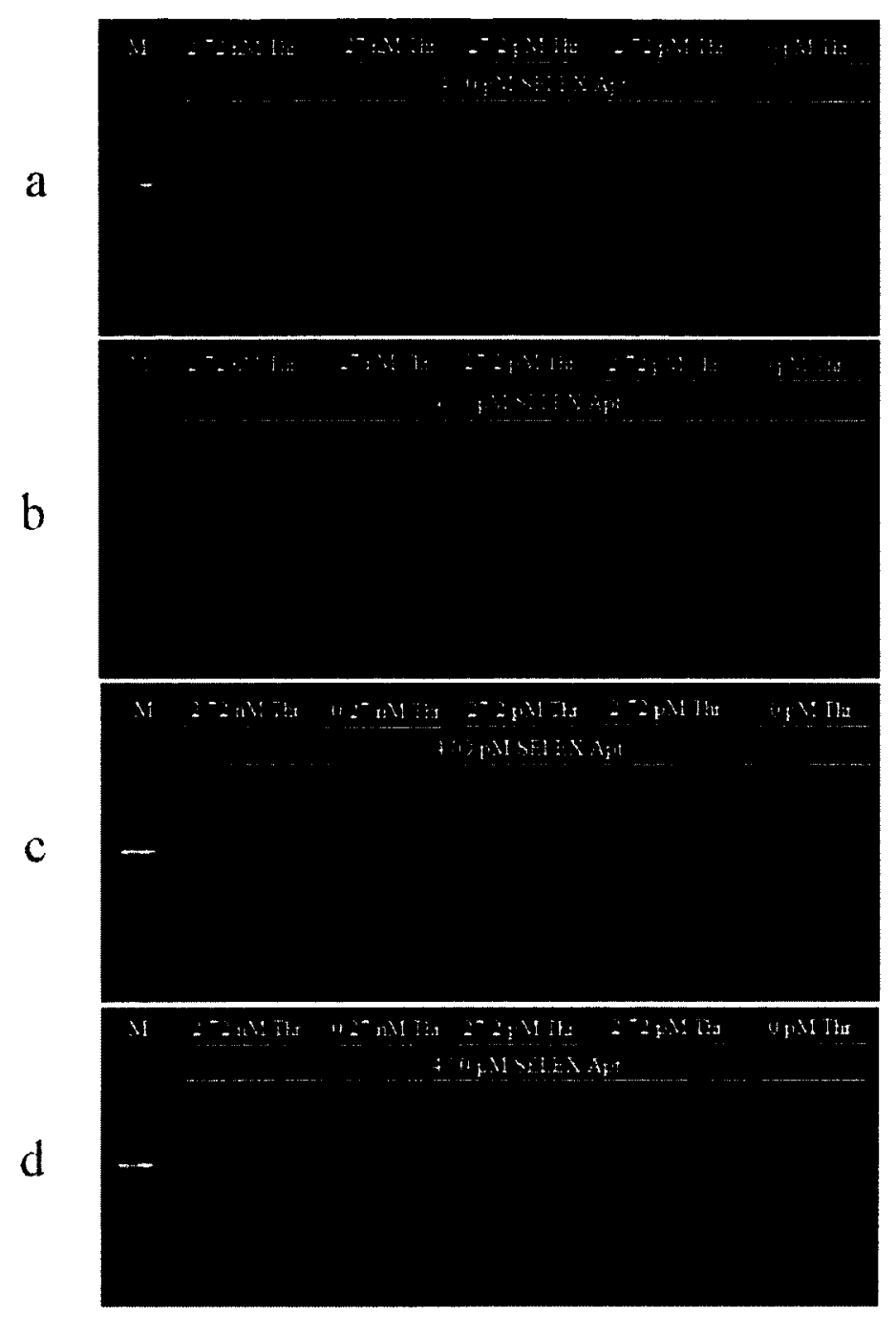

Figure 4.4 Detection of thrombin protein by the SELEX Apt from complex matrices in a microtiter plate, followed by PCR amplification. Various concentrations of thrombin diluted in PBS (a), 1\% milk (b), BHI broth (c), and beef broth (d) were added to antibody-coated wells in duplicate and detected by the SELEX Apt, followed by glycine elution and PCR detection as described in Methods. Samples were run alongside a DNA marker (M). These experiments were repeated in a separate trial with identical results (not shown). 
reagents for the mixture, including a cocktail of three different thermostable enzymes, which becomes quite costly. There are also issues with RNA digestions by exogenous ribonucleases. Thus, it was hypothesized that the SELEX Apt could similarly be amplified by PCR. Furthermore, one step in aptamer selection via SELEX involves the exponential amplification of aptamers with the highest binding affinity to the target. Seeing as PCR plays a role in the aptamer selection process, this nucleic amplification technique became a viable alternative for this application. Initial amplification experiments confirmed this hypothesis (Figure 4.1). Based on the results, amplification of the SELEX Apt by PCR seems to be more sensitive than amplification via NASBA (Figure 3.2). Whereas the detection limit via NASBA is $1.64 \mathrm{pg}$ of the SELEX Apt, the detection limit for PCR is $1.64 \times 10^{-3} \mathrm{pg}$, a 1000 -fold difference, thus demonstrating the ultrasensitivity of the PCR technique for application in the $\mathrm{A}^{3}$ system.

After confirming the amplifiability of the SELEX Apt by PCR, the goal was to apply this to the development of the PCR $\mathrm{A}^{3}$ system. Several attempts were made to develop this assay using PCR strip tubes as the solid phase (not shown). However, due to the lack of a proper washing method for the tubes that would eliminate contamination of neighbouring tubes, microtiter plates became the chosen solid phase since automated plate washers are available for use. Initial experiments in the development of the assay revealed non-specific binding of the aptamer, resulting in false-positives. Several attempts to eliminate the non-specific binding of the aptamer included heating the samples to $100^{\circ} \mathrm{C}$ to dissociate the aptamer from the protein and attempting to bind the SELEX Apt and thrombin separately before incubation with antibody-coated tubes to 
allow the specific capture of the SELEX Apt - thrombin complexes. However, these attempts were not successful in the elimination of the non-specific binding (not shown).

Based on the results obtained after attempting to develop the $\mathrm{A}^{3}$ assay in PCR strip tubes, microtiter plates were chosen due to the positive results obtained from the NASBA $\mathrm{A}^{3}$ system in which microtiter plates were used as the solid phase. However, to allow aptamer amplification, bound aptamer was eluted from the wells with a low acidic

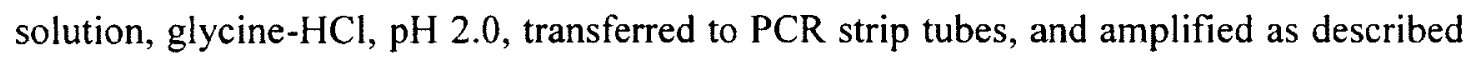
above. The glycine solution was chosen based on the previously observed dissociation of most antibody-antigen interactions in low $\mathrm{pH}$ conditions ( $\mathrm{Li}$ et al., 2007). It was hypothesized that similar conditions would dissociate the SELEX Apt from the thrombin protein. Unlike previous experiments, the use of these conditions resulted in a significant decrease of amplification signal of non-specifically bound aptamer in wells without thrombin (Figure 4.2). As expected, the negative controls, containing no added aptamer, did not produce amplification signal. However, amplification of non-specific binding was not completely eliminated in the case where aptamer was incubated in antibody-coated wells that did not contain captured thrombin protein.

Although the use of glycine buffer seemed to have a significant impact on the reduction of amplification of non-specific binding, further studies explored the use of various blocking agents. One study mentioned the use of yeast transfer RNA (tRNA) as a blocker agent used in an aptamer-immobilized ELISA assay for the detection of $E$. coli O157:H7 strains (Lee et al, 2012). Furthermore, calf thymus DNA, commonly used as a blocker (McPherson \& Møller, 2000) and the blocking agent Bio-Rad blocking protein were also assessed for their blocking abilities in this assay. Using the same procedure 
described above, a blocking step was included after coating the wells with thrombin antibody and before reacting with thrombin protein. Yeast tRNA was observed to have the most effective blocking, resulting in the elimination of non-specific binding (Figure 4.3). Based on these results, yeast tRNA was chosen for blocking in subsequent reactions, followed by optimization of tRNA concentration. The optimum concentration was determined to be $2 \mu \mathrm{g} / \mathrm{ml}$ (not shown), which was used in all subsequent experiments. Furthermore, in an attempt to decrease non-specific binding, further experiments determined that a decrease in aptamer concentration from $8.00 \mathrm{pM}$ to $4.00 \mathrm{pM}$ and performing eight washes versus six washes with the automatic plate washer seemed to decrease the non-specific binding (not shown).

Future investigations of the PCR $\mathrm{A}^{3}$ system will involve the development of the assay for the detection of microbial analytes. Thus it is essential to determine if the aptamer - target interaction is detectable amide the complexity of food samples, and achieve ultrasensitive detection of thrombin. Thus, sample matrices comprised of complex materials were used to determine if the SELEX Apt - thrombin interactions could be detected. Thrombin was prepared at various concentrations in PBS, $1 \%$ milk, BHI broth, and beef broth and added to antibody-coated wells. SELEX Apt was used to detect the captured thrombin from the complex matrices. Results for all four matrix conditions were similar and seemed to indicate that the aptamer was detecting thrombin protein diluted in the four sample matrices since there was a decrease in aptamer concentration as thrombin concentration decreased (Figure 4.4). The thrombin detection limit seemed to be $2.72 \mathrm{pM}$ in all four cases, which corresponds to $2.72 \times 10^{-4} \mathrm{pmol}$. When comparing the detectability of thrombin in the PCR $A^{3}$ system to that in the 
aptablot system, which was found to be $1.36 \times 10^{-3}$ pmol (Chapter 2), the PCR $\mathrm{A}^{3}$ system is 5 times more sensitive than the aptablot system. However, there also seems to be slight background signal that could not be blocked out in all four sample matrices. But, PBS seemed to have the least background signal out of all four sample matrices (Figure $4.4 \mathrm{a}$ ). The increased background signal in the other matrices may be due to endogenous divalent ions in the $1 \%$ milk, $\mathrm{BHI}$ broth, and beef broth that bind non-specifically within the wells, providing potential binding sites for the DNA aptamer (Sissi \& Palumbo, 2009; Pastré et al., 2003).

The experiments presented in this chapter demonstrated the use of the ultrasensitive PCR amplification technique for the generation of signal from aptamer specifically bound to a target, thus allowing for the ultrasensitive specific detection of analytes of interest. Following confirmation of the amplifiability of the SELEX Apt, the aptamer was used for the detection of thrombin captured by antibody-coated wells of a microtiter plate. Once again, although the results are promising, persistent signal resulting from non-specific binding of the SELEX Apt could not be eliminated completely. Therefore, future work can focus on the prevention of this non-specific binding. Furthermore, the present model relies on the use of agarose gel electrophoresis for amplification signal detection. Although this was sufficient for the demonstration of the $A^{3}$ system within these experiments, a foreseeable application of this system would be in the detection of microbial targets in food samples. Therefore, to further improve efficiencies, future work could focus on the real time detection of PCR amplicon with the incorporation of specific probes. These specifically designed fluorescently labeled probes bind to the target PCR amplicon as it is produced, resulting in a fluorescent signal that is 
read automatically by the PCR thermocycler. Hence, this method would result in the simultaneous enrichment, detection and confirmation of target-specific DNA, providing the results in real-time. Finally, more work would need to be done to develop this assay from the thrombin protein model system to the detection of pathogenic targets of interest. 


\section{CHAPTER 5}

General Conclusion 
The aptablot and the Amplified Aptamer Assay $\left(\mathrm{A}^{3}\right)$ systems described in this thesis are intended for the ultrasensitive detection of analytes of concern to food microbiological testing laboratories. The proposed aptablot and $\mathrm{A}^{3}$ systems were designed with the intention of enabling more sensitive and reliable detection of analytes at earlier timepoints during sample processing, possibly even permitting detection in real time for more timely interventions to minimize the spread of contamination. The basis of both systems is dependent on the use of aptamers as affinity binding reagents that can bind to specific targets with high affinity (Silverman, 2007). The use of thrombin-specific aptamers as both capture and detection agents has provided a detection model to develop the assay concepts described herein.

A simple aptablot system involving the use of a macroporous polyester cloth was developed in Chapter 2 for the detection of the model thrombin analyte. In the course of these experiments, it was determined that several different thrombin-binding aptamers described in the literature could be immobilized on polyester cloth by cross-linking with brief exposure to UV light. Thus the DNA aptamers constituted inexpensive synthetic capture reagents for the specific detection of thrombin in sample solutions, making them an attractive alternative to antibodies, which are traditionally used for specific capture of analytes. Furthermore, to improve the flexibility of two assay systems in terms of the choice of aptamers which could be used, the immobilization of shorter length aptamers was made possible with the addition of either a 5'- or 3'-poly-T tail that did not interfere with the aptamer binding properties. It was found that the longer the poly-T tail, the better the immobilization results for the thrombin aptamer. The ability of the aptamers to be immobilized on the polyester cloth surface and to still be able to detect thrombin provides 
the basis for either a sandwich aptablot in which the captured thrombin is immunoenzymatically detected, or a competitive inhibition or displacement assay, thus broadening the potential application of the aptablot from samples with multiple epitopes to samples with single epitopes. Furthermore, it is quite reasonably expected that as the number of aptamer sequences grows future applications may even replace the detector antibody with an enzyme or marker labeled second aptamer. Future development of this system for the detection of particular pathogenic targets of interest could lead to a simple and cost-effective tool for the detection of foodborne pathogens in food testing laboratories. However, based on the moderate success of the lysozyme aptamer in the detection of lysozyme, the results for which were not as strong as that of the thrombin model system, the aptablot system may not be applicable to all scenarios and is dependent on the availability of a suitable aptamer - target system.

The second half of the thesis described the development of the $A^{3}$ system in which aptamers were intended to be used for ultrasensitive signal generation after reaction with captured analyte. To achieve signal generation, aptamers were tested for their amplifiability by two different nucleic acid amplification techniques, NASBA and PCR. Chapter 3 examined the amplifiability of three different aptamers by NASBA and their subsequent ability to produce amplification signal upon binding to the target thrombin. The SELEX Apt was found to be amplified successfully by NASBA once bound to thrombin protein in antibody-coated wells; however, the resulting thrombin protein detectability of the NASBA $\mathrm{A}^{3}$ system was not greater when compared to the detectability of thrombin in the aptablot system. The isothermal NASBA technique was an attractive method because it permitted detection of bound aptamer to occur directly in 
the wells and did not require the use of a thermocycler; however, the results did not demonstrate ultrasensitivity in the detection of thrombin and the costly mixture of enzymes makes the NASBA technique impractical for high throughput analysis.

Thus, an alternative nucleic acid amplification technique, $\mathrm{PCR}$, for use in the $\mathrm{A}^{3}$ system was the focus of Chapter 4 due to its simpler reaction system and ultrasensitive properties. Only the SELEX Apt was chosen to demonstrate the PCR $\mathrm{A}^{3}$ system due to the successful results from its use in previous experiments and since it was specifically designed to include primer binding sites for its original SELEX selection. Results confirmed the SELEX Apt was amplifiable by PCR and its amplification detection limit via PCR was more sensitive than amplification via NASBA. Furthermore, it was determined the SELEX Apt was able to produce a detectable amplification signal upon binding with thrombin protein captured in antibody coated wells. However, since the system was developed using a microtiter plate and PCR requires the use of a thermocycler, it became necessary to elute the bound aptamer using a low acidic solution.

Since the primary intent in the development of the $\mathrm{A}^{3}$ system was to develop an ultrasensitive detection system, the detectability of the NASBA and PCR A $^{3}$ system was compared to that of the aptablot system, in which the detection resembles a more traditional immunoassay. Whereas the detectability of thrombin protein in the various complex matrices via the aptablot system was $1.36 \times 10^{-3} \mathrm{pmol}(0.27 \mathrm{nM})$ of thrombin protein, the detectability via the NASBA and PCR $\mathrm{A}^{3}$ systems were determined to be $0.27 \mathrm{pmol}(2.72 \mathrm{nM})$ and $2.72 \times 10^{-4} \mathrm{pmol}(2.72 \mathrm{pM})$ of thrombin protein, respectively. Based on these results, the detectability of the PCR $\mathrm{A}^{3}$ system seemed to be the best out of all three systems, since it is 1000 times better at thrombin detection than the NASBA 
$\mathrm{A}^{3}$ system and 5 times better than the aptablot system. When comparing the detectability of the proposed amplification assays to the thrombin detection limit of previously performed experiments, amplification of the aptamer seems to have an advantage. For instance, an electrochemical direct competitive assay was observed to have a thrombin detection limit of $430 \mathrm{nM}$ (Centi et al., 2008), an aptamer-based sandwich assay had a detection limit of $0.45 \mathrm{nM}$ (Centi et al., 2007), and a fluorescence assay was found to have a thrombin detectability of $8 \mathrm{pM}$ (Jin et al., 2010). So amplification of the aptamer can increase the detectability of the assay. Thus, the PCR $\mathrm{A}^{3}$ system can be considered ultrasensitive in the detection of thrombin protein when compared to the other two systems developed within this thesis.

Although the presently described systems do not completely eliminate the use of antibodies, they do provide an alternative option for the replacement of antibodies with aptamers. Aptamer use offers specificity to the assay similar to antibodies, but the advantages of aptamers, such as the low cost of production, ease of synthesis, and wider range of targets, makes their use more attractive. The present experiments were demonstrated using a thrombin model system since aptamers for this protein target have been well developed and characterized. The results of this thesis are promising and it is foreseeable that these systems could be implemented in routine food testing laboratories as they do not require sophisticated equipment for their operation, they are simple to perform, and are cost effective. However, future work is necessary to develop more relevant tests aimed at the detection of pathogenic targets of interest for microbiological food testing laboratories. In order for these assays to be applicable in food testing laboratories, aptamers specific to pathogenic targets of interest must be available. The 
aptamer field is still relatively new; however, it is expected that the number of available aptamers to different targets will grow in the coming years. Thus the success of the reaction is highly dependent on the identification of suitable aptamers. 


\section{REFERENCES}


Adler, M., Wacker, R., and Niemeyer, C.M. (2008) Sensitivity by combination: immmuno-PCR and related technologies. The Analyst 133: 702-718.

Aldus, C.F., Amerongen, A. van, Ariens, R.M.C., Peck, M.W., Wichers, J.H., and Wyatt, G.M. (2003) Principles of some novel rapid dipstick methods for detection and characterization of verotoxigenic Escherichia coli. Journal of Applied Microbiology 95: 380-389.

Alexander, C., Andersson, H.S., Andersson, L.I., Ansell, R.J., Kirsch, N., Nicholls, I.A., O'Mahony, J., and Whitecombe, M.J. (2006) Molecular imprinting science and technology: a survey of the literature for the years up to and including 2003. Journal of Molecular Recognition 19: 106-180.

Allmann, M., Candrian, U., Höfelein, C., and Lüthy, J. (1993) Polymerase chain reaction (PCR): a possible alternative to immunochemical methods assuring safety and quality of food. Detection of wheat contamination in non-wheat food products. $Z$ Lebensm Unters Forsch 196: 248-251.

Altekruse, S.F., Cohen, M.L., and Swerdlow, D.L. (1997) Emerging foodborne disease. Emerging Infectious Diseases 3: 285-293.

Baeumner, A.J., Humiston, M.C., Montagna, R.A., and Durst, R.A. (2001) Detection of viable oocysts of Cryptosporidium parvum following nucleic acid sequence based amplification. Analytical Chemistry 73: 1176-1180.

Blais, B.W., and Gauthier, M. (2007) Cloth-based hybridization array system for the identification of antibiotic resistance genes in Salmonella. Methods in Molecular Biology 394: 59-75.

Blais, B.W., and Martinez-Perez, A. (2011) A simple PCR-based macroarray system for detection of multiple gene markers in the identification of priority enterohemorrhagic Escherichia coli. Journal of Food Protection 74: 365-372.

Blais, B.W., and Yamazaki, H. (1989a) Use of a hydrophobic cloth for enzyme immunoassay. Biotechnology Techniques 3: 23-26.

Blais, B.W., and Yamazaki, H. (1989b) Rapid antibody assay based on initial rate of immunoreaction. Biotechnology Techniques 3: 253-265.

Blais, B.W., and Yamazaki, H. (1991) Application of polymixin-coated polyester cloth to the semi-quantification of Salmonella in processed foods. International Journal of Food Microbiology 14: 43-50.

Blais, B.W., and Yamazaki, H. (1997) Use of macroporous hydrophobic cloth as a solid phase for enzyme immunoassays in microbiological food safety testing. Recent Research and Development in Microbiology 1: 155-170. 
Blais, B.W., Martinez-Perez, A., Leggate, J., and Gauthier, M. (2007) Detection of multidrug-resistant Salmonella typhimurium DT104 in poultry by selective enrichment and cloth-based hybridization array system. Journal of Rapid Methods \& Automation in Microbiology 15: 332-344.

Blais, B.W., Oudit, D., and Pietrzak, E. (1998) Hemoglobin as a capture agent for lipopolysaccharide antigens in the enzyme immunoassay of gram negative bacteria. Journal of Rapid Methods and Automation in Microbiology 6: 17-27.

Blais, B.W., Phillippe, L.M., Burzynski, M., and Bielecki J. (1995) Applicability of the PCR technique in the food testing laboratory: Identification of Listeria monocytogenes. Biotechnology Techniques 9: 629-632.

Blais, B.W., Turner, G., Sooknanan, R., Malek, L.T., and Phillippe, L.M. (1996) A nucleic acid sequence-based amplification (NASBA) system for Listeria monocytogenes and simple method for detection of amplimers. Biotechnology Techniques 10: 189-194.

Blais, B.W., Yamazaki, H., and Rigby, C.E. (1989) Use of hydrophobic cloths as antibody adsorbents for enzyme immunoassay: Detection of Brucella antigens. Veterinary Microbiology 20: 155-163.

Bock, L.C., Griffin, L.C., Latham, J.A., Vermaas, E.H., and Toole, J.J. (1992) Selection of single-stranded DNA molecules that bind and inhibit human thrombin. Nature 355: 564-566.

Bohaychuk, V.M., Gensler, G.E., King, R.K., Wu, J.T., and McMullen, L.M. (2005) Evaluation of detection methods for screening meat and poultry products for the presence of foodborne pathogens. Journal of Food Protection 68: 2637-2647.

Bruno, J.G., Phillips, T., Carrillo, M.P. and Crowell, R. (2009). Plastic-adherent DNA aptamermagnetic bead and quantum dot sandwich assay for campylobacter detection. Journal of Fluorescence 19: 427-435.

Butler, J.E. (2000) Solid supports in enzyme-linked immunosorbent assay and other solid-phase immunoassays. Methods 22: 4-23.

CDC (2012) Questions and answers about foodborne illness (sometimes called "Food Poisoning"). http://www.cdc.gov/foodsafety/facts.html. Accessed on May $29^{\text {th }}$, 2012.

Centi, S., Messina, G., Tombelli, S., Palchetti, I., and Mascini, M. (2008) Different approaches for the detection of thrombin by an electrochemical aptamer-based assay coupled to magnetic beads. Biosensors and Bioelectronics 23: 1602-1609. 
Centi, S., Tombelli, S., Minunni, M., and Mascini, M. (2007) Aptamer-based detection of plama proteins by an electrochemical assay coupled to magnetic beads. Analytical Chemistry 79: 1466-1473.

CFIA (2012) Causes of food poisoning. http://www.inspection.gc.ca/food/consumercentre/food-safety-tips/causes-of-food-borneillness/eng/1331151916451/1331152055552. Accessed on May 29 ${ }^{\text {th }}, 2012$.

Chen, W., Martinez, G., Mulchandani, A. (2000) Molecular beacons: a real-time polymerase chain reaction assay for detecting Salmonella. Analytical Biochemistry 280: 166-172.

Chizhikov, V., Rasooly, A., Chumakov, K., and Levy, D.D. (2001) Microarray analysis of microbial virulence factors. Applied and Environmental Microbiology 67: 3258-3263.

Cho, E.J., Lee, J.-W., and Ellington, A.D. (2009) Applications of Aptamers as Sensors. Annual Reviews of Analytical Chemistry 10.1146/annurev.anchem.1.031207.112851.

Clark, R.B. and Engvall, E. (1980) Enzyme linked immunosorbent assay (ELISA). Theoretical and practical aspects. Enzyme immunoassays (Ed. Maggio, E. T.) pp. 169-179. Cleveland, CRC Press.

Compton, J. (1991) Nucleic acid sequence-based amplification. Nature 350: 91-92.

DeGrasse, J.A. (2012) A single-stranded DNA aptamer that selectively binds to Staphylococcus aureus enterotoxin B. PLoS ONE 7: 1-7.

Deiman, B., Jay, C., Zintilini, C., Vermeer, S., van Strijp, D., Venema, F., van de Wiel, P. (2008) Efficient amplification with NASBA of hepatitis B virus, herpes simplex virus and methicillin resistant Staphylococcus aureus DNA. Journal of Virological Mehtods 151: 283-293.

Doran, J.L., Collinson, S.K., Burian, J., Sarlos G., Todd, E.C.D., Munro, C.K., Kay, C.M., Banser, P.A., Peterkin, P.I., and Kay W.M. (1993) DNA-based diagnostic tests for Salmonella species targeting agfA, the structural gene for thin, aggregative fimbriae. Journal of Clinical Microbiology 31: 2263-2273.

Dwivedi, H.P., and Jaykus, L.A. (2011) Detection of pathogens in foods: the current state-of-the-art and future directions. Critical Reviews in Microbiology 37: 40-63.

Edwards, P. R., and Ewing, W. H. (1972) Identification of Enterobacteriaceae. 3rd ed. Burgess, Minneapolis. 
Ellington, A.D. and Szostak, J. (1990) In virto selection of RNA molecules that bind specific ligands. Nature 346: 818-822.

Espy, M.J., Uhl, J.R., Sloan, L.M., Buckwalter, S.P., Jones, M.F., Vetter, E.A., Yao, J.D.C., Wengenack, N.L., Rosenblatt, J.E., Cockerill, F.R., and Smith, T.F. (2006) Real-time PCR in clinical microbiology: applications for Routine laboratory testing. Clinical Microbiology Reviews 19: 165-256.

Feng, P. (1997) Impact of molecular biology on the detection of foodborne pathogens. Molecular Biotechnology 7: 267-278.

Gauthier, M. and Blais, B.W. (2005) Cloth-based hybridization array system for detection of toxin genes associated with major foodborne pathogenic bacteria. Journal of Rapid Methods \& Automation in Microbiology 13: 243-256.

Gazzaz, S.S., Rasco, B.A., and Dong, F.M. (1992) Application of immunochemical assays to food analysis. Critical Reviews in Food Science and Nutrition 32: 197229.

Hamaguchi, N., Ellington, A., and Stanton, M. (2001) Aptamer beacons for the direct detection of proteins. Analytical Biochemistry 294: 126-131.

Hill, W.E. (1996) The polymerase chain reaction: applications for the detection of foodborne pathogens. Critical Reviews in Food Science and Nutrition 36: 123173.

Hober, S., Nord, K., and Linhult, M. (2007) Protein A chromatography for antibody purification. Journal of Chromatography B 848: 40-47.

Hondinka, R.L. (1998) The clinical utility of viral quantitation using molecular methods. Clinical and Diagnostic Virology 10: 25-47.

Jayasena, S.D. (1999) Aptamers: An emerging class of molecules that rival antibodies in diagnostics. Clinical Chemistry 45: 1628-1650.

Jin, Y., Bai, J., and Li, H. (2010) Label-free protein recognition using aptamer-based fluorescence assay. Analyst 135: 1731-1735.

Joshi, R., Janagama, H., Dwivedi, H.P., Kumar, T.M.A.S., Jaykus, L.-A., Schefers, J., and Sreevatsan, S. (2009) Selection, characterization, and application of DNA aptamers for the capture and detection of Salmonella enteric serovars. Molecular and Cellular Probes 23: 20-28.

Kakizaki, E., Yoshida, T., Kawakami, H., Oset, M., Sakai, T., and Sakai, M. (1996) Detection of bacterial antigens using immune-PCR. Letters in Applied Microbiology 23: 101-103. 
Karmali, M.A., Petric, M., Winkler, M., Bielaszewska, M., Brunton, J., van de Kar, N., Morooka, T., Nair, G.B., Richardson, S.E., and Arbus, G.S. (1994) Enzymelinked immunosorbent assay for detection of immunoglobulin $\mathrm{G}$ antibodies to Escherichia coli vero cytotoxin 1. Journal of Clinical Microbiology 32: 14571463.

Khan, A.A., Nawaz, M.S., Khan, S.A., and Cerniglia, C.E. (2000) Detection of multidrug-resistant Salmonella typhimurium DT104 by multiplex polymerase chain reaction. FEMS Microbiology Letters 182: 355-360.

Kim, C.M., Graves, L.M., Swaminathan, B., Mayer, L.M., and Weaver, R.E. (1991) Evaluation of hybridization characteristics of a clones pRF 106 probe for Listeria monocytogenes detection and development of a nonisotopic colony hybridization assay. Applied and Environmental Microbiology 57: 289-294.

Kim, Y.S., Niazi, J.H., and Gu, M.B. (2009). Specific detection of oxytetracycline using DNA aptamer-immobilized interdigitated array electrode chip. Analytica Chimica Acta 634: 250-254.

Kuang, H., Chen, W., Xu, D., Xu, L., Zhu, Y., Liu, L., and Zhu, S. (2010). Fabricated aptamerbased electrochemical "signal-off" sensor of ochratoxin A. Biosensors and Bioelectronics 26: 710-716.

Lampel, K.A., Al-Khaldi, S., and Cahill, S.M. (2012) Bad Bug Book Foodborne Pathogenic microorganisms and natural toxins handbook. $2^{\text {nd }} \mathrm{Ed}$. Food and Drug Administration, USA.

Lavignac, N., Allender, C.J., and Brain, K.R. (2004) Current status of molecularly imprinted polymers as alternatives to antibodies in sorbent assays. Analytica Chimica Acta 510: 139-145.

Lee, Y.J., Han, S.R., Maeng, J.-S., Cho, Y.-J., and Lee, S.-W. (2012) In virto selection of Escherichia coli O157:H7-specific RNA aptamer. Biochemical and Biophysical Research Communications 417: 414-420.

Li, Q., Gordon, M., Cao, C., Ugen, K.E., and Morgan, D. (2007) Improvement of a low $\mathrm{pH}$ antigen-antibody dissociation procedure for ELISA measurement of a circulating anti-A $\beta$ antibodies. BMC Neuroscience 8: 22-32.

Liang H, Cordova, S.E., Kieft, T.L., and Rogelj, S. (2003) A highly sensitive immunoPCR assay for detecting Group A Streptococcus. Journal of Immunological Methods 279: 101-110.

Lindström, M., Keto, R., Markkula, A., Nevas, M., Hielm, S., and Korkeala, H. (2001) Multiplex PCR Assay for detection and identification of Clostridium botulinum 
types A, B, E, and F in food and fecal material. Applied and Environmental Microbiology 67: 5694-5699.

Lok, C.M. and Son, R. (2009) Applicaiton of molecularly imprinted polymers in food sample analysis - a perspective. International Food Research Jounral 16: 127140.

Mairal, T., Ozalp, V.C., Sanchez, P.L., Mir, M., Katakis, I., and O'Sullivan, C.K. (2008) Aptamers: molecular tools for analytical applications. Analytical and Bioanalytical Chemistry 390: 989-1007.

McClane, B.A. (2003) Clostridium perfringens. International Handbook of Foodborne Pathogens (Eds, Miliotis, M.D., and Bier, J.W.) Marcel Dekker, Inc., New York, New York, USA.

McPherson, M.J. and Møller, S.G. (2000) PCR, the basics from background to bench. BIOS Scientific Publishers. Abingolon, Oxon, UK.

Monteiro, L., Cabrita, J., and Mégraud, F. (1997) Evaluation of performances of three DNA enzyme immunoassays for detection of Helicobacter pylori PCR products from biopsy specimens. Journal of Clincal Microbiology 35: 293 1-2936.

Mullis, K., Faloona, F., Scharf, S., Saiki, R., Horn, G., and Erlich, H. (1986) Specific enzymatic amplification of DNA in vitro: the polymerase chain reaction. Cold Spring Harbor Symposia on Quantitative Biology 51: 263-273.

Murray, G.M., Jenkins, A.L., Bzhelyansky, A., and Uy O.M. (1997) Molecularly imprinted polymers for the selective sequestering and sensing of ions. John Hopkins Apl Technical Digest 18: 464-472.

Ng, S.P., Tsui, C.O., Roberts, D., Chau, P.Y., and Ng, M.H. (1996) Detection and serogroup differentiation of Salmonella spp. in food within 30 hours by enrichment-immnuoassay with a T6 monoclonal antibody capture enzyme-linked immunosorbent assay. Applied and Environmental Microbiology 62: 2294-2302.

Niazi, J.H., Lee, S.J., and Gu, M.B. (2008). Single-stranded DNA aptamers specific for antibiotics tetracyclines. Bioorganic \& Medicinal Chemistry 16: 7245- 7253.

O'Farrell, B. (2009) Evolution in lateral flow-based immunoassay systems. Lateral Flow Immunoassay. (Eds Wong, R., and Tse, H.) Humana Press, New York, New York, USA.

Oguma, K., Fujinaga, Y., and Inoue, K. (1997) Clostridium botulinum toxin. Toxin Reviews 16: 253-266. 
Osek, J. (2001) Multiplex polymerase chain reaction assay for identification of enterotoxigenic Escherichia coli strains. Journal of Veterinary Diagnostic Investigation 13: 308-311.

Pastré, D., Piétrement, O., Fusil, S., Landousy, F., Jeusset, J., David, M.-O., Hamon, L., Le Cam, E., and Zozime, A. (2003) Adsorption of DNA to mica mediated by divalent counterions: a theoretical and experimental study. Biophysical Journal 85: $2507-2518$.

Pfeifer, G.P. (1997) Formation and processing of UV photoproducts: effects of DNA sequence and chromatin environment. Photochemistry and Photobiology 65: 270283.

Poli, M.A.. Rivera, V.R., and Neal. D. (2002) Development of sensitive colorimetric capture ELISAs for Clostridium botulinum neurotoxin serotypes $\mathrm{E}$ and F. Toxicon 40: 797-802.

Rahn, K., De Grandis, S.A., Clarke, R.C., McEwen, S.A., Galan, J.E., Ginocchio, C., Curtiss III, R., and Gyles, C.L. (1992) Amplification of an invA gene sequence of Salmonella typhimurium by polymerase chain reaction as a specific method of detection of Salmonella. Molecular and Cellular Probes 6: 271-279.

Ricci, F., Volpe, G., Micheli, L., and Palleschi, G. (2007) A review on novel developments and applications of immunosensors in food analysis. Analytica Chimica Acta 605: 111-129.

Rio, D.C., Ares, M., Hannon, G.J., and Nilsen, T.W. (2010) Nondenaturing agarose gel electrophoresis of RNA. Cold Spring Harbor Protocols 6.

Samadpour, M., Liston, J., Ongerth, J.E., and Tarr, P.I. (1990) Evaluation of DNA probes for detection of Shiga-like-toxin-producing Escherichia coli in food and calf fecal samples. Applied and Environmental Microbiology 56: 1212-1215.

Sano, T., Smith, C.L., and Cantor, C.R. (1992) Immuno-PCR: Very sensitive antigen detection by means of specific antibody-DNA conjugates. Science 258: 120-122.

Scheu, P.M., Berghof, K., and Stahl, U. (1998) Detection of pathogenic and spoilage micro-organisms in food with the polymerase chain reaction. Food Microbiology 15: $13-31$.

Silverman S.K. (2007) Artificial functional nucleic acids: Aptamers, ribozymes, and deoxyribozymes identified by in vitro selection. Functional Nucleic Acids for Sensing and Other Analytical Applications. (Y. Lu and Y. Li, eds). Springer, NY.

Sissi, C. and Palumbo, M. (2009) Effects of magnesium and related divalent metal ions in topoisomerase structure and function. Nucleic Acids Research 37: 702-711. 
Song, S., Wang, L., Li, J., Zhao, J., and Fan, C. (2008) Aptamer-based biosensors. Trends in Analytical Chemistry 27: 108-117.

Stead, S.L., Ashwin, H., Johnston, B., Dallas, A., Kazakov, S.A., Tarbin, J.A., and Keely, B. J. (2010) An RNA-aptamer-based assay for the detection and analysis of malachite green and leucomalachite green residues in fish tissue. Analytical Chemistry 82: 2652-2660.

Stoevesandt, O. and Taussig, M.J. (2007) Affinity reagent resourses for human proteome detection: initiatives and perspectives. Proteomics 7: 2738-2750.

Strizhkov, B.N., Drobyshev, A.L., Mikhailovich, V.M., and Mirzabekov, A.D. (2000) PCR amplification on a microarray of gel-immobilized oligonucleotides: Detection of bacterial toxin- and drug-resistant genes and their mutations. BioTechniques 29: 844-857.

Swaminathen, B. and Feng, P. (1994) Rapid detection of food-borne pathogenic bacteria. Annual Review of Microbiology 48: $401-426$.

Tasset, D.M., Kubik, M.F., and Steiner, W. (1997) Oligonucleotide inhibitors of human thrombin that bind distinct epitopes. Journal of Molecular Biology 272: 688-698.

Tijssen, P. (1985) Practice and theory of enzyme immunoassays. Laboratory techniques in biochemistry and molecular biology. Vol 15 (Eds Burdon, R.H. and van Knippenberg, P.H.). Amsterdam, Elisevier.

Tombelli, S., Minunni, M., and Mascini, M. (2007) Aptamers-based assays for diagnostics, environmental and food analysis. Biomolecular Engineering 24: 191 200.

Tuerk, C. and Gold, L. (1990) Systematic evolution of ligands by exponential enrichment: RNA ligands to bacteriophage T4 DNA polymerase. Science 249: 505-510.

Uyttendaele, M., Bastiaansen, A., and Debevere, J. (1997) Evaluation of the NASBA nucleic acid amplification system for assessment of the viability of Campylobacter jejuni. International Journal of Food Microbiology 37: 13-20.

van der Vliet, G.M.E., Schukkink, R.A.F., Gemen, B.V., Schepers, P., and Klatser, P.R. (1993) Nucleic acid sequence-based amplification (NASBA) for the identification of mycobacteria. Journal of General Microbiology 139: 2423-2429.

Vasconcelos, N.G. and de Lourdes Ribeiro de Souza da Cunha, M. (2010) Staphylococcal enterotoxins: Molecular aspects and detection methods. Journal of Public Health and Epidemology 2: 29-42. 
Wang, L., Li, L., Xu, Y., Cheng, G., He, P., and Fang, Y. (2009) Simultaneously fluorescence detecting thrombin and lysozyme based on magnetic nanoparticle condensation. Talanta 79: 557-561.

Weigand, J.E. and Suess, B. Aptamers and riboswitches: perspectives in biotechnology. Applied Microbiology and Biotechnology 85: 229-236.

Wetmur, J.G. (1991) DNA probes: Applications of the principles of nucleic acid hybridization. Critical Reviews in Biochemistry and Molecular Biology 26: 227 259.

World Health Organization (WHO). (2007) Food safety and foodborne illness. http://www.who.int/mediacentre/factsheets/fs $237 / \mathrm{en} /$. Accessed on September $6^{\text {th }}$ 2012.

Wu, H.C., Huang, Y.L., Lai, S.C., Huang,Y.Y., and Shaio, M.F. (2001) Detection of Clostridium botulinum neurotoxin type A using immuno-PCR. Letters in Applied Microbiology 32: 321-325.

Yamamoto, C. and Sen, T. (2010) Aptamers that bind to Listeria surface proteins. US Patent Application Publication.

Ye, L. and Haupt, K. (2004) Molecularly imprinted polymers as antibody and receptor mimics for assays, sensors and drug discovery. Analytical and Bioanalytical Chemistry 378: 1887-1897.

Zhou, J., Battig, M.R., Wang, Y. (2010) Aptamer-based molecular recognition for biosensor development. Analytical and Bioanalytical Chemistry 398: 2471-2480. 